\title{
Internationalization and diversification strategies of companies from emerging economies: the case of fresh fruit export companies from Chile
}

\author{
Dissertation \\ to obtain the $\mathrm{Ph}$. D. degree \\ in the International Ph. D. Program for Agricultural Sciences in Goettingen (IPAG) \\ at the Faculty of Agricultural Sciences, \\ Georg-August-University Göttingen, Germany
}

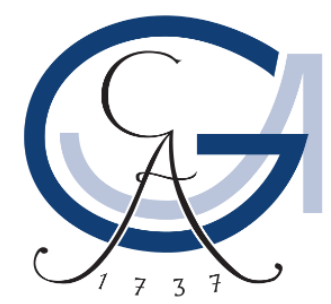

presented by

Luis Vinicio Losilla Solano

born in San José, Costa Rica

Göttingen, October 2018 
D7

1. Name of supervisor: Prof. Dr. Ludwig Theuvsen

2. Name of co-supervisor: Prof. Dr. Alejandra Engler

3. Name of examiner: Prof. Dr. Stephan von Cramon-Taubadel

Date of dissertation: 15 November 2018 


\section{Summary}

The food and agricultural value chains have experienced constant changes throughout the last decades having important organizational and economic implications that have shaped global markets. Among these changes, a rapid globalization and the increasingly openness of international trade have pushed firms to intensify their participation in international markets as an alternative to exploit new market opportunities. These changes have exposed firms to higher levels of internationalization, forcing them to adapt and develop strategies to be able to cope with a higher complexity of modern value chains. In this regard, firms follow different internationalization strategies and paths which at the same time may affect differently firm performance depending on the diversification strategies implemented. In a similar way, the perception of the existing psychic distance between countries may influence firms' internationalization strategies. Therefore, the analysis of these subjects has become an important research trend in the international business literature over the last decades. However, despite a great body of studies, some research gaps still remain unaddressed.

First, the heterogeneity and contradictory results of empirical studies regarding the internationalization strategies and paths of firms, the effects of the diversification strategies on firm performance, and the influence of the psychic distance on firm's market selection reveal the absence of agreement and the need for further research. Second, despite the importance of the emerging countries in the global economy, especially in the agricultural sector, most of the literature has mainly examined internationalization and diversification strategies of large multinational firms from North America, Europe or South East Asian countries. Therefore, there is a lack of scientific literature with such focus, particularly in the case of export firms in the agricultural sectors of emerging countries from Latin America. Third, there is a scarcity of longitudinal studies of the internationalization strategies and paths deeply analyzing their dynamic nature over time. Fourth, the empirical studies analyzing the geographic diversification-performance relationship have not disentangled the effects of diversification within and across geographic regions in the case of export firms. And fifth, there is a lack of studies examining the influence of the managers' perceived psychic distance on export market selection considering a multi-dimensional approach. 
Therefore, this dissertation consists of three essays contributing to fill these research gaps. The first essay aims to develop and apply a conceptual framework to classify and examine the internationalization strategies and paths of firms, paying special attention to their dynamic over time. To do so, we extend the matrix of multi-nationality developed by Aggarwal et al. (2011) by incorporating a new firm category ("host regional") and the scale and time dimensions. We employed this framework to classified 233 firms from the Chilean fresh fruit export sector over a seven-year time period (2009-2015) according to their internationalization strategies and paths. We find that most of the firms are transregionally or globally oriented, while the home regionally oriented firms show the lower frequency. Additionally, results indicate that most firms follow a linear internationalization path regarding the number of exports markets but act as born-global firms following non-linear paths regarding the psychic distance of the markets.

The second essay aims to explore the effect of geographical and product diversification on firms' export performance. To do so, we first separately examine the effect of geographic diversification within (intra) and across (inter) geographic regions on firms' export performance. Additionally, we examine the effect of product diversification on export performance and finally we examine the role of product diversification as moderator on the geographic (intra and inter) diversification-performance relationships. The analysis is based on panel data using 279 firms over a six-year time period (2010-2015). Our results show that the relationship of both intra- and inter-geographic diversification have an inverted U-shape, where moderate levels of diversification have positive effects on export performance, but higher levels or diversification become counterproductive. Regarding product diversification, results show that it has a positive effect on export performance and a negative moderating effect on the relationship between inter-regional diversification and export performance. We found no moderating effect product diversification in the case on the intraregional diversification-performance relationship.

The third essay aims to examine the influence of the managers' perceived psychic distance on export market selection and also to examine the strategies implemented by managers to cope with the psychic distance. To do so, we employ the cultural, administrative, geographic and economic (CAGE) distance multi-dimensional framework proposed by Ghemawat (2001) and analyze the effect of each distance dimensions individually. This qualitative 
research is based on 30 in-depth interviews with managers of export companies of fresh fruits in Chile. Our finding show that the perceived psychic distance has an influence on export market selection, especially the economic and administrative distance dimensions, while the cultural dimension resulted to be the less significant. We also identify the most important factors driving the influence of each of the psychic distance dimensions as well as the strategies implemented by the managers to cope with these factors.

Based on the findings of the three essays, we can draw important conclusions. Internationalization strategies and paths need to be analyzed longitudinally over time to really understand the dynamics of these processes. The use of a more inclusive framework permits to capture with more precision the strategies that have been implemented by firms. We also show that diversification strategies may enhance export performance when individually implemented; however, firms need to find their optimum levels of diversification to avoid counterproductive results. Furthermore, despite the strategies implemented by firms' managers to cope with the perceived psychic distance, our results confirm that it still influences the international market selection, and thus, affecting the way that businesses internationalize. 


\section{Acknowledgments}

The $\mathrm{PhD}$ has been a unique journey and it would have not been the same or even possible without the support of many people that I want to thank. First of all, I would like to thank God for letting me achieve this important goal. Yours is the honor and the glory Lord!

I want to thank my supervisors, Prof. Dr. Ludwig Theuvsen and Prof. Dr. Alejandra Engler for the support and advice provided over this process. My special thanks to Dr. Verena Otter for all the guidance, feedback, advice and support over this research. Thanks for everything! I would also like to thank Prof. Dr. Stephan von Cramon-Taubadel for being my third supervisor and for his support as director of the Joint PhD Program in Agricultural Economics (JPPAE), which I was part of. I want to thank Dr. Sebastian Lakner as academic coordinator of the JPPAE for his support and comments in the first stages of my research. My gratitude goes also to the Doctorado en Ciencias Agrarias (DCA) at the Universidad de Talca for the support provided, especially during my stay in Chile. Thanks also to my colleagues and friends in Talca for all the good moments which made of my stay there an even more enjoyable experience.

My special thank also goes to Prof. Dr. Bernhard Brümmer for his great support and advice in the second paper of this dissertation.

Furthermore, I would like to thank the German Academic Exchange Service (DAAD) and the Universidad de Costa Rica (UCR) for all the support provided during this $\mathrm{PhD}$.

I thank my colleagues from the Department of Agricultural Economics and Agribusiness at the UCR, especially don Olman, Enrique, Suria, Grettelita, and Manuel for all the support in many ways over this process.

I would like to express my gratitude to my colleagues of the Department of Agricultural Economics and Rural Development for sharing part of this journey with me and all the people that took the time to listen to me, share their ideas or gave me a piece of advice at some stage of my research. Also, to the members of the "Chair of Agribusiness Management", especially the members of the "Center for Management in International Agribusiness (CMIA)" for the nice moments, the chair lunches, the chair conferences and the traditional 
"Grünkohlwanderung”. My special thanks to my office mate Louisa for being so nice, attentive, supportive and a great office mate. Thanks Lou!

Doing this $\mathrm{PhD}$ in Göttingen would have never been the same without all the friends that I have made over these years and that are among the best things this experience has given me. Especially thanks to Sebas, Lu, Cae and Sabri with whom we shared so many moments and who became our little family far from home. ¡Gracias por todo chicos! ¡Pura Vida!

I would also like to express my gratitude to my family, especially my mother Norma and my brother Jonathan who have always been there for me and have encouraged me not only over this process, but over my whole life.

Last but not least, I would like to thank the best life partner I could have ever dreamed, my wife Gloriana. I will never be able to thank you enough for joining me in this journey, for your sacrifices, for always being there for me, for all your unconditional support in everything, even with things that you had no idea about. But more importantly, thank you for always have believed in me. This PhD would have never been possible without you and a huge part of it is thanks to you. ¡Te Amo! 


\section{Table of Contents}

Summary …..............................................................................................................................................

Acknowledgments ..................................................................................................................................iv

Table of Contents.......................................................................................................... vi

List of Tables.................................................................................................................................ii

List of Figures ...............................................................................................................................................

List of Abbreviations ............................................................................................................... $\mathrm{x}$

Chapter 1 ......................................................................................................................................... 1

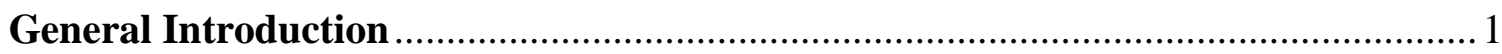

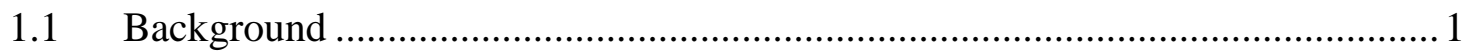

1.2 Research Gaps ..........................................................................................

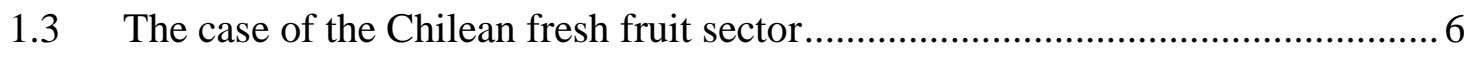

1.4 Outline

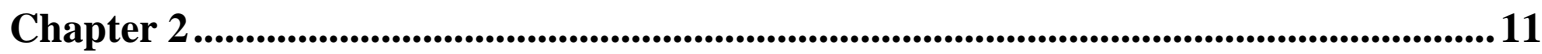

Internationalization paths of fruit export companies from emerging economies: Are

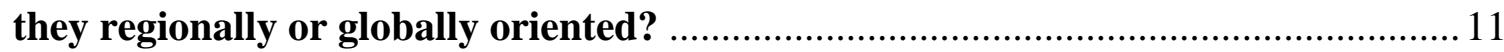

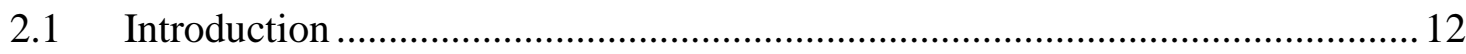

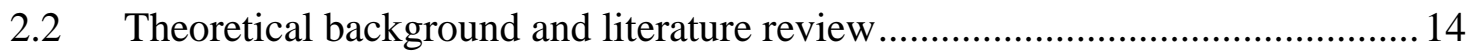

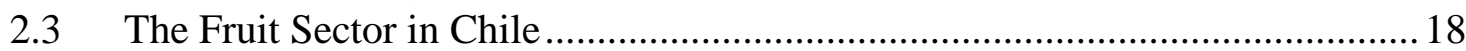

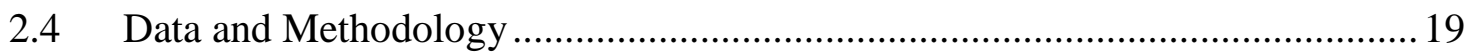

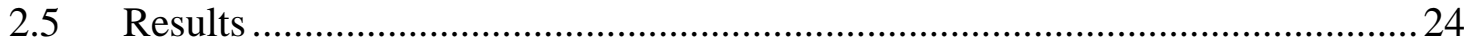

2.5.1 Geographical distribution of the fruit exports ............................................24

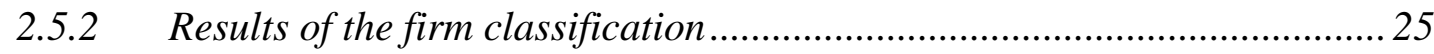

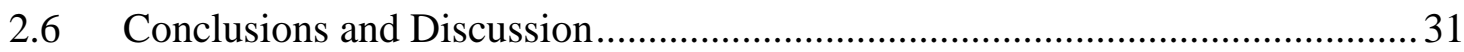

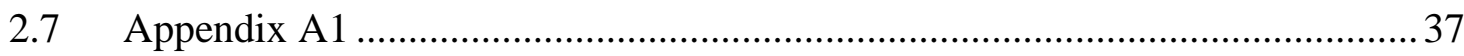

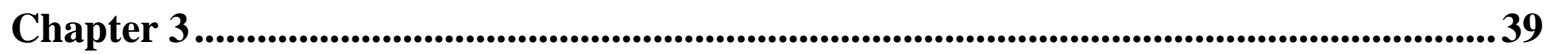

Effects of intra- and inter-regional geographic diversification and product diversification on export performance: Evidence from the Chilean fresh fruit export

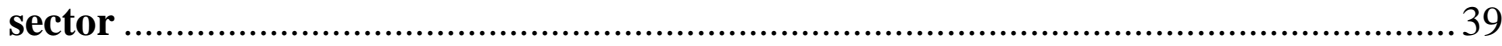

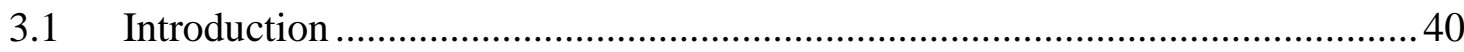

3.2 Theoretical Framework and Hypotheses ............................................................4

3.2.1 Geographic Diversification and Performance …………………...............4

3.2.2 Product Diversification and Performance ...................................................46

3.2.3 Interaction between geographic diversification-product diversification ... 47 


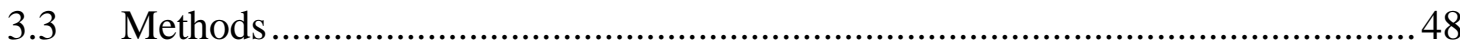

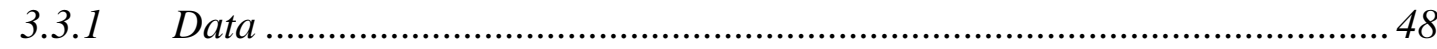

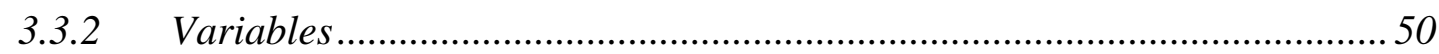

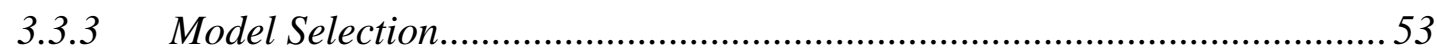

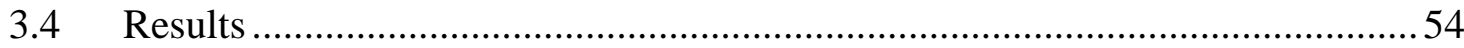

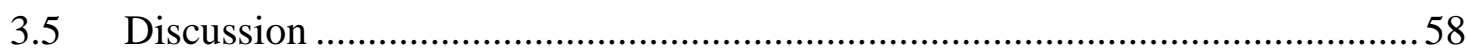

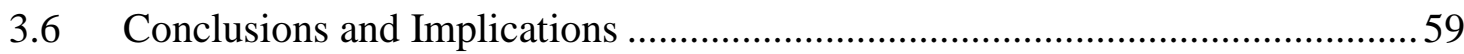

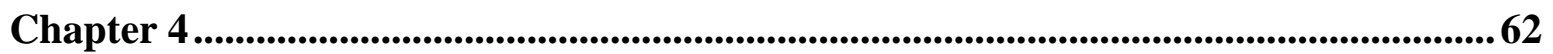

Perceived psychic distance and export market selection: Influence and strategies on the Chilean fresh fruit export sector ................................................................................62

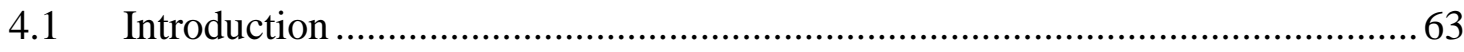

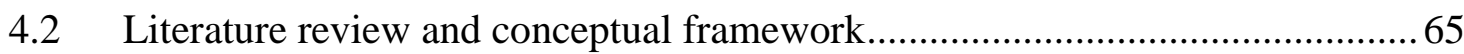

4.2.1 The concept of psychic distance and its measures........................................65

4.2.2 Psychic distance, a multi-dimensional concept ...........................................67

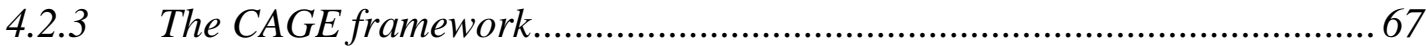

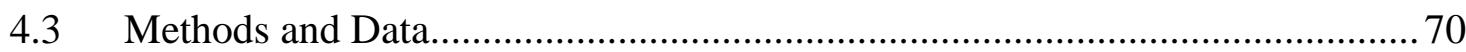

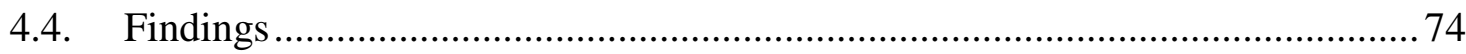

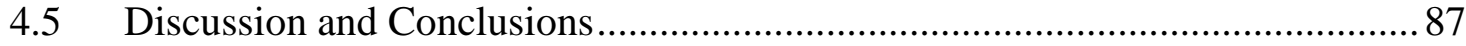

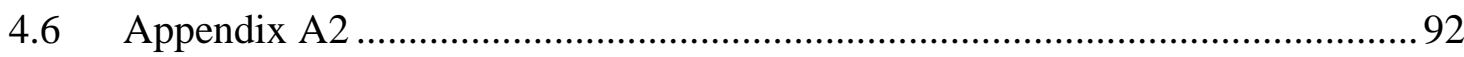

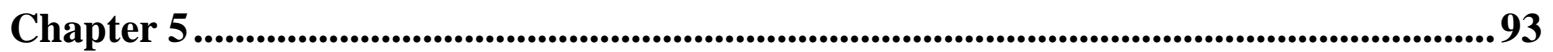

General Conclusions ..............................................................................................................93

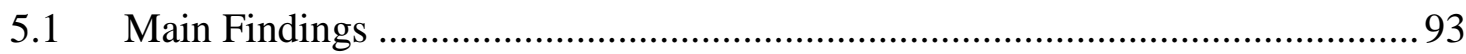

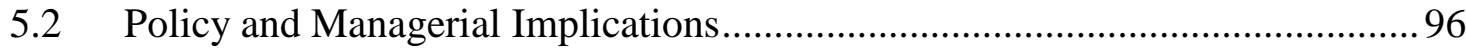

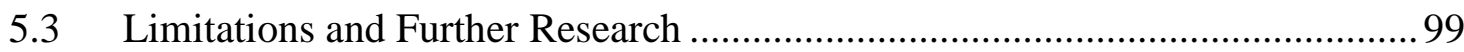

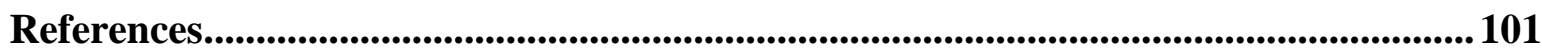




\section{List of Tables}

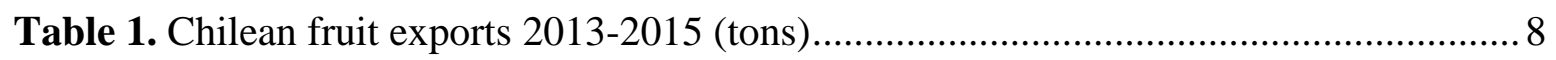

Table 2. Distribution of total exports and number of firms by geographical region ............24

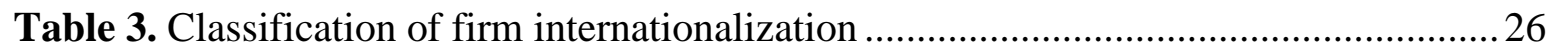

Table 4. Geographical distribution of average exports by internationalization category

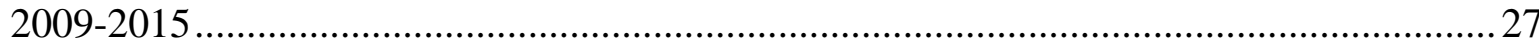

Table 5. Changes in classifications of firm internationalization from 2009 to 2015 ...........29

Table 6. Firms' internationalization and de-internationalization paths ..................................30

Table 7. Firms' average exports and age by internationalization category 2009-2015 ........31

Table A1. Changes in the classifications of firm internationalization by year..............37

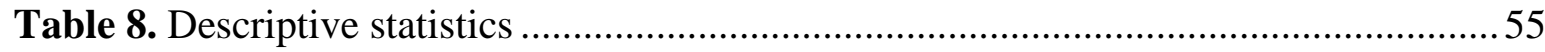

Table 9. Regression analysis for panel data with SGMM .................................................56

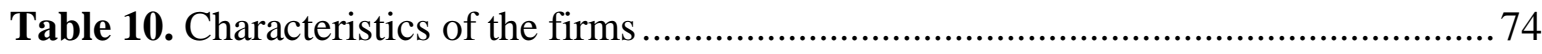

Table 11. Importance of the psychic distance dimensions for export market selection ......75

Table 12. Distribution of firms according to the influence of the psychic distance dimensions

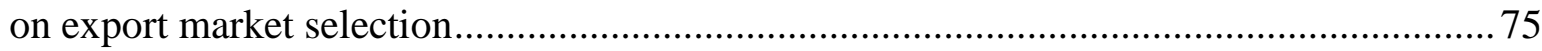

Table 13. Factors denoting the influence of psychic distance on export market selection.. 76

Table A2. Individual characteristics of the firms interviewed.............................92 


\section{List of Figures}

Figure 1. Firms' internationalization classification scheme .............................................21

Figure 2. Number of firms changing internationalization category and corresponding

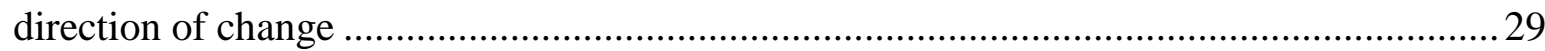

Figure 3. Relationships between intra- and inter-regional diversification and export

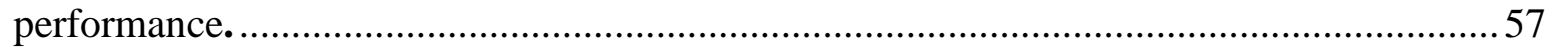

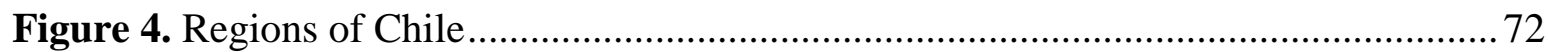




\section{List of Abbreviations}

\begin{tabular}{|c|c|}
\hline ANOVA & Analysis of Variance \\
\hline ASOEX & Association of Chilean Fruit Exporters \\
\hline CAGE & Cultural, Administrative, Geographic and Economic \\
\hline DGMM & Difference Generalized Method of Moments \\
\hline DIRECON & Chilean General Directorate of International Economic Relations \\
\hline FDI & Foreign Direct Investment \\
\hline FS/TS & Foreign Sales to Total Sales \\
\hline FEDEFRUTA & Federation of Chilean Fruit Producers \\
\hline GDP & Gross Domestic Product \\
\hline GNP & Gross National Product \\
\hline MNC & Multinational Company \\
\hline ODEPA & Chilean Office of Agricultural Studies and Policies \\
\hline OECD & Organization of Economic Cooperation and Development \\
\hline OLT & Organizational Learning Theory \\
\hline PROCHILE & Chilean Governmental Export Promotion Bureau \\
\hline RBV & Resource-Based View \\
\hline ROA & Return on Assets \\
\hline ROS & Return on Sales \\
\hline SAG & Chilean Agriculture and Livestock Service \\
\hline SGMM & System Generalized Method of Moments \\
\hline SIC & Standard Industrial Classification \\
\hline SII & Chilean Tax Administration Office \\
\hline USD & United states Dollars \\
\hline VIF & Variance Inflation Factor \\
\hline
\end{tabular}


Para la Flak 


\section{Chapter 1}

\section{General Introduction}

\subsection{Background}

In the last decades, food and agricultural value chains have experience substantial changes with significant economic development implications (Swinnen and Maertens 2007; Reardon et al. 2009; Maertens and Swinnen 2015). Population and income growth, changes in the global consumer demand patterns, a global tendency onwards urbanization, political and economic changes mostly related to structural adjustment programs and multilateral liberalization, organizational and institutional changes of the agrifood economy, and a rapid technological change transforming the production and distribution structures are the most important factors that have shaped and transformed agribusinesses worldwide (Reardon and Barrett 2000). These developments have put companies from developed, transformation and developing economies under severe pressure to adapt. The case of firms ${ }^{1}$ from emerging countries $^{2}$ differs from other cases in so far as they were not exposed to the competition generated by these factors until the last three decades due to a high governmental control of food and agricultural supply chains that prevailed after the end of colonial times in those countries (Reardon and Barrett 2000; Swinnen and Maertens 2007; Reardon et al. 2009; Aksoy 2005a). But during the 1980s and 1990s, emerging economies experienced drastic and turbulent changes during a "liberalization/globalization" stage where the liberalization of trade, prices and exchange rates, the privatization of state-owned enterprises, the general reduction of the state control, and a structural transformation of the agrifood system and other economic sectors resulted in a shift from domestically oriented to globally integrated food supply chains and a sharp increase in the international food trade (Swinnen and Maertens 2007; Reardon et al. 2009).

\footnotetext{
1 The terms "company", "firm" and "exporter" are used interchangeably in this study.

${ }^{2}$ Countries different than the most advanced ones are classified by Guillén and García-Canal (2009) as uppermiddle-income economies (e.g. Spain, Portugal, South Korea, and Taiwan), emerging economies (e.g. Brazil, Chile, Mexico, China, India and Turkey), and oil-rich countries such United Arab Emirates, Nigeria and Venezuela.
} 
According to Swinnen and Maertens (2007), the globalization in emerging economies has been driven by four specific factors: First, the trade liberalization which caused major changes in agrifood trade, reorienting the food trade flows in some regions and increasing the participation of developing countries in the world trade of agricultural and food products. Second, the investment liberalization that attracted foreign direct investment in the agricultural and food sector along the whole value chain. Third, a change in the structure of the world agricultural and food trade with an increase in the participation of high-value products such as fishery products and fruits and vegetables; products where developing countries have presented a significant increase due, for instance, to more favorable climatic conditions compared to many developed countries. And fourth, increasing food safety and quality requirements with increasingly stringent public and private standards which more and more turned out to become necessary to access high-value markets worldwide, especially in the case of fresh products such as fruit and vegetables.

As a result of the increasing globalization of the business environment, firms around the world have been forced to constantly search for new markets outside their home countries to maintain and gain competitive advantages and exploit those market opportunities that allow them to improve profitability (Aulakh, Kotabe and Teegen 2000; Reardon and Barrett 2000). However, despite a large number of studies, globalization is a not well understood phenomenon, neither are the strategies implemented by firms to internationalize (Rugman and Verbeke 2004).

In the literature, studies follow different approaches to measure the level of firms' internationalization. Such approaches have changed over time, including first only global strategy and local strategy as possible scenarios, while the regionalization strategy was latter introduced as an intermediate scenario (Asmussen 2009). The most frequently employed approach by empirical studies was proposed by Rugman and Verbeke (2004) which is based on the firms' geographic internationalization level and classifies firms according to their sales dispersion in the broad triad region ${ }^{3}$. However, this approach has been criticized by more recent studies for being strongly focused on the triad region and employing subjective thresholds to classify firms which produces biased results (Osegowitsch and Sammartino

\footnotetext{
${ }^{3}$ The broad triad region is formed by the European Union, North America and Asia.
} 
2008; Sammartino and Osegowitsch 2013; Aggarwal et al. 2011; Berrill 2015; Asmussen 2009). Aggarwal et al. (2011) suggested a more inclusive classification scheme which has been widely employed as well and that includes all countries in the world and does not impose thresholds.

A large number of studies in international business have examined firms' internationalization strategies with mixed results. Many authors claim that firms are regionally oriented and that the globalization is a myth (see, e.g., Rugman and Verbeke 2004; Rugman and Oh 2013; Rugman, Oh and Lim 2012). Others found growing degrees of globalization, the implementation of more global strategies and higher internationalization levels (see, e.g., Aggarwal et al. 2011; Berrill and Mannella 2013; O’Hagan-Luff and Berrill 2016). Therefore, despite a huge body of literature, the question of whether companies are more global or regional still remains open.

In a related vein, it is argued that different internationalization strategies and paths may result in different effects on firm performance depending on their level of diversification (Asmussen 2009; Hennart 2007). An improved understanding of this relationship will enable firm' managers to evaluate their diversification strategies in comparison to other firms in the same sector in order to know what to expect and to decide how to proceed as a way of looking for competitive advantages and above-average firm performance (Contractor, Kumar and Kundu 2007; Hitt et al. 2006). Firms that are more diversified are generally expected to have a higher performance in comparison to those which are less diversified due to a better access to resources, higher market power and economies of scale and scope (Geringer et al. 2000; Hennart 2007; Kumar 2009). Other research strands such as the resource-based view (RBV) and the organizational learning theory (OLT) stress the important role of resources and competences. In this regard, the knowledge acquired by firms from previous experiences in markets and products represents an important intangible resource to be implemented in other new markets (Kumar 2009; Boehe and Jiménez 2016; Fernández Olmos and Díez-Vial 2015; Aulakh et al. 2000).

A large number of empirical studies have explored the relationship between the level of firms' geographic diversification and firm performance finding mixed results with different functional shapes (e.g. Heyder Makus, C., Theuvsen, L. 2011; Contractor et al. 2007; 
Kistruck, Qureshi and Beamish 2013; Cieślik, Kaciak and Thongpapanl 2015; Fernández Olmos and Díez-Vial 2015; Benito-Osorio et al. 2016; Oh, Sohl and Rugman 2015). Similar situation has been found by studies examining the relationship between the level of product diversification and firm performance (Chen and Yu 2012; Chang and Wang 2007; Borda et al. 2017) and the moderating effect of product diversification on the relationship between geographic diversification and firm performance (Kistruck et al. 2013; Hitt, Hoskisson and Kim 1997; Li, Qian and Qian 2012; Geringer et al. 2000; Tallman and Li 1996). This heterogeneity of results evidences a clear lack of consensus and the need for more research on the diversification-performance relationship (Boehe and Jiménez 2016; Li et al. 2012; Borda et al. 2017; Oh et al. 2015; Benito-Osorio et al. 2016).

As mentioned above, an increasing globalization has forced firms towards a higher degree of internationalization; thus, an increasing number of firm managers face important decisions regarding where and how to internationalize (Malhotra, Sivakumar and Zhu 2009). In this regard, the existing distance between countries may influence firm internationalization strategies (Hutzschenreuter, Kleindienst and Lange 2014). Johanson and Vahlne (1977) and Johanson and Wiedersheim-Paul (1975) define psychic distance as all the factors that hinder an adequate flow of information between a firm and a foreign market such as culture, language, level of development, level of education, political and administrative system among others. A higher psychic distance to a specific country represents higher difficulties to access, analyze and interpret information related to that market (Håkanson and Ambos 2010). In this sense, according to the Uppsala internationalization process model, firms will gradually internationalize preferring first those markets which are at a shorter psychic distance with respect to the firm's home country (Johanson and Vahlne 1977; Johanson and Wiedersheim-Paul 1975). Therefore, the managers' perception of psychic distance strongly influences firms' orientation with respect to foreign markets.

Research related to distance has received a great of attention within the international business. A large number of studies have examined the effect of different distance dimensions in cross-border businesses, being the cultural dimension the most frequently analyzed (Hutzschenreuter et al. 2014; Hutzschenreuter, Kleindienst and Lange 2016; Avloniti and Filippaios 2014). In general, the empirical evidence of negative effects of distance seem to be stronger than the evidence of positive effects (Hutzschenreuter et al. 
2016) however the findings are mixed and contradictory (Stöttinger and Schlegelmilch 1998; Brewer 2007; Berry, Guillén and Zhou 2010; Dow and Karunaratna 2006; Dow 2000; Malhotra et al. 2009). This lack of agreement regarding the role of distance evidences a "clear sign of intellectual involvement in further developing the concept of distance" and the need for further research (Hutzschenreuter et al. 2016, p.165).

\subsection{Research Gaps}

The literature available examining firms' internationalization and diversification strategies has been growing for decades. However, there are still some research gaps that are relevant for this topic and have remained uncovered so far. This study aims to address some of those gaps.

Over a long period of time and until the 1980s, large companies from the major industrialized countries heavily dominated the world markets. However, as a result of political changes and economic liberalization, firms from many emerging economies have shown a sharply and rapid growth changing their position in the global economy and, thus, becoming key competitors (Hoskisson et al. 2000; Craig and Douglas 1997; Aulakh et al. 2000; Grosse 2016). Yet, most of the literature studying firms' internationalization and diversification strategies have been strongly focused on foreign direct investment (FDI) of large multinational companies (MNC) mostly located in developed countries in Europe and North America. In the case of emerging economies, studies have primarily focused on cases of Asian countries related to industrial and high technology sectors. In this sense, there is a lack of studies on firms' internationalization and diversification strategies of export firms from Latin American countries, where a shift from an import-orientation to an export-orientation paradigm resulted in a high export growth in the past decades (especially the agricultural sector), representing an enormous contribution to the development of their economies (Aksoy 2005b; Sonntag et al. 2016; Otter and Theuvsen 2014). Studies on firms from Latin America are scarce so far, and, to our knowledge, the scientific literature with such focus examining cases in the agricultural sector is even scarcer.

Regarding internationalization strategies, there is a lack of longitudinal studies considering the time dimension which provides an in-depth view of the firms' internationalization 
strategies and paths dynamics. When studying the relationship between geographic diversification and performance, it is important to include both the related or intradiversification (within geographic regions) and the unrelated or inter-diversification (across geographic regions) (Verbeke and Brugman 2009). It is also important to examine possible moderators of these relationships (Borda et al. 2017; Benito-Osorio et al. 2016). However, to our knowledge there are no studies including the differentiation of intra- and inter-geographic diversification or taking into account moderating effects with product diversification when studying the effect of export firms' performance.

In the case of the literature examining the psychic distance, most studies focus on one single dimension. Nevertheless, it is important to consider multiple dimensions of distance to obtain a more holistic and complete understanding of psychic distance and its influence on firms and avoid having a simplistic and biased perspective of this phenomenon. Additionally, many studies employed solely objective measures of the psychic distance without considering its perceptual aspect. Yet, managers' psychic distance perception is essential to capture its real effect on the firms' final decisions related to foreign market selection and to understand the strategies implemented to cope with the different psychic distance dimensions.

Against this background, it is the main objective of this study to analyze the internationalization and diversification strategies of firms from emerging economies using the case of the fresh fruit export sector in Chile. The analysis is mainly based on information contained in the database Eximfruit (2009-2015) of Inglobo, which gathers seasonal information of Chilean fresh fruit exports showing its distribution by fruit variety and market destination.

\subsection{The case of the Chilean fresh fruit sector}

The Chilean fresh fruit export sector was chosen as a case study for this dissertation. As mentioned above, during the last decades emerging economies have experienced drastic structural changes. In some of these countries, especially in Latin America, the agricultural sector has played a key role in their economic development turning them into major global players in some products segments, for instance beef, poultry, oil seeds, and fruits and vegetables (Aksoy 2005b; Sonntag et al. 2016). This was also the case of Chile, where a 
series of structural policy reforms after 1974 based on the privatization of the land and a radical trade liberalization program incentivized the export diversification and ended up with a strongly export-oriented agricultural sector, particularly with regard to non-traditional agricultural activities such as the fruit crops (Gwynne 1999; Foster and Valdes 2006; Arnade and Sparks 1993; Agosin and Bravo-Ortega 2009; Otter, Engler and Theuvsen 2014; Gwynne 2003). Initially, the fruit sector was heavily concentrated in the production of apples and grapes. However, during the 1990s the production of more varieties such as pears, peaches, nectarines and stone fruits increased lowering the export concentration (Arnade and Sparks 1993). At the end of the 1990s new varieties considered non-traditional were introduced including kiwis, strawberries, blueberries, avocados, and others (Agosin and Bravo-Ortega 2009).

With almost 320,000 hectares cultivated, 5 million tons of fruit of which 2.8 million are exported as fresh fruit generating more than 4,800 billion USD per year on sales (ODEPA 2017), the fruit production is nowadays the most important activity in the Chilean agricultural sector. It accounts for almost $50 \%$ of the total exports and over $40 \%$ of the gross agricultural production and represents $1.46 \%$ of the total gross domestic product (GDP) but reaches $2.6 \%$ when indirect activities are included (Retamales and Sepúlveda 2011; Klerkx, Villalobos and Engler 2012). In total this sector involves 28,000 fruit growers of which 19,000 have less than 5 hectares, provides 450,000 direct employments and more than one million indirect employments (Retamales and Sepúlveda 2011; Fedefruta 2018). Between the years 2009 and 2015, there were on average 577 fruit exporters of which 16 account for $50.10 \%$ of the total exports and 42 for $80 \%$ (Eximfruit 2009-2015).

Table 1 shows the distribution of the Chilean fruit exports for the period between 2013 and 2018 . By 2018, the main fruits exported are apples, grapes, cherries, kiwis, avocados, pears and plums. The exports of cherries have grown exponentially over the last years becoming the third most important export product following grapes and apples which constantly interchange the first and the second place. The main export destinations of the Chilean fresh fruit are North America, Europe, and Asia. Nowadays Chile is the main fruit exporter of the

\footnotetext{
${ }^{4}$ The quantities showed corresponds to the Chilean fruit season which goes from September to August of the following year.
} 
Southern Hemisphere, the global leader of table grapes exports and the second largest of cherries and blueberries (ODEPA 2017)

Table 1. Chilean fruit exports 2013-2015 (tons)

\begin{tabular}{lcccccc}
\hline Products & 2013 & 2014 & 2015 & 2016 & 2017 & 2018 \\
\hline Apples & $882,116.81$ & $830,865.68$ & $660,744.26$ & $776,253.51$ & n/a & $799,577.44$ \\
Grapes & $803,646.93$ & $738,243.69$ & $793,281.67$ & $705,900.22$ & n/a & $750,997.14$ \\
Cherries & $47,539.73$ & $55,821.35$ & $117,012.15$ & $89,013.92$ & n/a & $198,049.71$ \\
Kiwis & $223,740.62$ & $115,141.07$ & $175,416.82$ & $216,773.61$ & n/a & $183,936.48$ \\
Avocados & $68,005.99$ & $131,151.39$ & $65,282.08$ & $119,808.60$ & n/a & $142,414.91$ \\
Pears & $139,282.49$ & $118,803.56$ & $139,318.20$ & $130,902.10$ & n/a & $132,255.80$ \\
Plums & $122,216.67$ & $49,466.38$ & $105,171.08$ & $122,197.22$ & n/a & $130,407.37$ \\
Blueberries & $75,440.36$ & $46,225.92$ & $60,995.37$ & $57,324.57$ & n/a & $74,297.36$ \\
Nectarines & $59,540.64$ & $22,326.19$ & $59,535.48$ & $58,082.22$ & n/a & $67,755.68$ \\
Others & $224,737.14$ & $222,235.72$ & $289,770.09$ & $361,452.79$ & n/a & $343,441.28$ \\
Total & $2,646,267.38$ & $2,330,280.95$ & $2,466,527.19$ & $2,637,708.76$ & n/a & $2,823,133.17$ \\
\hline Source: $(O D E A, ~$ & & & & &
\end{tabular}

Source: (ODEPA 2018)

Notes: n/a: Not available

Despite being geographically far away from most of the main fruit markets of the world, due to the power of export groups which are the most important players and responsible of the success of the economic model of export promotion, and after pursuing an aggressive free trade agreement policy, Chile is nowadays considered one of the most open economies in the world with 26 free trade agreements with a total of 64 markets (DIRECON 2018; Wehner 2011). Additionally, as a result of a strong economic development, in 2010 Chile was the first country from Latin America to be admitted as member of the Organization of Economic Cooperation and Development (OECD) (OECD 2010) and one of the most stable countries in the region. All these factors make Chile to be considered a model for other Latin American countries and therefore, an interesting case and a prime example to be analyzed.

\subsection{Outline}

The remainder of this dissertation consists of three essays addressing the research gaps outlined above and is structured as follows:

Chapter 2 presents the first essay, which develops and applies a framework based on the matrix of multi-nationality developed by Aggarwal et al. (2011). This framework is 
employed to examine the internationalization strategies and paths followed by agricultural export firms located in emerging economies, with a focus on the locus of destination markets. The design of the framework offers more precision and flexibility of separation in the classification matrix, accounting for strategies that seem to be relevant among agricultural export firms in emerging economies. Special attention is given to the firms' internationalization dynamics by closely examining the changes in geographical internationalization (and de-internationalization) strategies and paths over seven years period of time (2009-2015) through a longitudinal analysis. Studies with such focus are rarely found in the literature. The sample employed for this essay comprises 233 fresh fruit exporters from Chile.

In Chapter 3, the second essay is presented, analyzing how the geographic and product diversification strategies of export firms affect their performance. First, we separately analyze the effect of export diversification within (intra) and across (inter) different geographic regions on firm performance. Second, we analyze the effect of product diversification on firm performance. Third, we analyze the moderating effect of product diversification on the relationships between intra- and inter-regional diversification and firm performance. We hypothesize that both intra-regional diversification and product diversification have a linear and positive relationship with firms export performance, while the inter-regional diversification is expected to have an inverted U-shape relationship. In the case of the moderating effect of the product diversification on the relationship between geographic diversification and firm export performance, we hypothesize a positive effect for the intra-regional diversification and a negative effect for the inter-regional diversification. We employ a dynamic panel data model using information on 279 fresh fruit export firms from Chile over a six-year time period (2010-2015) .

Chapter 4 presents the third essay, which examines the influence of the perceived psychic distance on export market selection by firms' managers. Additionally, the essay examines the strategies implemented by the firms to cope with the main factors denoting this influence. As mentioned above, in order to capture the real effect of psychic distance on firms' decisions, it is necessary to capture the perception that those managers have of the psychic

\footnotetext{
${ }^{5}$ For this essay we employed country-level export reports, which are not available for all the firms in the year 2009; thus, we limited the study to the period 2010-2015.
} 
distance. Thus, we employ a qualitative case study analysis using in-depth interviews with 30 export firms. We employ a multi-dimensional approach by following the CAGE framework (Ghemawat 2001) which considers the distance caused by the differences between two countries regarding cultural, administrative, geographic and economic dimensions. A multi-dimensional approach offers a more comprehensive, holistic and insightful perspective of the psychic distance and avoid misleading or biased results due to an overemphasize on a single distance dimension.

Chapter 5 provides overall conclusions as well as implications and recommends areas for further research. 


\title{
Chapter 2
}

\section{Internationalization paths of fruit export companies from emerging economies: Are they regionally or globally oriented? ${ }^{6}$}

\begin{abstract}
The aim of this paper is to develop and apply a framework that examines the dynamics in internationalization strategies employed by agricultural export companies in emerging economies over time, with a focus on the locus of destination markets from the Chilean fruit sector. The matrix of multi-nationality developed by Aggarwal et al. (2011) is extended by incorporating the firm category "host regional" and the dimensions scale and time. This framework is utilized to classify 233 Chilean fresh fruit exporters according to their internationalization strategies based on a geographical distribution of their exports. An uniand bivariate longitudinal analysis is conducted over a seven-year time period (2009-2015) to explore the dynamics of this internationalization process. Results show that most firms are "transregionally" $(65.12 \%)$ or "globally" oriented $(16.06 \%)$ while a significant number $(12.75 \%)$ of firms classified as "host regional" are identified. Firms mainly follow a linear internationalization path in terms of number of export markets. But there is also evidence of "born-global" firms, mainly following non-linear internationalization paths in more geographically and psychically distant markets. The extended framework developed in this research can be applied to future studies, particularly in the case of economies where a significant share of firms focused their export strategies on mainly one single international market. Based on the findings, concrete measures have been suggested to aid Chilean policy makers in instituting evidence-based economic policies, as well as the country's public trade organizations and private export associations in the fruit sector, in relation to services (e.g. training, strategy consulting, trade network development) provided to export firms.
\end{abstract}

Keywords: Latin America, emerging economies, agricultural products, fruit exports, internationalization strategy, matrix of multi-nationality, longitudinal analysis

\footnotetext{
${ }^{6}$ This or a similar version of this paper has been submitted and invited to resubmit to the International Journal of Emerging Markets. This paper is co-authored by Verena Otter and Alejandra Engler.
} 


\subsection{Introduction}

For centuries, large companies from developed countries have shaped the globalization trend, through participation in international markets to overcome intense domestic competition and exploit additional sales opportunities. Since the 1970s, companies from emerging countries have also shown rapid export growth and an increasing corresponding share of the world's goods and services markets. As a consequence of the increasing strength of their position in the global economy, these companies have become key competitors, challenging established MNCs from developed economies (Aulakh 2007; Aulakh et al. 2000; Aksoy 2005b; Guillén and García-Canal 2009; Berrill and Mannella 2013; Sethi 2009; Cyrino, Barcellos and Tanure 2010; Bianchi 2014; Hoskisson et al. 2000; Grosse 2016). While this is evident in world markets for industrial products, which are widely penetrated by products from Asia-Pacific countries, it also holds true in those for agricultural products, in which MNCs from emerging countries have risen significantly in status (Aksoy 2005b; Sonntag et al. 2016). In particular, Latin American countries such as Chile, Brazil and Argentina have shown high export growth rates in past decades, contributing immensely to the development in their economy as a result of general paradigm shifts from one of import-orientation to export-orientation, and a corresponding pioneering role among the developing and transition countries regarding ambitious political agricultural export strategies (Otter and Theuvsen 2014). Subsequently, Latin America represents around one-third of the worlds' developing economies in terms of the gross national product (GNP), and ranks second amongst emerging economic regions after the Asia-Pacific region (Aulakh et al. 2000; Otter and Theuvsen 2014). Chile is one of the emerging countries in Latin America which was noted for particularly high export growth in agricultural products worldwide and meaningful economic development since the beginning of the $21^{\text {st }}$ century (Otter et al. 2014; Lakner, Brenes-Muñoz and Brümmer 2017). Recently, Chile has also experienced an increase in South-South trade ${ }^{7}$, expanding opportunities for agricultural products (especially fruits) along with providing new challenges for their exporting companies, primarily driven by an increasing number of competitors and potential export markets (Sonntag et al. 2016). This trend also affects other emerging economies, both inside and outside Latin America. In light of expanding business

\footnotetext{
${ }^{7}$ Refers to trade flows between developing countries.
} 
complexity, a deeper understanding of differences in internationalization strategies of firms in emerging economies is long overdue. This understanding could provide politicians and national trade agencies with the necessary information to implement policies that strength their expansion into destination markets, and thus contributing to overall development in those countries. In particular, internationalization strategies and paths followed by export companies may provide relevant information to aid the sustainability of such companies. Hence, effective economic policies require a deep understanding of the relevant sector, developing what are known as "evidence-based policies". The necessity of investigating internationalization strategies in a globalized world has provoked a bulk of conceptual literature in business research on firms' internationalization pathways, and the systems used for categorization. However this literature shows contradictory viewpoints resulting in inconsistent identification of the degree of firms' globalization, a lack of research emphasizing the locus of destinations for firms' internationalization strategies (Rugman and Oh 2013; Rugman and Verbeke 2004), a dearth of longitudinal investigation (Aggarwal et al. 2011; Mullen and Berrill 2015; O'Hagan-Luff and Berrill 2016; Chadha and Berrill 2016; Kuivalainen et al. 2012; Welch and Paavilainen-Mäntymäki 2014) and relatively little evidence on emerging economies agricultural export sectors (Aulakh et al. 2000; Bianchi and Garcia 2007; Bianchi 2014; Cuervo-Cazurra 2008; Cyrino et al. 2010; Hermelo Diaz and Vassolo 2012; Lopez, Kundu and Ciravegna 2009; Sahaym and Nam 2013; Sethi 2009). In particular, most studies in internationalization have focused on international investments strategies of MNCs; whereas internationalization through export strategies has received less attention.

Therefore, it is the aim of this study to develop and apply a conceptual framework that examines the dynamics in internationalization strategies of emerging economies' agricultural export companies over time, with a focus on the locus of destination markets. Thereby, the article contributes to international business literature in three ways; first, extending the Aggarwal et al. (2011) approach to measure firms' internationalization by adding a new category to account for host regionally oriented firms, which is highly relevant in the specific case of emerging economies. Second, as recommended by Reuber, Dimitratos and Kuivalainen (2017) and Welch and Paavilainen-Mäntymäki (2014), in providing an in-depth view of the firm's internationalization dynamics by closely examining the changes in 
geographical internationalization (and de-internationalization) strategies over time through a longitudinal analysis using a seven-year time period between 2009 and 2015. Thirdly, by testing the extended approach on a sample of 233 fresh fruit exporting companies from Chile, where Chile is a prime example for other emerging economies, since it shows the greatest economic development among all Latin American countries based on the export growth of one single sector. This study contributes to closing the gap of empirical evidence in research on internationalization strategies in the agricultural sectors of emerging countries from Latin America.

The remainder of this paper is structured as follows: the first two sections review the main conceptual literature and theoretical background relating to firms' internationalization strategies, and introduce the Chilean fruit export sector to justify its importance as a case study. The subsequent section describes the data and the classification framework employed in the study. The last two sections provide results, main findings and the conclusions of the study, to identify limitations and recommend areas for further research.

\subsection{Theoretical background and literature review}

Different definitions for internationalization can be found in international business literature. Following Calof and Beamish (1995), internationalization involves the establishment of a series of processes where firms must adapt in order to fit into international markets. According to Chetty and Campbell-Hunt (2003), this concept suggests that internationalization is a dynamic process and does not only occur in one direction (forward), but also can be reversed (backward). This implies the possibility of de-internationalization, when a firm reduces its international sales or presence in international markets (Chetty and Campbell-Hunt 2003). Periods of re-internationalization are also possible, when firms that had de-internationalized re-enter international markets (O’Hagan-Luff and Berrill 2016).

Firms' internationalization strategies may have different stages. Cavusgil (1980; 1984) argues that to engage in international businesses, firms experience a process shaped by different stages including pre-involvement, reactive involvement, limited experimental involvement, active involvement, and committed involvement. The stages of limited experimental involvement and active involvement are the most important for export 
companies. With limited experimental involvement, firms initiate exporting activities at a very low level, and in only a few markets. In this step, the international business is just a marginal part of the firm's overall business. Active involvement means that international business operations become an important activity of the firm's long-term objectives, and international markets are warranted more attention via exports. This concept is defined by Aggarwal et al. (2011) as the depth of market engagement, which varies from import and export activities where the level of engagement is lower, to foreign direct investment which involves a much higher level of involvement. A significant share of companies from emerging economies and small to medium enterprises remain in the earliest stages of internationalization, so depend intensively on exports as their only means of participation in international markets (Bianchi and Garcia 2007; D’Angelo et al. 2013; Bianchi 2014; Sagheer, Yadav and Deshmukh 2009). However, few studies have researched the internationalization strategies employed by this kind of firms. Instead, they have tended to focus on large MNCs which are at a more developed stage of internationalization, mainly through foreign direct investment and overseas subsidiaries (Bianchi and Garcia 2007; Cieślik, Kaciak and Welsh 2012; Rugman and Oh 2013; D'Angelo et al. 2013).

Regarding the strategy employed by firms to internationalize, there are three key dimensions that define an internationalization strategy: scope, scale, and time $e^{8}$ (Fernández Olmos and Díez-Vial 2015; Kuivalainen et al. 2012; Aggarwal et al. 2011). Johanson and Vahlne (1977) capture these concepts when the model of the internationalization process was developed, better known as the Uppsala model, later extended by Johanson and Vahlne (1990; 2009). It proposes that internationalization does not occur sporadically, but rather as a process which gradually takes place as a firm carries out transactions and accumulates international market knowledge. This implies that firms will start exporting to a few markets, and then extend their international portfolio as they gradually gain experience and resources (McNaughton 2003; Fernández Olmos and Díez-Vial 2015; Lopez et al. 2009; Welch and PaavilainenMäntymäki 2014).

\footnotetext{
${ }^{8}$ Scope is mainly measured as the geographical spread of operations, scale as the extent or intensity of foreign operations (FS/TS), and time as the time in international markets or time to internationalize. Aggarwal et al. (2011) refers to the concept of scope as breadth of internationalization.
} 
However, not all firms internationalize following an incremental or sequential process. The so-called "born-global" firms experience rapid expansion into international markets. Also known as international new ventures or start-ups, Knight and Cavusgil (2004, p.124) define born-global firms as "businesses and organizations that, from or near their founding, seek superior international business performance from the application of knowledge-based resources to the sale of outputs in multiple countries". To be considered a true born-global firm, this rapid internationalization should occur simultaneously in terms of time (usually three years after the date of a firm's foundation), scale (significance of export intensity) and scope (broad market diversification strategy), otherwise firms are only born-regional or borninternational (Kuivalainen, Sundqvist and Servais 2007; Kuivalainen et al. 2012).

When analyzing internationalization, in addition to the number of markets served, it is also important to consider firms' orientation regarding the type of markets, which can be geographically related or not (Cieślik et al. 2012). Ghemawat (2001) argues that the cultural, administrative and economic distances between countries play a key role in the firm's global expansion into new markets, in addition to the geographic distance. Psychic distance refers to factors that hamper an adequate exchange of information between foreign companies and local markets, such as language, development levels and political systems. Companies are expected to venture into new markets gradually, focusing first on those which are at a shorter psychic distance in relation to their country of origin (Johanson and Vahlne 1977; Johanson and Wiedersheim-Paul 1975). This concept is also called the "liability of foreignness" (Hymer 1976; Zaheer 1995). Rugman and Verbeke (2004; 2007) later extended this concept and applied it at regional level, noting the liability of inter-regional foreignness as the disadvantages faced by companies when competing in geographic regions differing from their local region. In line with the Uppsala model, Rugman and Verbeke $(2004 ; 2007)$ expect that firms' international operations will gradually increase, initially concentrating in regions with similar characteristics to their own region, and then extending their scope to other regions. In the case of born-global firms, there is a major difference: they are capable of internationalizing to geographically and psychically distant markets from the moment they are created, without having much accumulated knowledge or resources (Lopez et al. 2009).

D'Angelo et al. (2013) and Chetty and Campbell-Hunt (2003) contend that the geographic internationalization pathway, classified as either regionally or globally oriented, is another 
way to explain firms' internationalization paths by considering political, cultural and geographical aspects as driving forces in the process. The most employed classification systems for firms' internationalization levels are the multi-nationality classification developed by Rugman and Verbeke (2004), and the matrix of multi-nationality developed by Aggarwal et al. (2011). Results of previous empirical studies find geographic internationalization strategies are mixed, with some arguing that most firms are regionally oriented (Rugman and Verbeke 2004; Rugman and Oh 2013; Delios and Beamish 2005; Banalieva and Dhanaraj 2013; Cerrato 2009; Rugman et al. 2012; Sethi 2009), while others claim that firms are more globally oriented (Aggarwal et al. 2011; Osegowitsch and Sammartino 2008; Berrill and Mannella 2013; O'Hagan-Luff and Berrill 2016).

While Rugman and Verbeke (2004), with their multi-nationality classification, have been criticized for using subjective thresholds ${ }^{9}$ and focusing only on the broad triad region, Aggarwal et al. (2011) developed a rather inclusionary approach with their matrix of multinationality. However, there is still a lack of research emphasizing the locus of destinations (scope) of firms' internationalization strategies (Rugman and Oh 2013; Rugman and Verbeke 2004), and a dearth of longitudinal studies taking a time dimension into account when analyzing the internationalization process (Aggarwal et al. 2011; Mullen and Berrill 2015; O'Hagan-Luff and Berrill 2016; Chadha and Berrill 2016; Kuivalainen et al. 2012; Welch and Paavilainen-Mäntymäki 2014). Furthermore, despite the fact that "emerging economies represent half of the global GDP and more than the half of the economic growth" (Hermelo Diaz and Vassolo 2012, p.264), there is little research on emerging countries regarding international business and the differences in the behavior between firms from those countries in comparison to more developed ones (Bianchi and Garcia 2007; Berrill and Mannella 2013; Sahaym and Nam 2013; Sethi 2009). Overall, research on internationalization strategies has been mainly focused on large MNCs from either developed countries, or Asian countries as representatives for emerging economies, but only a few studies have investigated Latin American cases, mostly in Mexico and Brazil (e.g. Aulakh et al. 2000; Bianchi and Garcia

\footnotetext{
${ }^{9}$ Rugman and Verbeke's (2004) classification imposes export thresholds when building the categories (e.g. at least $50 \%$ of firm's exports in the home region to be classified as a home region oriented and more than $50 \%$ of firm's export in any region other than their home region to be classified as host region oriented). By modifying these thresholds, Osegowitsch and Sammartino (2008) showed that the results were not robust because they changed depending in the thresholds selected.
} 
2007; Bianchi 2014; Cuervo-Cazurra 2008; Cyrino et al. 2010; Hermelo Diaz and Vassolo 2012; Lopez et al. 2009; Sahaym and Nam 2013; Sethi 2009). Moreover, scientific literature focused on internationalization of export firms from Latin America (including goods from the agricultural sector) is even scarcer. To our knowledge the studies by Bianchi and Garcia (2007), Bianchi (2014), Crick, Chaudhry, and Batstone (2000), Heyder et al. (2011), and Sethi (2009) are the only cases available. However, they do not explore firms' internationalization strategies over time, or do not target firms from Latin America.

\subsection{The Fruit Sector in Chile}

After the period between 1960 and 1973 when an import substitution model prevailed, and the national economy was mainly based on copper mining, an open economic model and strong agricultural export strategy was established by the government. Consequently, Chile achieved exponential growth in exports leading to a significant increase in GDP. In addition, there was a gradual elimination of tariff barriers, and the country opened up significantly to international markets through the establishment of a significant number of trade agreements with countries all over the world. With the introduction of non-traditional agricultural exports in the late 1970s, it became a global exporter of fruit and vegetables (Agosin and BravoOrtega 2009; Otter et al. 2014; Gwynne 2003; Foster and Valdes 2006). The fruit sector specifically has contributed to the Chilean economy by accounting for almost $50 \%$ of total exports, making this country the main fresh fruit exporter in the Southern Hemisphere and one of the most important in the world (Klerkx et al. 2012; ODEPA 2017) North America and Europe have become the main markets for Chilean fruit exports due to Chile's counterseasonal location in the Southern Hemisphere, and the introduction of non-traditional agricultural exports in Latin America (Sparks and Bravo-Ureta 1993). Nowadays, with more than 26 free trade agreements in 64 markets, Chile is one of the most open economies in the world (DIRECON 2018). During the study period, Chile signed trade agreements with Malaysia (2012), Vietnam (2014), Hong Kong (2014) and Thailand (2015). More recently, Chile signed a new agreement with Indonesia (2017), which has not yet been implemented, and is currently negotiating one with South Korea and re-negotiating their agreement with China. 
Fruit exports remain the most important activity in Chile's agricultural sector, representing around $2.6 \%$ of the total GDP, almost $50 \%$ of the total agricultural exports and $40 \%$ of gross agricultural production over the last decade (Retamales and Sepúlveda 2011; Klerkx et al. 2012). Chile is the most important fruit exporter in the Southern Hemisphere, the leading exporter of table grapes worldwide and the second of blueberries and cherries. The fruit sector in Chile accounts for 320 thousand hectares and generates around 5 million tons of total production quantity, of which 2.6 million tons are exported as fresh fruit resulting in more than 4,800 billion USD of sales volume per year. The main fruits exported are apples, grapes, kiwifruit, pears, plums and avocados (ODEPA 2017; Barrena et al. 2013). With a membership of more than 350 fresh fruit producers/exporters, which represents around $96 \%$ of the total fruit exported and $63 \%$ of the fruit produced in the country, the existence of the Association of Chilean Fruit Exporters (ASOEX) indicates forward integration in the Chilean fruit value chain. This is particularly important for large scale producers, who gain increased bargaining power and demand more managerial control both in the export process and with regards to the choice of destination markets (Melo et al. 2014). The great dependence of Chilean agricultural firms on export activities is clear from the very low proportion of firms in the agricultural sector making use of foreign direct investments over the past few decades. For the period between 1990 and 2014, foreign direct investments in this sector accounted for only $2.6 \%$ in total (DIRECON 2015).

The unprecedented economic development in Chile has led to its admittance to the OECD as the first country from Latin America, and its categorization as a high-income country by the World Bank in recent years was also based on the sizable importance of the agricultural export sector in the country's economy (World Bank 2017; OECD 2010). Consequently, it becomes almost self-evident that Chile can be considered a prime example for firms' internationalization strategies in the agricultural sector of an emerging economy in Latin America.

\subsection{Data and Methodology}

This empirical longitudinal study is based on data from Eximfruit (2009-2015). As we are interested in studying firms' internationalization strategies over time, only firms who 
reported uninterrupted international sales over a seven-year time period from 2009 to 2015 were included in the analysis, ensuring the inclusion of only those which are committed to the internationalization of their businesses, that have established stable market relations, and are not sporadic exporters. Thus, the final sample used in this study includes 233 exporters, which represents on average $40.38 \%$ of all the exporters included in the database of Eximfruit (2009-2015), but their export volume accounts on average for $83.48 \%$ of the total fruit exports. The time period selected corresponds to the most recent disaggregated statistics available on Chilean fresh fruit exports. This period also leaves out the year of the financial crisis (2008), which heavily affected Latin American economies and the markets where they exported, restraining export volumes. Therefore, including this year may bias the results of this study.

The matrix of multi-nationality developed by Aggarwal et al. (2011) was selected as a methodological base for this study due to its flexibility, intuitiveness and the consideration of two important internationalization dimensions (depth and scope). Additionally, it is neutral with respect to a firm's entry mode and facilitates the longitudinal analysis of firms' internationalization, from slowly evolving firms to born-global firms. This framework was combined with the multi-nationality classification of Rugman and Verbeke (2004), as it is one of the most important and widely employed internationalization classification systems in international business literature. At the same time, even when the matrix of multi-nationality doesn't include an explicit measure for distance, it incorporates geographic distance (which is correlated to cultural and psychic distance due to physical proximity) by classifying firms according to their sales dispersion in different geographic regions. Therefore, home regional activities will be less distant than trans-regional or global activities (Aggarwal et al. 2011).

The framework employed to asses firms' internationalization level in this study includes internationalization depth and scope (Aggarwal et al. 2011) and the two additional dimensions suggested by Fernández Olmos and Díez-Vial (2015) and Kuivalainen et al. (2012): scale and time (Figure 1). Regarding internationalization depth, foreign sales (trade) and foreign subsidiaries (investment) are the two variables most commonly used in both single-attribute and multi-attribute studies when measuring the level of multinationality in international business research (Aggarwal et al. 2011). In line with previous authors (Rugman and Verbeke 2004; Berrill and Mannella 2013; Mullen and Berrill 2015), this study focuses 
on the level of trade by using foreign sales to measure internationalization depth. Rugman and Verbeke (2004) pointed out that even when there are more measures that can be employed to analyze internationalization, sales spreads turn out to be the only real measurement of performance at an observed output level, and the correct measure of international diversification (Hennart 2007).

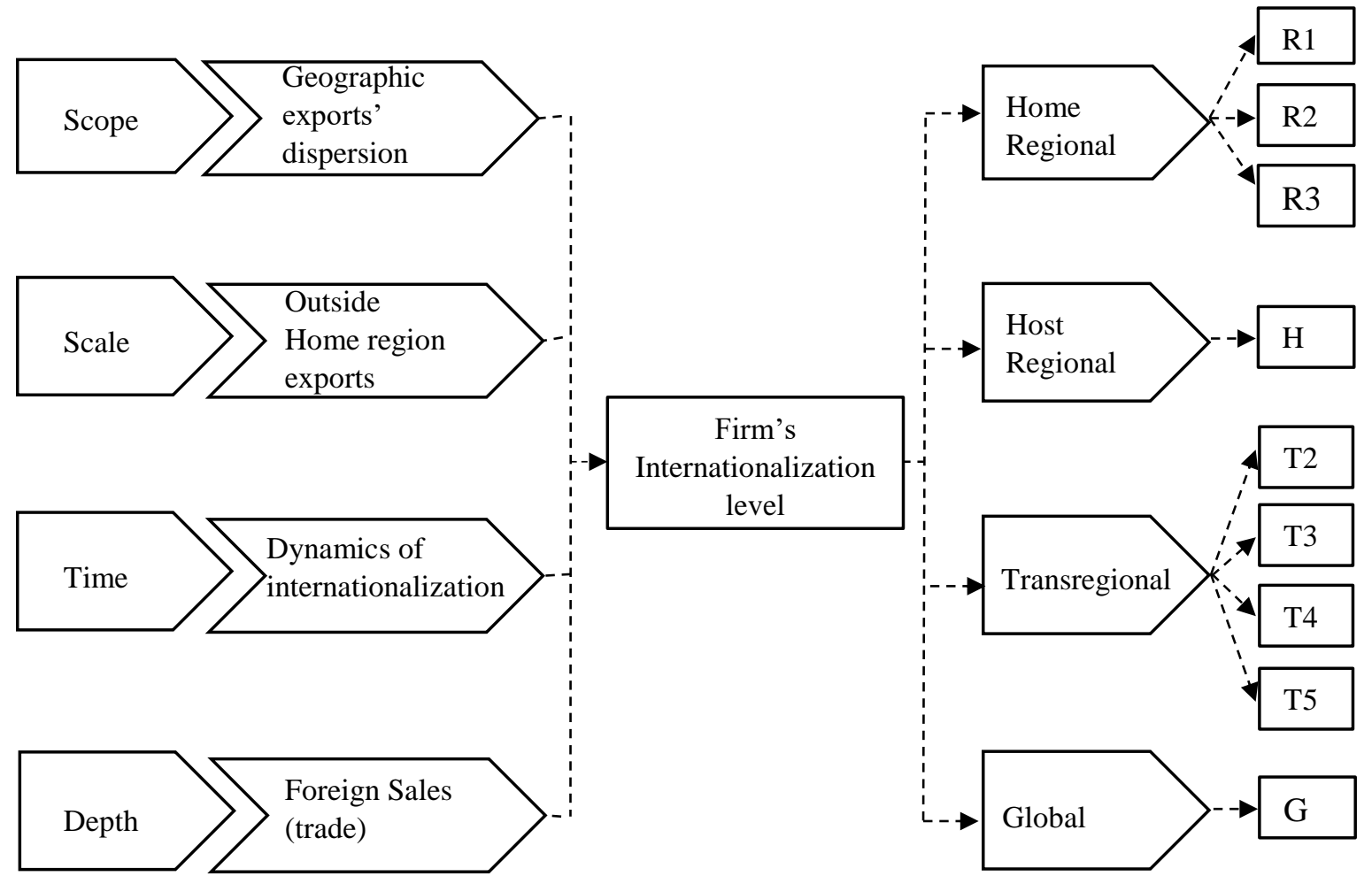

Figure 1. Firms' internationalization classification scheme

Notes: R (Regional firms), R1 (exports to less than 1/3 of home region countries), R2 (exports to more than 1/3 but less than $2 / 3$ of home region countries), R3 (exports to more than $2 / 3$ of home region countries), $\mathrm{H}$ (Host regional firms), $\mathrm{T}$ (Transregional firms: from 2 to 5 geographic regions), $\mathrm{G}$ (Global firms).

Geographic scope $e^{10}$ is defined by Banalieva and Dhanaraj (2013, p.108) as: "the extent, dispersion and diversity of the foreign markets that a firm expands into". Firms' internationalization scope or breadth is measured in this study by using the number of geographic regions they have as export destinations. Similar to previous studies on internationalization in Latin America (Aulakh et al. 2000; Boehe and Jiménez 2016) and

\footnotetext{
${ }^{10}$ This geographic definition of scope differs from that given by Hennart (2011, p.138) for multinationality, where it refers to "the number of technologically separate stages the firm has integrated".
} 
following the geographical distribution generally employed in Chile to report export destinations, six geographic regions are distinguished in this study: the Far East \& South Pacific, the Middle East \& Africa, North America, Mexico, Central America \& the Caribbean, South America, and Europe. Such continent based classification in defining geographic regions is preferable over political or economic based classification, due to a lower likelihood of changes in the period of analysis (Aggarwal et al. 2011; Banalieva and Dhanaraj 2013).

Unlike other authors, who have limited the analysis to the triad or the broad triad region (Rugman and Verbeke 2004; Rugman and Oh 2013; Rugman et al. 2012; Asmussen 2009; Osegowitsch and Sammartino 2008; Rugman and Verbeke 2008), all the inhabited continents are included in the analysis, as suggested by Rugman and Oh (2013) for obtaining comprehensive results on a globalized market, in which notably emerging economies have recently benefited as recipients of significant investment and international sales from other emerging economies (Berrill 2015; Sethi 2009).

In this study, firms are classified in terms of their internationalization level by following the Aggarwal et al. (2011) multi-nationality matrix, since it does not impose any subjective and exclusionary thresholds, unlike the one proposed by Rugman and Verbeke (2004). Aggarwal et al. (2011) classify firms as domestic (D) when they do not export, regional (R) if they export only to their home region ${ }^{11}$, transregional $(\mathrm{T})$ when they export to more than one region and global $(\mathrm{G})$ if the firms export to all the geographic regions. This scheme excludes firms exporting only to one region other than the home region. However, as mentioned before, in the case of Chilean fruit exports, several other emerging economies located in the Southern Hemisphere, particularly in Latin America, North America and Europe are considered the natural target markets (Agosin and Bravo-Ortega 2009; Otter et al. 2014; Sparks and Bravo-Ureta 1993). For this reason, it could be expected that otherwise a significant number of firms exporting only to one of these two regions could be excluded from or miss-categorized during the analysis. Thus, the framework proposed by Aggarwal et al. (2011) is extended by adding the category "host regional" $(\mathrm{H})$, which is based on the

${ }^{11}$ Home region refers to the geographic region where a firm is physically located, which in this case turns to be South America. 
definition of a "host regionally" oriented firm in Rugman and Verbeke's (2004) classification system, but without imposing any threshold on the firm's exports to be included. Conversely, the domestic category (D) is excluded from the analysis since this study focuses on export companies only. Thereby, the framework employed classifies firms as home regional (R), host regional $(\mathrm{H})$, transregional $(\mathrm{T})$ or global $(\mathrm{G})$. A firm is classified as regional $(\mathrm{R})$ when it exports only to the home region. Simultaneously, a regional firm (R) will be sub-classified as $\mathrm{R} 1$ if it exports to less than one third of the countries in the home region, $\mathrm{R} 2$ if it does to more than one third but less than two third of the countries and R3 if it exports to more than two third of the countries. A host regional firm $(\mathrm{H})$ exports to only one geographic region different than the home region. Firms exporting to more than one region, but less than six, are classified as transregional $(\mathrm{T})$. They are then subdivided as $\mathrm{T} 2$ when exporting to two regions, T3 to three regions, T4 to four regions and T5 to five regions. Finally, firms are classified as global $(\mathrm{G})$ when they export to all the six geographic regions.

In their classification system Aggarwal et al. (2011) only consider firms' geographic distribution of exports unweighted. In this study, the Chadha and Berrill (2016) suggestion is followed by including in the analysis the share of every geographic region to total exports, and complementing it with the outside of home region sales percentage as a measure of scale. Using both measures (scope and scale) allows for a more robust analysis including the spread of exports, while simultaneously controlling for companies with a strong orientation towards a specific region (Chadha and Berrill 2016). Accounting for the relevance of foreign sales of firms and grouping their exports by similar markets (in this case geographic regions) permits us to identify the diversity of firms' markets, resulting in a real and correct measurement of internationalization (Hennart 2011).

According to Kuivalainen et al. (2012), time is a key dimension in the internationalization analysis because it incorporates dynamism in the concept. In our analysis, time is considered by analyzing the dynamics of firms' internationalization categories over the time and by only including firms with uninterrupted exports over the seven-year period between 2009 and 2015. Possible survivor bias effects are acknowledged (Rugman and Verbeke 2008) but the exclusion of firms without uninterrupted exports permits exploring the changes and the path or patterns of firms' internationalization and the speed of the process (O'Hagan-Luff and Berrill 2016; Chadha and Berrill 2016; Mullen and Berrill 2015). 


\section{$2.5 \quad$ Results}

\subsubsection{Geographical distribution of the fruit exports}

The distribution of total Chilean fruit exports and the number of companies exporting to the different regions in the data set identifies North America and Europe as the main destinations during the whole period of analysis (Table 2). Nevertheless, the importance of these two regions decreases between the years 2009 and 2015 by 4.84 and 6.47 percentage points respectively in terms of export shares, and $0.54 \%$ and $1.73 \%$ regarding the number of exporting firms. The latter shows that the decreases in reported export shares are due to sales redistribution, and not due to general shifts in export destinations. The case of the Far East \& South Pacific is different; the export share growth (13.04 percentage points) has also been accompanied by an increase of 35 additional firms selling fresh fruit to this region in 2015, representing a growth of $26.72 \%$.

Table 2. Distribution of total exports and number of firms by geographical region. $\mathrm{N}=233$

\begin{tabular}{|c|c|c|c|c|c|c|c|c|c|}
\hline Region & 2009 & 2010 & 2011 & 2012 & 2013 & 2014 & 2015 & Average & $\begin{array}{l}2009-2015 \\
\text { (Growth) }\end{array}$ \\
\hline \multicolumn{10}{|c|}{ Panel A: Distribution of exports (\%) } \\
\hline South America & 7.92 & 5.64 & 7.41 & 9.01 & 8.19 & 8.71 & 8.39 & 7.89 & 0.48 \\
\hline Europe & 32.97 & 33.53 & 31.53 & 29.39 & 29.58 & 28.98 & 26.50 & 30.35 & -6.47 \\
\hline Far East \& South P & 9.88 & 10.50 & 13.69 & 16.83 & 17.57 & 20.42 & 22.92 & 15.97 & 13.04 \\
\hline $\begin{array}{l}\text { Mexico, Central America \& } \\
\text { Caribbean }\end{array}$ & 3.88 & 2.94 & 3.12 & 3.15 & 2.89 & 3.09 & 2.87 & 3.13 & -1.01 \\
\hline Middle East \& Africa & 4.54 & 4.57 & 5.06 & 3.93 & 3.99 & 2.46 & 3.35 & 3.98 & -1.19 \\
\hline North America & 40.81 & 42.82 & 39.19 & 37.70 & 37.78 & 36.35 & 35.97 & 38.66 & -4.84 \\
\hline \multicolumn{10}{|c|}{ Panel B: Distribution of firms (number) } \\
\hline South America & 106 & 129 & 123 & 133 & 132 & 130 & 128 & 125,86 & $22(20.75)$ \\
\hline Europe & 173 & 179 & 179 & 177 & 183 & 174 & 170 & 176,43 & $-3(-1.73)$ \\
\hline Far East & 131 & 148 & 164 & 163 & 169 & 166 & 166 & 158,14 & $35(26.72)$ \\
\hline $\begin{array}{l}\text { Mexico, Central America \& } \\
\text { Caribbean }\end{array}$ & 89 & 83 & 78 & 79 & 74 & 74 & 70 & 78,14 & $-19(-21.35)$ \\
\hline Middle East \& Africa & 43 & 48 & 61 & 58 & 62 & 51 & 57 & 54,29 & $14(32.56)$ \\
\hline North America & 185 & 191 & 190 & 194 & 195 & 191 & 184 & 190,00 & $-1(-0.54)$ \\
\hline
\end{tabular}

Notes: Last column in Panel A shows variations between 2009 and 2015 expressed as absolute changes (percentage points) and not as percentage changes to facilitate the analysis. Last column in Panel B shows variations between 2009 and 2015. Figures in parentheses correspond to percentages.

The other foreign regions represent lower export shares and show less significant changes. South America, the home region in this study, represents on average $7.89 \%$ of total exports with a rate of change of 0.48 percentage points over the seven years analyzed. However, the 
number of firms rises to $22(20.75 \%)$, showing either the entry of firms with a low volume of exports, or a redistribution of export shares among enterprises. Along with total export shares, the total number of firms exporting to the Mexico, Central America \& the Caribbean region also exhibit a large decrease $(21.35 \%)$. Even though export market shares to the Middle East \& Africa decrease between the years 2009 and 2015 (1.19 percentage points), the number of firms increases, representing a growth rate of $32.56 \%$, suggesting that some export firms which were already established in these markets reduced their exports, while new firms entering the market started by exporting lower quantities. A similar strategy was pointed out by Sonntag et al. (2016) by which exporting firms minimize their risk.

\subsubsection{Results of the firm classification}

The classification by distribution of the loci of destinations as a measure for scope in accordance with the extended multi-nationality matrix, shows that on average during the period under analysis that $65.12 \%$ of the sample are transregional firms $(\mathrm{T}), 16.06 \%$ are global (G), 12.75\% are host regional $(\mathrm{H})$ and 6.07\% are classified as regional firms (R) (Table 3). Similar results were found by Aggarwal et al. (2011), Berrill and Mannella (2013), and O'Hagan-Luff and Berrill (2016) regarding the importance of global and transregional firms from other sectors or industrialized countries. However, $\mathrm{H}$ firms were not identified with the original matrix of multi-nationality. Thereby the distribution of firm numbers shows yearly variability to differing extents and directions among these particular categories. The $\mathrm{T}$ category, with its subcategories T2, T3, T4 and T5, shows a high variability over the period of analysis. Therefore, most of the firms are subcategorized as T3 (average of firms: 19.93\%). However, the T3 subcategory experiences extreme changes in firm-numbers with large increases until the year 2011 followed by substantial decreases. Similar patterns can be observed for the second largest category, the G category. Firm numbers in this category show a notable increase until the year 2013 and decreases afterwards. The H-category contains on average $12.75 \%$ of the firms over the seven years. Firms in this category show a partial reverse trend in changes: the number of firms diminishes drastically between the years 2011 and 2013, to then increases again until 2015. Compared to the other firm categories, firm numbers in the R-category show less variability. All R firms are subclassified as R1 until the year 2015 when two firms are classified as R2 firms. None of the companies are subclassified as R3 classification within the time period analyzed. Overall, the distribution of the firms in 
the different categories over the period of analysis reveals a trend towards greater export market diversification in the sample of companies. Simultaneously, the variability in firm numbers of the different (sub-) categories over time implies certain classification changes of firms and, thus, dynamics in internationalization strategies (time dimension) which will be analyzed in more detail in connection to Table 5 later in this section.

Table 3. Classification of firm internationalization. $\mathrm{N}=233$

\begin{tabular}{lcccccccc}
\hline Category & 2009 & 2010 & 2011 & 2012 & 2013 & 2014 & 2015 & Average \\
\hline R1 & 13 & 16 & 14 & 14 & 13 & 14 & 13 & 14 \\
& $(5.58)$ & $(6.87)$ & $(6.01)$ & $(6.01)$ & $(5.58)$ & $(6.01)$ & $(5.58)$ & $(5.95)$ \\
R2 & 0 & 0 & 0 & 0 & 0 & 0 & 2 & 0 \\
& $(0.00)$ & $(0.00)$ & $(0.00)$ & $(0.00)$ & $(0.00)$ & $(0.00)$ & $(0.86)$ & $(0.12)$ \\
Total R & 13 & 16 & 14 & 14 & 13 & 14 & 15 & 14 \\
& $(5.58)$ & $(6.87)$ & $(6.01)$ & $(6.01)$ & $(5.58)$ & $(6.01)$ & $(6.44)$ & $(6.07)$ \\
H & 41 & 30 & 25 & 24 & 22 & 32 & 34 & 30 \\
& $(17.6)$ & $(12.88)$ & $(10.73)$ & $(10.3)$ & $(9.44)$ & $(13.73)$ & $(14.59)$ & $(12.75)$ \\
T2 & 46 & 41 & 39 & 37 & 39 & 32 & 36 & 39 \\
& $(19.74)$ & $(17.6)$ & $(16.74)$ & $(15.88)$ & $(16.74)$ & $(13.73)$ & $(15.45)$ & $(16.55)$ \\
T3 & 40 & 39 & 55 & 50 & 52 & 46 & 43 & 46 \\
& $(17.17)$ & $(16.74)$ & $(23.61)$ & $(21.46)$ & $(22.32)$ & $(19.74)$ & $(18.45)$ & $(19.93)$ \\
T4 & 35 & 36 & 27 & 38 & 30 & 45 & 38 & 36 \\
& $(15.02)$ & $(15.45)$ & $(11.59)$ & $(16.31)$ & $(12.88)$ & $(19.31)$ & $(16.31)$ & $(15.27)$ \\
T5 & 27 & 37 & 33 & 30 & 36 & 26 & 29 & 31 \\
& $(11.59)$ & $(15.88)$ & $(14.16)$ & $(12.88)$ & $(15.45)$ & $(11.16)$ & $(12.45)$ & $(13.37)$ \\
Total T & 148 & 153 & 154 & 155 & 157 & 149 & 146 & 152 \\
& $(63.52)$ & $(65.67)$ & $(66.1)$ & $(66.53)$ & $(67.39)$ & $(63.94)$ & $(62.66)$ & $(65.12)$ \\
& & & & & & & & \\
G & 31 & 34 & 40 & 40 & 41 & 38 & 38 & 37 \\
& $(13.30)$ & $(14.59)$ & $(17.17)$ & $(17.17)$ & $(17.6)$ & $(16.31)$ & $(16.31)$ & $(16.06)$ \\
\hline
\end{tabular}

Notes: R (Regional firms), R1 (exports to less than 1/3 of home region countries), R2 (exports to more than 1/3 but less than $2 / 3$ of home region countries), $\mathrm{H}$ (Host regional firms), $\mathrm{T}$ (Transregional firms: from 2 to 5 geographic regions), $\mathrm{G}$ (Global firms). Category R3 is omitted in the table because it does not contain any firm. Figures in parentheses correspond to percentages.

Further, average exports distributed by geographical region are analyzed according to the internationalization category (Table 4). It becomes evident that North America is the most important region for firms in all categories, especially for the less internationalized $(\mathrm{H}, \mathrm{T} 2$ and T3). Particularly for firms in the $\mathrm{H}$ category, which export $64.80 \%$ of their total exports to North America, it represents a key-export destination. The second most important destination region is Europe, especially in the case of the most internationalized firm categories (T4, T5 and G). In fact, for G firms, North America and Europe show an almost identical share of export distribution. The regions Mexico, Central America \& the Caribbean and Middle East \& Africa are still less important for Chilean fruit export companies. Finally, 
for almost all categories (except $\mathrm{H}$ ), the ratio of exports outside the home region to total exports (as a measure of internationalization scale) is greater than $91 \%$. South America is the third most important export market for T2 firms and the fourth most important market for T3, T4, T5 and G firms. Notably H firm's high export shares to the regions North America, Europe and Far East \& South Pacific, coupled with a zero percent export share to South America, gives evidence on the presence of a so called "born-global internationalization".

Table 4. Geographical distribution of average exports by internationalization category 2009-2015. $\mathrm{N}=233$

\begin{tabular}{lcccccc}
\hline Region & $\mathrm{H}$ & $\mathrm{T} 2$ & $\mathrm{~T} 3$ & $\mathrm{~T} 4$ & $\mathrm{~T} 5$ & $\mathrm{G}$ \\
\hline Europe (\%) & 22.58 & 22.24 & 23.29 & 30.93 & 29.76 & 32.21 \\
Far East \& South Pacific (\%) & 8.24 & 7.01 & 15.09 & 15.23 & 16.34 & 17.09 \\
Mexico, Central America \& & 0.87 & 4.82 & 2.14 & 1.59 & 2.57 & 3.56 \\
Caribbean (\%) & 3.51 & 2.74 & 1.26 & 0.81 & 2.22 & 5.42 \\
Middle East \& Africa (\%) & 64.80 & 54.38 & 53.96 & 45.66 & 42.54 & 32.95 \\
North America (\%) & $0.00(-)$ & $8.81(-14.15)$ & $4.26(0.56)$ & $5.78(0.52)$ & $6.57(0.06)$ & $8.76(1.69)$ \\
South America (\%) &
\end{tabular}

Notes: H (Host regional firms), T (Transregional firms: from 2 to 5 geographic regions), G (Global firms). Category $\mathrm{R}$ is omitted because exports to home region are 100\%. Figures in parentheses in last row (South America) shows variations between 2009 and 2015 expressed as absolute changes (percentage points) and not as percentage changes to facilitate the analysis.

Dynamics in firms' internationalization strategies (time dimension) were first analyzed longitudinally by comparing the distribution of the firms' changes in categories between 2009 and 2015. Thereafter the yearly variation between the categories each firm had experienced over the seven-year period was tracked, to identify if they followed a linear or a non-linear internationalization/de-internationalization path.

Results of the analysis of the changes between 2009 and 2015 are shown in Table 5 (The yearly internationalization changes experienced by firms for each category can be found in the Table A1 in the appendix). From the 13 firms categorized as regional (R) in 2009, ten (76.92\%) remain in this category by 2015 , while three firms internationalize (two firms achieve T2 category and one firm reaches T3).

The $\mathrm{H}$ category represents, with a number of $25(60.98 \%)$, the highest share of firms internationalizing in the dataset and simultaneously the only category with any firm deinternationalizing. In fact, this category includes the only firm to advance five categories, and two firms advancing four categories by the end of the seven-year period. These numbers 
represent even greater support to the "born-global internationalization" hypothesis with regard to firms in the $\mathrm{H}$ category. Among the $\mathrm{T} 2$ firms, twelve $(26.09 \%)$ do not change in classification, 14 (30.43\%) de-internationalize and 20 (43.48\%) expand to other geographic regions and enter higher categories by 2015. One of the latter even advances four categories. In the case of $\mathrm{T} 3$ firms, 15 firms (37.50\%) internationalize over the time period 2009 until 2015, thus, almost as many as remain in the same category 14 (35.00\%), while eleven companies do not show any classification-change. The T4 category shows the highest share of firms de-internationalizing $(45.71 \%)$, with one reducing four categories to become regional again. Beside this firm, only one T3 firm and two T2 firms become regional firms again by 2015. From the 27 firms classified as T5 in 2009, seven (25.93\%) advance in their internationalization level and become global by 2015, twelve (44.44\%) remain in the same category and the remaining eight $(29.63 \%)$ de-internationalize. Among the $31 \mathrm{G}$ firms, 25 $(80.65 \%)$ remain global in 2015 while only six (19.63\%) de-internationalize.

When analyzing the distribution of the firms changes in categories from 2009 to 2015 as aggregate data (last column in Table 5), it becomes evident that 102 (43.78\%) of the firms are sorted in the same category in 2015 as they were in 2009. From the remaining 131 firms, $74(31.76 \%)$ shift one category and $57(24.46 \%)$ more than one. The share of firms internationalizing $(32.62 \%)$ is more prominent than those de-internationalizing $(23.61 \%)$ when comparing 2009 and 2015.

Regarding the number of firms changing category and the corresponding direction of change on a yearly basis of the entire sample (see Figure 2), it becomes evident that deinternationalization constantly increases, exceeding internationalization in 2013/2014, showing reversed trends in the following year. After the convergence in trends, the numbers reveal a more balanced scenario in the year 2015. Over the entire period of time observed, the share of those exporters showing no variation is higher than those changing. 
Table 5. Changes in classifications of firm internationalization from 2009 to 2015 . N=233

\begin{tabular}{lcccccccc}
\hline $\begin{array}{l}\text { Number of } \\
\text { categories changed }\end{array}$ & $\mathrm{R}$ & $\mathrm{H}$ & $\mathrm{T} 2$ & $\mathrm{~T} 3$ & $\mathrm{~T} 4$ & $\mathrm{~T} 5$ & $\mathrm{G}$ & Total \\
\hline-4 & - & - & - & - & 1 & 0 & 0 & 1 \\
& & & & 1 & $(2.86)$ & $(0.00)$ & $(0.00)$ & $(0.43)$ \\
-3 & - & - & - & $(2.50)$ & $(5.71)$ & $(3.70)$ & $(3.23)$ & $(2.15)$ \\
& & & 3 & 5 & 3 & 2 & 3 & 16 \\
-2 & - & - & $(6.52)$ & $(12.50)$ & $(8.57)$ & $(7.41)$ & $(9.68)$ & $(6.87)$ \\
& & 0 & 11 & 5 & 10 & 5 & 2 & 33 \\
-1 & - & $(0.00)$ & $(23.91)$ & $(12.50)$ & $(28.57)$ & $(18.52)$ & $(6.45)$ & $(14.16)$ \\
& 10 & 16 & 12 & 14 & 13 & 12 & 25 & 102 \\
0 & $(76.92)$ & $(39.02)$ & $(26.09)$ & $(35.00)$ & $(37.14)$ & $(44.44)$ & $(80.65)$ & $(43.78)$ \\
& 0 & 13 & 10 & 9 & 2 & 7 & - & 41 \\
+1 & $(0.00)$ & $(31.71)$ & $(21.74)$ & $(22.50)$ & $(5.71)$ & $(25.93)$ & & $(17.60)$ \\
& 2 & 5 & 4 & 6 & 4 & - & - & 21 \\
+2 & $(15.38)$ & $(12.20)$ & $(8.70)$ & $(15.00)$ & $(11.43)$ & & & $(9.01)$ \\
& 1 & 4 & 5 & 0 & - & - & - & $(4.29)$ \\
+3 & $(7.69)$ & $(9.76)$ & $(10.87)$ & $(0.00)$ & & & & 3 \\
+4 & 0 & 2 & 1 & - & - & - & - & $(1.29)$ \\
& $(0.00)$ & $(4.88)$ & $(2.17)$ & - & & & & 1 \\
+5 & 0 & 1 & - & - & - & - & - & $(0.43)$ \\
Total & $(0.00)$ & $(2.44)$ & - & - & & & & 233 \\
\hline
\end{tabular}

Notes: $\mathrm{R}$ (Regional firms), $\mathrm{H}$ (Host regional firms), $\mathrm{T}$ (Transregional firms: from 2 to 5 geographic regions), $\mathrm{G}$ (Global firms). Figures in parentheses correspond to percentages in every category.

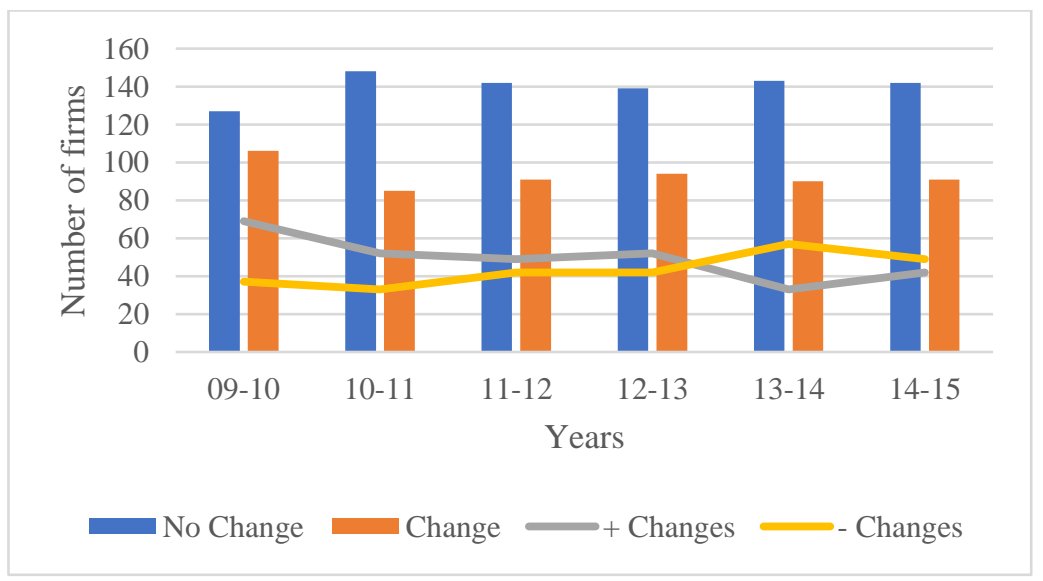

Figure 2. Number of firms changing internationalization category and corresponding direction of change

With respect to the internationalization and de-internationalization paths followed by the firms in terms of the number of new markets accessed, results indicate that firms do not follow only one path, but they show evidence of both internationalization and deinternationalization interchangeably over the years. Thus, separation into pure 
internationalizing or de-internationalizing firms cannot be considered logical. Consequently, Table 6 shows distributions of both paths for the whole sample. These distributions show evidence that from those firms internationalizing, 105 (45.06\%) follow a linear path, 25 firms (10.73\%) follow a non-linear path ${ }^{12}$, while 37 firms (15.88\%) interchange periods of linear and non-linear internationalization (mixed path). The remaining 66 firms (28.33\%) do not show any evidence of internationalization. Simultaneously, in the case of firms' deinternationalization, $123(52.79 \%)$ follow a linear path, 38 firms (16.31\%) a non-linear path, $12(5.15 \%)$ follow a mixed path and $60(25.75 \%)$ do not show de-internationalization developments. These results imply that most firms prefer to increase or decrease their market portfolio by only one additional geographic region per year, which could indicate the existence of some liability of inter-regional foreignness when accessing new markets. Results also highlight the dynamism of the Chilean fresh fruit export sector, especially in the case of the host region and transregional oriented firms.

Table 6. Firms' internationalization and de-internationalization paths. $\mathrm{N}=233$

\begin{tabular}{lcc}
\hline Path & Internationalization & De-internationalization \\
\hline Linear & $105(45.06)$ & $123(52.79)$ \\
Non-linear & $25(10.73)$ & $38(16.31)$ \\
Mixed & $37(15,88)$ & $12(5.15)$ \\
No change & $66(28.33)$ & $60(25.75)$ \\
Total & 233 & 233 \\
\hline
\end{tabular}

Notes: Figures in parentheses correspond to percentages. Internationalization and de-internationalization paths are shown separately because firms show evidence of both paths, however the sample size remains $\mathrm{N}=233$.

Finally, the average export levels of the firms (in thousands of boxes) and the average age of the firms (in years) were examined according to the different internationalization categories to see if differences exist between them (See Table 7). According to the ANOVA analysis ${ }^{13}$, in both cases there is a positive correlation with the level of internationalization, so higher levels of internationalization correspond to higher levels of firms' exports and higher firm age. T4 firms present a significantly higher level of exports, in comparison to R, H and T2 firms, while T5 firms show in addition higher export levels than T3 firms. Global firms have

\footnotetext{
${ }^{12}$ Firms following a linear path include only one single additional market per year to their portfolio, while firms following a non-linear path add more than one.

${ }^{13}$ Results available upon request to the authors.
} 
significantly higher levels of exports than the other categories. In the case of the firms' age, the ANOVA analysis shows that $\mathrm{R}$ firms are significantly younger than the other categories, while $\mathrm{G}$ firms are significantly older. There are no other statistically significant differences other than the ones afore mentioned.

Table 7. Firms' average exports and age by internationalization category 2009-2015. N=233

\begin{tabular}{lcc}
\hline Category & $\begin{array}{c}\text { Firms' Average Exports } \\
\text { (Thousands of boxes) }\end{array}$ & $\begin{array}{c}\text { Firms' Average Age } \\
\text { (Years) }\end{array}$ \\
\hline R & $40,747.89$ & 8.36 \\
H & $111,506.24$ & 13.05 \\
T2 & $186,557.30$ & 13.05 \\
T3 & $347,183.90$ & 13.83 \\
T4 & $666,175.50$ & 13.90 \\
T5 & $871,552.10$ & 15.51 \\
G & $3,194,283.30$ & 19.41 \\
\hline
\end{tabular}

Notes: R (Regional firms), H (Host regional firms), T (Transregional firms: from 2 to 5 geographic regions), G (Global firms).

\subsection{Conclusions and Discussion}

This paper has examined the internationalization strategies of export companies from the agricultural sector in Chile, as a prime example of emerging economies especially in Latin America. The multi-nationality matrix developed by Aggarwal et al. (2011) was extended and tested, to classify 233 fruit export firms according to their internationalization strategies over a seven-year period from 2009 to 2015. Overall, the results are in line with previous studies from other sectors or industrialized countries (Aggarwal et al. 2011; Berrill and Mannella 2013; O’Hagan-Luff and Berrill 2016; Chetty and Campbell-Hunt 2003), showing that most companies are transregionally $(65.12 \%)$ and globally oriented $(16.06 \%)$. This is an assumption that has not been tested before in the academic literature and gives strong evidence on the general applicability and adaptability of the framework regarding the case of emerging economies' agricultural sectors. However, based on the extension of the Aggarwal et al. (2011) classification system, it was possible to identify a significant share of the firms (12.75\%) that export only to one geographic region outside South America. This result supports the need to include the $\mathrm{H}$ category as an extension of the matrix of multi-nationality for this specific group of countries in this sector, in order to account for such "host regional" firms. In particular, this category allows for more precision and flexibility of separation in the classification matrix, by giving evidence on the presence of so called "born-global 
internationalization" as a strategy among agricultural export companies from emerging economies.

Additionally, by including each firm's share of exports to every geographic region in relation to total exports as a measure of scale in the framework, the importance of every region for Chilean fruit exports is highlighted to provide a more robust analysis. North America appears as the most important export market, especially for firms lower on the internationalization scale (H, T2 and T3), while Europe constitutes the second most important with relatively greater export shares among firms higher on the internationalization scale (T4, T5 and G). Notably, firms of the $\mathrm{H}$ category export nearly $90 \%$ of their total exports to these markets. However, both regions have overall seen significant decreases in their export shares in recent years, relativizing the importance of these markets, which have been the key markets since the beginning of the agricultural globalization era. Currently, firms highly concentrated in the North America region may face even higher risks due to the overall increasing insecurity associated with trade relations to the United States. These findings imply that it is recommended that public organizations and private trade associations, such as the Chilean Governmental Export Promotion Bureau (PROCHILE), ASOEX (private, non-profit) and the Federation of Chilean Fruit Producers (FEDEFRUTA) (private, non-profit), pay close attention to firms in the categories $\mathrm{T} 2$ and $\mathrm{T} 3$, but particularly $\mathrm{H}$, to assist them in stabilizing trade relations with these regions, while simultaneously identifying new market opportunities as a basis for broadening their export scope and scale. In line with these implications, the Far East \& South Pacific has become the most important emerging market for all categories, showing increases in both the number of firms and the export share destined to this region. Referring to Sonntag et al. (2016), these changes in export shares towards South-South trade can be explained by two main factors: first, by the economic growth of some Asian economies over the past several years that is reflected by an increasing demand and willingness to pay for products such as fresh fruits; and second, by the diminished attractiveness of developed countries (such as Europe) as export markets due to price reductions, currency devaluations and stricter food standards. Additionally, the technological restrictions that curtail exporting perishable products to remote markets has been overcome by advances and improvements in packing and transport systems that extend the life-cycle of fruits, allowing a penetration of geographically distant markets (León 2016). The trend 
towards South-South trade is accompanied by an increase of free trade agreements recently signed by Chile with countries in the Far East \& South Pacific region (DIRECON 2018), reflecting the particular relevance assigned to international political relations for developing global market diversification; efforts that should be further extended. The relative importance of the South American region as another option for market diversification becomes evident in the increasing number of firms exporting to this destination rather than in export volumes. Consequently, public organizations and private trade associations, should assign more resources to further exploit the fresh fruit markets in South America as part of their home region, revitalizing trade agreements and fostering "business to business" operations. These markets could be a good alternative due to shorter geographical distances and similar culture and language (Rugman and Verbeke 2004; Rugman and Verbeke 2007). Finally, the regions Mexico, Central America \& the Caribbean and Middle East \& Africa are still of minor importance concerning the export distribution for all the internationalization categories.

Furthermore, the results of this study indicate the relevance of a longitudinal analysis (time dimension) in the investigation of firms' internationalization strategies, which is still underrepresented in international business literature so far. When tracking the changes experienced by firms over time, it becomes evident that $\mathrm{R}$ firms in particular show the lowest number of internationalization attempts, implying that these firms may need more support from extension services and export/trade associations in order to overcome the entry barriers of non-home region markets, such as lack of market knowledge, uncertainty regarding legal environment and liability, as well as differences in business ethics due to cultural differences (León 2016). Simultaneously, H firms show a higher number of internationalization attempts, leading to the interpretation that born-global firms which initially exported to non-home markets face lower entry barriers when entering new export markets, at least those showing similar characteristics (e.g. cultural, economic, and administrative) (Reuber et al. 2017). For entries in new markets with a great disparity in characteristics, the probability of success depends mostly on the capabilities and resources of the particular firm (Barney 1991). Vice versa, internationalization may bear the risk of destabilization of an export firm in the absence of these capabilities and resources (Reuber et al. 2017). In this regard, export support organizations can aid less experienced firms, by providing information on particular markets, legal conditions and particular codes of conduct in those regions. Additionally, it is crucial 
for export firms to receive background information on importers, including their reliability. Export supporting organizations should therefore regard the establishment and extension of business networks as their main focus, by activities such as opening external offices and forming new business alliances in countries with upcoming markets. Finally, private export associations should also place focus on their role as lobby groups to influence political decisions regarding international trade in favor of exporting firms' interests, and in particular, those that reduce trade risk. This is true for firms with lower export volumes that stick with a strategy that usually involves being regional or host at most. This is clearly an issue that policy makers need to take into account when designing policies to support small firms.

Additionally, when more deeply investigating the internationalization paths of the export firms over time, it becomes clear that firms do not follow only a single path, but rather that most of them interchange over the years following non-linear and mixed paths as well. However, a linear or incremental path of internationalization/de-internationalization can be observed in the majority of fruit exporting firms in Chile, considering the number of geographic regions served by their exports. Firms mainly prefer to extend their market scope by one single geographic region per year, indicating the presence of some liability of interregional foreignness. However, similar to large Brazilian agribusiness firms (Cyrino et al. 2010), Chilean fruit exporters do not follow the Uppsala gradualist internationalization approach in terms of psychic distance, as proposed in earlier studies on firms from the industrial sector (Rugman and Oh 2013; D’Angelo et al. 2013; Lopez et al. 2009). Instead, most of the firms do not start internationalizing by first entering nearby markets, and then expanding their export activities to more remote regions gradually. Rather, they act as bornglobal and born-international firms by entering distant regions directly (Kuivalainen et al. 2012; Kuivalainen et al. 2007). The higher risk of failure caused by such managerial "jumps into the deep end" further increases the importance and implications of public trade organizations and private export associations as already identified.

The high share of firms switching between categories/subcategories one or more times both forwards and/or backwards, plus the number of firms changing internationalization pathways over the years indicate the high dynamism in internationalization in the Chilean fruit export sector. Hence, internationalization cannot be considered a one-off management goal or status, but rather a dynamic process in which firms are constantly changing their strategy (Reuber 
et al. 2017). In this regard, policymakers and trade facilitation agencies in the Chilean fruit sector must focus not only on helping firms to become internationalized, but also on offering more flexible and adaptable services and training to prepare them to maintain their presence in international markets over time. Further research may address the reasons and impact on profitability behind the linear and non-linear internationalization strategies. We can expect that non-linear patterns may reduce profits as management focus and effort is switching year by year.

Even though Chile is a prime example of emerging economies in Latin America, there might be differences with other countries or sectors regarding cultural, political and economic systems that hinder the general applicability of the conceptual and practical implications offered by this study, that need to be considered in context. Thus, future studies using the extended framework developed here should therefore include and combine more exportbased activities from other sectors, as well as other emerging economies either from Latin America or different continents, to compare the results of this study and extend the evidence on its generalization and related empirical insights. In a related vein, further studies should employ other regional definitions different than the geographic (e.g. cultural, administrative and economic distance dimensions) to try to capture different effects on internationalization strategies. Additionally, this study focuses on one mode of international business activities only, namely the export of products, implying further research on developing and testing the framework regarding other entry modes such as foreign direct investments, strategic alliances and licensing/franchising which have a higher depth of internationalization. Apart from the potential for conceptual research on the matrix of multi-nationality, empirical follow-up studies should focus on the determination of managers' strategic choices regarding internationalization processes, and how that influences firm performance in emerging economies' agricultural export sectors. Since this study is mainly aimed at conceptual developments, it does not seek to explain managers' strategical behavior in making internationalization decisions. Hence, it is necessary to go further than the classification (Reuber et al. 2017) and derive additional concrete management implications, both through identifying and quantifying the determinants of the adoption of different internationalization strategies such as the managers' profiles (D'Angelo et al. 2013) and exploring the influences of different internationalization strategies on an agribusiness performance, as international 
diversification may (or may not) affect firms' profitability differently due to economies of scale, learning processes, access to resources and managers' decisions (Asmussen 2009; Hennart 2007). The role of some important macroeconomic factors such as exchange rates in internationalization strategies should be also included in further research (Aggarwal et al. 2011). 


\subsection{Appendix A1}

Table A1. Changes in the classifications of firm internationalization by year. $\mathrm{N}=233$

\begin{tabular}{|c|c|c|c|c|c|c|c|}
\hline Category & $\begin{array}{c}\text { Internationalization } \\
\text { Changes }\end{array}$ & $09-10$ & $10-11$ & $11-12$ & $12-13$ & $13-14$ & $14-15$ \\
\hline \multirow{6}{*}{$\mathrm{R}$} & \multirow{2}{*}{ No Change } & 13 & 13 & 12 & 12 & 12 & 13 \\
\hline & & $(100,00)$ & $(81,25)$ & $(85,71)$ & $(85,71)$ & $(92,31)$ & $(92,86)$ \\
\hline & \multirow{2}{*}{ De-internationalization } & 0 & 0 & 0 & 0 & 0 & 0 \\
\hline & & $(0,00)$ & $(0,00)$ & $(0,00)$ & $(0,00)$ & $(0,00)$ & $(0,00)$ \\
\hline & \multirow{2}{*}{ Internationalization } & 0 & 3 & 2 & 2 & 1 & 1 \\
\hline & & $(0,00)$ & $(18,75)$ & $(14,29)$ & $(14,29)$ & $(7,69)$ & $(7,14)$ \\
\hline \multirow{6}{*}{$\mathrm{H}$} & \multirow{2}{*}{ No Change } & 21 & 21 & 17 & 16 & 20 & 26 \\
\hline & & $(51,22)$ & $(70,00)$ & $(68,00)$ & $(66,67)$ & $(90,91)$ & $(81,25)$ \\
\hline & \multirow{2}{*}{ De-internationalization } & 0 & 0 & 0 & 1 & 0 & 0 \\
\hline & & $(0,00)$ & $(0,00)$ & $(0,00)$ & $(4,17)$ & $(0,00)$ & $(0,00)$ \\
\hline & \multirow{2}{*}{ Internationalization } & 20 & 9 & 8 & 7 & 2 & 6 \\
\hline & & $(48,78)$ & $(30,00)$ & $(32,00)$ & $(29,17)$ & $(9,09)$ & $(18,75)$ \\
\hline \multirow{6}{*}{$\mathrm{T} 2$} & \multirow{2}{*}{ No Change } & 18 & 20 & 22 & 19 & 18 & 18 \\
\hline & & $(39,13)$ & $(48,78)$ & $(56,41)$ & $(51,35)$ & $(46,15)$ & $(56,25)$ \\
\hline & \multirow{2}{*}{ De-internationalization } & 9 & 3 & 4 & 4 & 11 & 7 \\
\hline & & $(19,57)$ & $(7,32)$ & $(10,26)$ & $(10,81)$ & $(28,21)$ & $(21,88)$ \\
\hline & \multirow{2}{*}{ Internationalization } & 19 & 18 & 13 & 14 & 10 & 7 \\
\hline & & $(41,30)$ & $(43,90)$ & $(33,33)$ & $(37,84)$ & $(25,64)$ & $(21,88)$ \\
\hline \multirow{6}{*}{$\mathrm{T} 3$} & \multirow{2}{*}{ No Change } & 15 & 22 & 28 & 29 & 29 & 22 \\
\hline & & $(37,50)$ & $(56,41)$ & $(50,91)$ & $(58,00)$ & $(55,77)$ & $(47,83)$ \\
\hline & \multirow{2}{*}{ De-internationalization } & 11 & 9 & 13 & 11 & 15 & 13 \\
\hline & & $(27,50)$ & $(23,08)$ & $(23,64)$ & $(22,00)$ & $(28,85)$ & $(28,26)$ \\
\hline & \multirow{2}{*}{ Internationalization } & 14 & 8 & 14 & 10 & 8 & 11 \\
\hline & & $(35,00)$ & $(20,51)$ & $(25,45)$ & $(20,00)$ & $(15,38)$ & $(23,91)$ \\
\hline \multirow{6}{*}{$\mathrm{T} 4$} & \multirow{2}{*}{ No Change } & 14 & 18 & 16 & 15 & 16 & 18 \\
\hline & & $(40,00)$ & $(50,00)$ & $(59,26)$ & $(39,47)$ & $(53,33)$ & $(40,00)$ \\
\hline & \multirow{2}{*}{ De-internationalization } & 10 & 12 & 6 & 9 & 7 & 15 \\
\hline & & $(28,57)$ & $(33,33)$ & $(22,22)$ & $(23,68)$ & $(23,33)$ & $(33,33)$ \\
\hline & \multirow{2}{*}{ Internationalization } & 11 & 6 & 5 & 14 & 7 & 12 \\
\hline & & $(31,43)$ & $(16,67)$ & $(18,52)$ & $(36,84)$ & $(23,33)$ & $(26,67)$ \\
\hline \multirow{4}{*}{ T5 } & \multirow{2}{*}{ No Change } & 20 & 24 & 16 & 17 & 16 & 14 \\
\hline & & $(74,07)$ & $(64,86)$ & $(48,48)$ & $(56,67)$ & $(44,44)$ & $(53,85)$ \\
\hline & \multirow{2}{*}{ De-internationalization } & 2 & 5 & 10 & 7 & 14 & 7 \\
\hline & & $(7,41)$ & $(13,51)$ & $(30,30)$ & $(23,33)$ & $(38,89)$ & $(26,92)$ \\
\hline
\end{tabular}


Chapter 2. Internationalization paths of fruit export companies from emerging economies: Are they regionally or globally oriented?

\begin{tabular}{cccccccc}
\hline Category & $\begin{array}{c}\text { Internationalization } \\
\text { Changes }\end{array}$ & $09-10$ & $10-11$ & $11-12$ & $12-13$ & $13-14$ & $14-15$ \\
\hline \multirow{4}{*}{ Internationalization } & 5 & 8 & 7 & 5 & 5 & 5 \\
& $(18,52)$ & $(21,62)$ & $(21,21)$ & $(16,67)$ & $(13,89)$ & $(19,23)$ \\
& & & & & & \\
& No Change & 26 & 30 & 31 & 31 & 32 & 31 \\
& $(83,87)$ & $(88,24)$ & $(77,50)$ & $(77,50)$ & $(78,05)$ & $(81,58)$ \\
$\mathrm{G}$ & 5 & 4 & 9 & 9 & 9 & 7 \\
& & $(16,13)$ & $(11,76)$ & $(22,50)$ & $(22,50)$ & $(21,95)$ & $(18,42)$ \\
& De-internationalization & 0 & 0 & 0 & 0 & 0 & 0 \\
& & $(0,00)$ & $(0,00)$ & $(0,00)$ & $(0,00)$ & $(0,00)$ & $(0,00)$
\end{tabular}

Notes: R (Regional firms), H (Host regional firms), T (Transregional firms: from 2 to 5 geographic regions), $\mathrm{G}$ (Global firms). Figures in parentheses correspond to percentages in every category. For example, from the 31 firms categorized as Global in 2009, $26(83,37 \%)$ remain in the same category by 2010 , while 5 firms $(16,13 \%)$ de-internationalized. 


\title{
Chapter 3
}

\section{Effects of intra- and inter-regional geographic diversification and product diversification on export performance: Evidence from the Chilean fresh fruit export sector ${ }^{14}$}

\begin{abstract}
This study examines separately the effects of intra- and inter-regional geographic diversification on export performance of firms from the Chilean fresh fruit sector. It also explores the direct effect of related product diversification on export performance and its role as a moderator in the relationship between geographic diversification and export performance. By employing panel data of 279 firms over a six-years period (2010-2015), we found that both intra- and inter-regional diversification have an inverted U-shaped relationship with export performance. Results also showed that related product diversification has a positive effect on firm export performance and a negative moderating effect on the relationship between inter-regional diversification and export performance. In the case of intra-regional diversification, we did not find any moderating effect of product diversification. By focusing on firms from the agricultural sector based in an emerging economy, this study offers practical implications for firm managers, trade organizations and private export associations, that may also be applicable to other export-based activities and emerging economies.
\end{abstract}

Keywords: Latin America, Chile, Geographic diversification, Product diversification, Firm performance, fruit exports

\footnotetext{
${ }^{14}$ This or a similar version of this paper has been submitted to Food Policy. This paper is co-authored by Bernhard Brümmer, Verena Otter and Alejandra Engler.
} 


\subsection{Introduction}

The rising importance of firms from emerging countries in global agri-food markets (Aulakh 2007; Borda et al. 2017; Bianchi and Wickramasekera 2016; Swinnen and Maertens 2007) and the increasing trend towards international South-South trade (Sonntag et al. 2016), has put the spotlight on the lack of research in export diversification strategies and economic performance of firms in these regions. In recent decades, emerging countries have placed significant emphasis on promoting policies that lower trade barriers (tariffs and technical barriers) and open new markets, which has fostered growth and economic development in their agricultural sectors (Sheth 2004; Melo et al. 2014; Agosin and Arango 2015; LlorcaJaña 2015; Swinnen and Maertens 2007; Reardon and Barrett 2000). Thus, there are several valid questions regarding these countries, such as to what extent diversification in markets and products improve firm performance, under which conditions, and the influence and effects of the region targeted. Policy makers can benefit from this study by understanding the performance of firms' diversification strategies and their limitations, and for managers to evaluate alternative market strategies to increase competitiveness.

Overall, in various emerging economies, governments have implemented specific programs for their agricultural sectors to promote firms' exports by targeting a higher number of foreign markets (Aulakh et al. 2000). Among those countries, Chilean trade policy has emerged as a pioneer in developing free trade agreements, lowering tariffs and providing supportive policy instruments since the mid-1970s, with favorable results in terms of aggregate export growth as well as market and product diversification (Otter and Theuvsen 2014; Fleming and Abler 2013). These supportive policy measures are comprised of such actions as providing the legal foundation for establishing a comprehensive network of public and private governmental organizations, the provision of various services including the negotiation of trade agreements, the facilitation of both trade missions and fairs, and also technological transfers (Llorca-Jaña 2015; Geldres-Weiss and Monreal-Pérez 2018; Agosin and Arango 2015). Additionally, as part of Chile's internationalization strategy, exchange programs with research institutions abroad (often with institutions in target export markets) were established to secure the availability of sector-specific human capital. An early example is the exchange program between the University of Chile (public) and the University of 
California which lasted from 1965 until 1978, and was mainly used in the field of agricultural sciences with a specific focus on fruticulture (Agosin and Bravo-Ortega).

A great deal of management and business literature is dedicated to understanding the geographic and product diversification ${ }^{15}$-performance relationship (Hitt et al. 2006; Geringer et al. 2000; Boehe and Jiménez 2016; Qian, Li and Rugman 2013; Li et al. 2012; Hennart 2007; Oh et al. 2015; Borda et al. 2017). However, most of these studies have focused on FDI of large MNCs, while despite its relevance to both theoretical implications and practical perspectives, export diversification is rarely analyzed. Exports and multinational foreign investments share communalities; however, they also have distinct characteristics that do not allow for the extrapolation of results between them. Additionally, "export diversification studies mitigate drawbacks of existing research by focusing only on one element of the value chain (sales), by limiting itself to only one entry mode (exporting) and by focusing on only one internationalization motive (market-seeking)" (Boehe and Jiménez 2016, p.1262). Apart from this gap, most studies up to now have been limited in focus to companies mainly located in North America, Europe or South East Asian countries, and only a few have focused on emerging countries (e.g. Aulakh 2007; Boehe and Jiménez 2016; Borda et al. 2017; Lopez et al. 2009; Thomas 2006; Sheth 2004).

From a theoretical perspective, higher level of diversification on the one hand translates into positive effects on performance due to economies of scale and scope, better access to resources, higher market power, risk reduction and learning effects (Geringer et al. 2000; Hennart 2007; Kumar 2009; Tallman and Li 1996). On the other, it is also associated with greater coordination, distribution, and management costs ( $\mathrm{Lu}$ and Beamish 2004; Hitt et al. 1997; Aulakh et al. 2000; Boehe and Jiménez 2016) which may equal or even exceed the economic advantages (Hitt et al. 1997; Cieślik et al. 2015; Thomas 2006). Empirical studies find evidence of this trade-off in different functional shapes; namely as linear and positively shaped relationships (e.g. Heyder et al. 2011), U-shaped (e.g. Contractor et al. 2007; Kistruck et al. 2013), inverted U-shaped (e.g. Boehe and Jiménez 2016), S-shaped (e.g. Benito-Osorio et al. 2016), or inverted S-shaped (e.g. Oh et al. 2015). The variety of functional forms found indicates a great heterogeneity among sectors and countries. Consequently, the possibilities

\footnotetext{
${ }^{15}$ See definitions in Section 3.2.
} 
to transfer findings to other cases are limited due to their inconclusiveness, reasoning the importance of case-specific consideration. This similarly holds true for the relationship between product diversification and performance (Chen and Yu 2012; Chang and Wang 2007; Tallman and Li 1996; Geringer et al. 2000; Borda et al. 2017; Kistruck et al. 2013; Li et al. 2012), and a potential interaction effect among both diversification types (Kistruck et al. 2013; Hitt et al. 1997; Li et al. 2012; Chang and Wang 2007; Borda et al. 2017; Geringer et al. 2000; Tallman and Li 1996).

Geographic diversification also ensnares different alternatives regarding regions and choice of markets, where inter-regional versus intra-regional ${ }^{16}$ diversification strategies have drawn the attention of recent research. Intra-regional diversification exploits lower marginal costs derived from entering similar markets given the small psychic distance for firms (Johanson and Vahlne 1977; Johanson and Vahlne 2009), while inter-regional diversification, although allowing for larger expansion, could be counterproductive for firms' performance due to the organizational and managerial challenges faced (Fernández Olmos and Díez-Vial 2015; Thomas 2006). This has not been investigated in the case of export firms yet, thus, the question of where to expand and diversify is open, and in this context the trend of increasing South-South trade becomes highly relevant.

Following on from the preceding discussion, the objective of this paper is to explore in depth the role of geographical and product diversification in the performance of export firms from the agricultural sector in emerging economies. To meet this objective, a dynamic panel data model is employed for the analysis of secondary data of 279 Chilean fresh fruit export firms over a six-year period (2010-2015). We first test whether the functional form of the relationship between intra- and inter-regional geographic diversification and product diversification and firm performance is linear or curvilinear in shape. Afterwards, we examine the moderating effect of product diversification on the affiliation between geographic diversification and firm performance. This study contributes to the literature by shedding light on three internationalization facets which are still scarcely covered by the academic literature: a) we focus on export diversification, which is sparsely mentioned in economic literature compared to MNCs' diversification strategies, b) we examine intra- and

\footnotetext{
${ }^{16}$ See definitions in Section 3.2.
} 
inter-regional diversification separately when determining their effects on export firms' performance, and the moderating role of product diversification on these relationships, c) our study is conducted in the Chilean fruit export sector, adding to the evidence from current literature on emerging economies in Latin America, which is rarely covered. Hence, results can add relevant information for developing and conducting policy strategies in emerging export markets.

The remainder of this paper is structured as follows: section 2 reviews the theoretical background and empirical studies on diversification and performance to develop the hypotheses. Section 3 describes the data and the methodology employed in the study. Section 4 provides the results and main findings, while section 5 presents the conclusions and implications of the study.

\subsection{Theoretical Framework and Hypotheses}

\subsubsection{Geographic Diversification and Performance}

In this study, geographic diversification refers to the expansion of a firm into new markets in countries different than the one where it is established. In this sense, the markets and their respective weights within a portfolio determine the level of a firm's international diversification (Hitt et al. 1997; Li et al. 2012). From a theoretical perspective, as a result of economies of scale and scope, moderating effects of economies of scope over scale, and increasing management costs due to the higher complexity of more diversified firms that might off-set the benefits of diversification, empirical studies present mixed results regarding the direction of this relationship. Some studies show that geographic diversification positively affects firm performance (linear and positive shaped relationship) (Heyder et al. 2011; Balabanis 2001; Chang and Wang 2007; Tallman and Li 1996; Geringer et al. 2000; Pangarkar 2008), while others found that low levels of diversification negatively affect firms' performance but higher levels have positive effects (U-shaped relationship) (Contractor et al. 2007; Kistruck et al. 2013; Thomas 2006) and others found a contrary effect where moderate geographic diversification levels have positive effects on firm performance but higher levels may be counterproductive (inverted U-shaped relationship) (Aulakh et al. 2000; Hitt et al. 1997; Li et al. 2012; Cieślik et al. 2015; Fernández Olmos and Díez-Vial 2015; Boehe and 
Jiménez 2016; Chao and Kumar 2010). A third set of studies found that the previous shapes may be integrated, therefore forming an S-shaped relationship (Contractor, Kundu and ChinChun 2003; Lu and Beamish 2004; Benito-Osorio et al. 2016) or an inverted S-shaped relationship (Thomas and Eden 2004; Oh et al. 2015). These results indicate that the shape of the trade-off between costs and benefits of geographical diversification in a sector may be the result of the firms' strategic management decisions under case-specific circumstances.

Firms aim to enhance their performance by increasing their level of geographic diversification therefore improving resource access, reducing market risk, increasing their market power, improving learning effects, achieving economies of scale and optimizing the internationalization cost-benefit ratio (Geringer et al. 2000; Hennart 2007; Cieślik et al. 2015; Boehe and Jiménez 2016; Fernández Olmos and Díez-Vial 2015). For this reason, in emerging economies several governments have implemented programs to promote firms' exports by targeting a larger number of foreign markets (Aulakh et al. 2000). According to the RBV, moderately diversified firms take advantage of economies of scale regarding tangible and intangible resources through diversification, allowing higher returns by exploiting and leveraging established capabilities and competences that are firm-specific (Aulakh et al. 2000; Chen and Yu 2012; Cieślik et al. 2015; Kim, Hoskisson and Lee 2015; Qian et al. 2013; Li et al. 2012; Fernández Olmos and Díez-Vial 2015). Also, from the OLT perspective it is argued that the acquisition of knowledge by the firm through the experience of repetitive and continuous transactions determines its success (Kim et al. 2015; Hitt et al. 1997; Thomas 2006). Following Hitt et al. (1997), this concept is integrated in this study from a management point of view, as a key determinant of international diversification. Thereby, "a moderate geographic spread exposes the firm not only to a rich array of environmental conditions (e.g. different customers and competitors), but also to a broad range of experiences, ideas, and concepts" ( $\mathrm{Li}$ et al. 2012). In this sense, the knowledge and experience in reaching international markets and the production know-how has created a critical intangible resource for firms (Kumar 2009), that can be applied more efficiently to other regions with similar characteristics to achieve competitive advantages (Aulakh et al. 2000; Boehe and Jiménez 2016; Fernández Olmos and Díez-Vial 2015).

Recent literature has disentangled the study of firms' diversification strategies and their benefits within and across geographic regions. In this sense and following previous studies, 
inter-regional geographic diversification is defined as the diversification of firms across different geographic regions, and intra-regional diversification as diversification within a single geographic region (Qian et al. 2010; Qian et al. 2013; Oh et al. 2015). Until now, most studies focus solely on inter-regional diversification, and only a few consider intra-regional diversification in their analysis, showing that each diversification strategy follows their own pattern when related to performance. Qian et al. (2010) studied the diversification of large US manufacturing firms, and found an inverted U-shape in the relationship between interregional diversification and firm performance, while intra-regional diversification showed a linear positive shape. Oh et al. (2015) are focused on large European retailers and found an inverted S-shape relationship between inter-regional diversification and firm performance, but an S-shape with intra-regional diversification.

In the case of intra-regional diversification, countries located in the same geographic region are supposed to present smaller psychic distances for firms. Thus, it is expected that once firms have penetrated a specific geographic region, it will be easier and quicker to move to other countries within the same region (Johanson and Vahlne 1977; Johanson and Vahlne 2009). Therefore, the marginal costs of diversifying to additional countries within the same region (liability of country foreignness) are relatively lower, even when the sales strategy implemented in previous countries may need some modifications, since knowledge and experience acquired in similar countries of the same region will facilitate the implementation and replication of analogous strategies (Qian et al. 2013; Oh et al. 2015). At the same time, this facilitates the penetration and acceptance of the products in new neighboring countries within the region (Balabanis 2001).

H1: The relationship between the intra-regional geographic diversification of Chilean fruit exporters and export performance has a linear and positive shape.

Inter-regional diversification poses a higher challenge to firms. Even firms that become familiar with new markets, aspects such as geographic, socioeconomic, administrative and cultural differences between geographic regions matter, and may be bigger than within a single region (Ghemawat 2001). These differences increase the disadvantages and costs faced by firms when doing business across regions (liability of regional foreignness) (Qian et al. 2013; Rugman and Verbeke 2007; Li et al. 2012). The firm's knowledge considered as 
"universally valuable" or applicable to all markets may have limits (Qian et al. 2010, p.1020).

Thus, coordination, distribution and management costs related to the global distribution of products increase with higher inter-regional dispersion (Lu and Beamish 2004; Hitt et al. 1997; Aulakh et al. 2000; Boehe and Jiménez 2016) and they will eventually exceed the benefits generated due to the high overwhelming organizational complexity (Hitt et al. 1997; Cieślik et al. 2015; Thomas 2006). For fresh fruit export firms, the complexity is exacerbated by the highly perishable nature of the fruits.

H2: The relationship between the inter-regional geographic diversification of Chilean fruit exporters and export performance has an inverted U-shape: with a positive slope for moderate degrees of diversification and a negative slope for high levels of diversification.

\subsubsection{Product Diversification and Performance}

Product diversification is defined as the incursion of a firm into new products or segments where production did not previously occur. In a similar way that international diversification, the level of product diversification of a firm will reflect the number of goods or services offered and their importance to the firm (Hitt et al. 1997; Li et al. 2012). There are two different kinds of product diversification: related product diversification is defined as "diversification into businesses associated with similar products, vertically integrating complementary activities (corresponding to backward or forward integration), or sharing intangible assets" (Chen and Yu 2012, p.521). Unrelated product diversification refers to the diversification into businesses that share only financial resources (Chen and Yu 2012). This study focuses on related product diversification only.

Previous studies examining the link between product diversification and firms' performance show mixed results. Some studies found a linear positive relationship (Chen and Yu 2012; Balabanis 2001), others a negative linear relationship (Chang and Wang 2007), others an inverted U-shape relationship (Tallman and Li 1996; Geringer et al. 2000; Borda et al. 2017; Kistruck et al. 2013) and a few did not find any relationship (Li et al. 2012).

From the RBV perspective, related product diversification allows firms to take advantage of market knowledge and the know-how that previous products generated, and at the same time enhance the familiarization of consumers with firms' subsequent products (Chen and Yu 2012; Geringer et al. 2000; Li et al. 2012; Tallman and Li 1996) and, thus, exploiting the 
advantages of economies of scope (Kumar 2009; Chang and Wang 2007; Li et al. 2012; Geringer et al. 2000). Consequently, product diversification may improve firms' stability and diminishes firms' risk (Hitt et al. 1997), as it reduces the vulnerability of firms to market cycles and the volatility of single products (Balabanis 2001). Even when diversifying into new products may represent higher costs, in the case of related product diversification those are mitigated since managers already have some knowledge that can be applied to the new products (Li et al. 2012). Thus, higher levels of related product diversification will have positive effects on the performance of firms.

H3: The relationship between the related product diversification of Chilean fruit exporters and export performance has a linear and positive shape.

\subsubsection{Interaction between geographic diversification and product diversification}

According to Borda et al. (2017) and Benito-Osorio (2016), geographic diversification and product diversification may interact, resulting in differing performance responses. From the RBV perspective, the competences developed by firms when diversifying in terms of products are expected to be easily transferred and implemented when they diversify into new markets, achieving synergies between both strategies (Hitt et al. 1997; Chang and Wang 2007; Kumar 2009). This allows cost sharing and organizational learning across business units, spreading and diminishing the risks generated (Li et al. 2012). Previous empirical studies examining this interaction show mixed results. Some studies found that product diversification has a negative moderating effect on the relationship between geographic diversification and performance (Kistruck et al. 2013), others a positive effect (Hitt et al. 1997; Li et al. 2012; Chang and Wang 2007; Borda et al. 2017) and others no effect (Geringer

et al. 2000; Tallman and Li 1996). Oh et al. (2015) also examined the moderating effect of product diversification on the relationship of performance with intra- and inter-regional diversification, and observed a different pattern in the relationship; a negative moderating effect in the case of inter-regional diversification and no effect in the case of intra-regional diversification.

Despite the possible positive effects mentioned above, simultaneously implementing product and inter-regional diversification strategies may stretch managerial resources, resulting in higher coordination and transaction costs for the firms, and therefore hamper their 
performance ( $\mathrm{Li}$ et al. 2012; Chang and Wang 2007; Geringer et al. 2000). Even if the management costs of related products are supposed to be lower, such products still need to be adjusted to the requirements of new consumers, which can differ significantly from previous ones when a firm enters more distant geographic regions (Oh et al. 2015; Li et al. 2012). Learning benefits from previous related product diversification experiences may also not be easily transferable to more distant geographic regions due to the existence of greater differences, generating higher complexity and coordination costs (Oh et al. 2015; Chang and Wang 2007).

Considering the aforementioned arguments, we propose two additional hypotheses.

H4: Related product diversification has a positive moderating effect in the relationship between the intra-regional geographic diversification of Chilean fruit exporters and their performance.

H5: Related product diversification has a negative moderating effect in the relationship between the inter-regional geographic diversification of firms and their performance.

\subsection{Methods}

\subsubsection{Data}

This study employs firm-level information of fresh fruit exporters located in Chile drawn from the database Eximfruit (2010-2015) over a six-year period from 2010 to 2015. This period of time leaves out the year of the financial crisis (2008), which heavily affected Latin American economies and the markets where they exported, restraining firm performance (Borda et al. 2017). From Eximfruit database we gathered seasonal information of fresh fruit export quantities per products and destination markets to measure firm performance and diversification variables. Additionally, the information regarding the age of the firm was obtained from the web page of the Chilean Tax Administration Office (SII), while the GDP information of the countries was collected from the World Bank and the International Monetary Forum.

In total, the database Eximfruit (2010-2015) includes on average 577 exporters per year. However, in this study we only considered firms that exported uninterrupted during the six- 
year time period, assuring that they are no sporadic exporters but long time survivors, so and that firms are committed to the international expansion of their businesses (Cieślik et al. 2015) and have established stable market relations. This selection criteria also ensures that all the firms have existed at least six years since they were incorporated, so that they have already overcome the turbulent period that the early years of a firm represents ( $\mathrm{Li}$ et al. 2012). Similar to Benito-Osorio et al. (2016), we included all firms that fulfilled the requirements and simultaneously analyze them regardless of their export volume, offering a more representative overview of the diversification strategies of the sector. Data cleaning was done according to an initial screening and data check to detect possible errors. Based on these criteria, the final sample consists of 279 firms, resulting in a balanced panel data with 1,674 firm-year observations.

The Chilean fruit sector represents an interesting case to examine the diversificationperformance relationship for three reasons; first, by perceiving a particularly high growth of agricultural exports since the beginning of the 21 st century, Chile has experienced significant economic development, becoming one of the most stable and prosperous nations in Latin America (Otter et al. 2014; Engler et al. 2012; Bianchi and Wickramasekera 2016). Specifically, the fruit sector has contributed to the Chilean economy by accounting for almost $50 \%$ of total exports, making the country the main fresh fruit exporter in the southern hemisphere, the leading exporter of table grapes worldwide and the second largest of blueberries and cherries (ODEPA 2017; Engler et al. 2012). Second, Chile is generally one of the most open economies in the world with more than 26 free trade agreements in 64 markets for all sectors, which offers a wide spectrum for diversification. And third, by being an emerging economy from Latin America, it offers a different context compared to Europe, North America, or Asian countries, where most of the research in diversificationperformance have taken place (Aulakh 2007; Borda et al. 2017; Lopez et al. 2009; Thomas 2006).

By focusing this analysis on firms from one single country, we eliminate the potential effects that different conditions (e.g. cultural, administrative and economic) may have on firms from distinct countries, which can enhance or restrict their possibilities of diversification (Qian et al. 2010). 


\subsubsection{Variables}

\section{Dependent Variable}

Accounting-based indicators such as return on assets (ROA) or return on sales (ROS) are frequently used as performance measures when studying the diversification-performance relationship. However, these indicators have been criticized due to discrepancies caused by different accounting rules, and their affliction by volatile factors such as exchange rates, inflation and depreciation (Geringer et al. 2000; Balabanis 2001; Chang and Wang 2007). Rugman and Verbeke (2004) pointed out that sales spread turns out to be the only real measurement of performance at the output level. Thus, we measure firms' performance as the first difference of the natural logarithm of firms' export sales in two consecutive years. This is the same as obtaining the natural logarithm of the moving ratio of export sales growth, calculated as the annual change in export sales of a firm in two consecutive years. Thus, firms' performance is expressed as:

$$
\text { Exports_growth }=\text { ln_exports }_{t}-\text { ln_exports }_{t-1}
$$

Export growth has been used as measurement of performance in previous studies (Cieślik, Kaciak and Welsh 2010; Cieślik et al. 2015; Ruzo et al. 2011; Balabanis 2001; Park and Jang 2010; Geringer et al. 2000; Kuivalainen et al. 2007).

\section{Independent Variables}

Most empirical studies wrongly employ the share of foreign sales to total sales (FS/TS) as a measure of international diversification, while the correct measure should be the geographic dispersion or concentration of foreign sales (Hennart 2007). This measure reveals the level of commitment in terms of resources that a firm has in every geographic region where they export to (Li et al. 2012). Following previous studies (Hitt et al. 1997; Aulakh et al. 2000; Li et al. 2012; Qian et al. 2010; Qian et al. 2013; Oh et al. 2015) we measure geographic diversification using the entropy measure. First developed by Shannon (1948) $)^{17}$ for information theory and then adapted to measure industrial concentration by Hirsch and Lev (1971) and later by Jacquemin and Berry (1979), the entropy measure has been frequently

\footnotetext{
${ }^{17}$ Shanon's entropy formula was originally $G D_{\text {Inter }}=-\sum_{i=1}^{m} P^{i} \ln \left(P^{i}\right)$ which is the same measure that we employ but with different notations.
} 
used to capture firms' diversification, offering a more valid and reliable estimation because it considers both the number of foreign markets where they export (diversification breadth) and the relative weight of each foreign market (diversification depth) (Oh et al. 2015; Balabanis 2001). Following Qian et al., (2010; 2013), we separate geographic diversification into intra- and inter-regional diversification. The measure of inter-regional diversification is given by:

$$
G D_{-} \text {Inter }=\sum_{i=1}^{m} P^{i} \ln \left(\frac{1}{P^{i}}\right)
$$

where $m$ represents the number of geographic regions to which the firm exports and $P^{i}$ is the relative weight of the $i$ th geographic region in the firm's total exports. To calculate these measures, we distinguish six geographic regions: Far East \& South Pacific, Middle East \& Africa, North America, Mexico-Central America \& the Caribbean, South America, and Europe. Similar regional distributions were employed by Aulakh et al., (2000) and Boehe and Jiménez (2016) in their studies of diversification in Latin American export firms.

Measuring intra-regional diversification involves two steps; first, we obtain the individual diversification within each geographic region $\left(G D_{-} I n t r a_{a}\right)$, and second, we add them together to obtain the diversification in all the geographic regions (GD_Intra $\left.a_{j}\right)$.

$$
G D_{-} \operatorname{Intra}_{a}=\sum_{i \in a} P_{i a}^{a} \ln \left(\frac{1}{P_{i a}^{a}}\right)
$$

where $G D \_I n t r a_{a}$ represents the firm's export diversification across countries within the $a$ th geographic region and $P_{i a}^{a}$ is the relative weight of the $i$ th country in the firm's total exports to the ath geographical region. Assuming that there are $j$ geographic regions in total, $G D_{-} I n t r a_{j}$ will be the weighted average of $G D_{-} I_{\text {Int }} a_{a j}(a \in j)$, with the weight defined previously as $P_{a j}$.

$$
G D_{-} \operatorname{Intra}_{j}=\sum_{a=1}^{j} P_{a j}^{j} \times G D_{-} \text {Intra } a_{a j}
$$

Product diversification was also operationalized using an entropy measure (Hitt et al. 1997; Balabanis 2001; Li et al. 2012; Chang and Wang 2007; Chen and Yu 2012; Kistruck et al. 2013; Qian et al. 2010; Oh et al. 2015). Similar to geographic diversification, this index considers both the number of products sold by the firm, and their importance in total exports. 
Thus, product diversification is defined as:

$$
P D=\sum_{i=1}^{m} P^{i} \ln \left(\frac{1}{P^{i}}\right)
$$

where $m$ represents the number of products that the firm exports and $P^{i}$ is the relative weight of the $i$ th product in the firm's total exports (including all products). As all the firms are fresh fruit exporters, all the products belong to the same 2-digit Standard Industrial Classification (SIC) system, which is agricultural production crops (SIC 01). Thus, only related product diversification was estimated.

\section{Control Variables}

Following previous studies (Chen and Yu 2012; Li et al. 2012; Fernández Olmos and DíezVial 2015; Aulakh et al. 2000; Boehe and Jiménez 2016; Contractor et al. 2007), we included variables that are have been proven to be relevant as controls. We controlled for firm age because it influences the magnitude of international operations, and the opportunities of firms to venture into new products and markets due to the lack of resources and capabilities in early stages (Chen and Yu 2012; Contractor et al. 2007; Li et al. 2012). At the same time, more stable, older firms are considered to be less flexible and less open in adapting to changes in external conditions in comparison to younger firms (Fernández Olmos and Díez-Vial 2015; Contractor et al. 2007). Firm age was measured as the difference in years between the first year of analysis (2010) and the year when the firm started operations (extracted from the SII webpage). We included the average GDP of the firm's destination markets, because the size of an economy may affect export strategies and performance due to a higher concentration of resources and competitors, and more demanding consumers in developed countries (Aulakh et al. 2000; Boehe and Jiménez 2016). As in Boehe and Jiménez, (2016), the average GDP was measured by the sum of the GDP of the export destination countries of a firm, weighted by their share of the firm's total exports. The data were extracted from the World Bank and the International Monetary Fund. We also included the firm's volume of exports to control for installed capacity of the firm and economies and diseconomies of scale. This was measured as the natural logarithm of the average total exports reported by firms over the six-years period of analysis (2010-2015). Structural characteristics of some industries or sectors may affect firms' performance in different ways (Chen and Yu 2012). Thus, we included dummy variables representing the firm's primary sub-sector to control for product- 
specific effects. Using 4-digits SIC system, the products exported fell into five groups: berry crops (SIC 0171), grapes (SIC 0172), citrus fruits (SIC 0174), deciduous tree fruits (SIC 0175), and other fruits not elsewhere classified (SIC 0179). Finally, we included yearly dummies to control for unobserved specific effects of time on firms' performance.

\subsubsection{Model Selection}

In this study we employ panel data including a time series dimension (six-years period) and a cross-sectional dimension (279 firms). In comparison to aggregated time series data, panel data allows dynamic estimations which take into account the heterogeneity between firms without microeconomic dynamic biases due to data aggregation (Bond 2002). Because a firm's behavior may present dynamic characteristics that are not captured by static panel models, similar to previous studies (Cieślik et al. 2015; Li et al. 2012; Oh et al. 2015; Park and Jang 2010) we employed a dynamic model which includes lagged dependent variables as explanatory variables accounting for autocorrelation while allowing us to obtain consistent estimates of the other parameters (Bond 2002). Dynamic panel data is specially designed to work with micro panels where the number of individuals is large (wide panel) but the time periods are small (short panel) (Bond 2002; Roodman 2009b; Roodman 2009a), which is evident in our case. We applied a system generalized method of moments (SGMM) estimator to the panel data ${ }^{18}$. Because the differences of the instrumental variables are assumed to be uncorrelated within the fixed effects model, a SGMM estimator augments the difference generalized method of moments (DGMM) by combining a set of equations in differences instrumented by lagged levels with a set of equations in levels using lagged differences as instruments, resulting in more efficient estimations (Bond, Hoeffler and Temple 2001; Roodman 2009b; Roodman 2009a). Additionally, by using SGMM, all the time-invariant regressors that would disappear using DGMM remain and can be included in the analysis (Roodman 2009b). We treated the diversification variables as predetermined in our model.

\footnotetext{
${ }^{18}$ We applied two-step system GMM employing robust standard errors, Windmeijer correction and adjusting the covariance matrix estimate for small-sample size (Roodman 2009a).
} 
Thus, the model employed ${ }^{19}$ in this study is:

$$
\text { Exports_growth }_{i, t}=\alpha+\beta \text { Exports_growth } h_{i, t-1}+\gamma \boldsymbol{X}_{i, t}+\delta \boldsymbol{Z}_{i, t}+\theta_{t}+v_{i}+\varepsilon_{i t}
$$

where Exports_growth Ert $_{\text {is }}$ is the export performance measured as exports growth, Exports_growth $h_{i, t-1}$ is the preceding year's firm exports growth, $\boldsymbol{X}_{i, t}$ is a vector of the product and international diversification variables and their interactions, $\boldsymbol{Z}_{i, t}$ represents the control variables, $\theta_{t}$ are dummy variables for each year, $v_{i}$ is the unobserved firm specific effect and $\varepsilon_{i t}$ is the random disturbance term.

\subsection{Results}

Table 8 reports the descriptive statistics and time patterns of the variables employed in the study ${ }^{20}$. On average exports grow $2.4 \%$, presenting a decreasing tendency after high growth in 2011. The intra- and inter-regional diversification present stable and similar patterns. However, the latter is higher over the entire period showing that most firms diversify more in different geographic regions than within the same region. Product diversification shows a stable trend as well. The high maximum value indicates that some firms have strong product diversification strategies. Considering the average destination GDP, firms are focusing their exports in countries with higher GDP.

Table 9 presents the results obtained from the SGMM estimation. Results show that export growth is negatively correlated with lagged export growth, and although this might be counter-intuitive, the explanation may lie in the cyclical nature of the fresh fruit export business. Several aspects affect the amount exported by a firm yearly: the availability of fruit in Chile (which because of climatic conditions can have large variations), the availability of fruit in the global market, plagues and diseases that may affect orchards, and so on. Hence,

\footnotetext{
${ }^{19}$ As robustness checks we included the interaction of the quadratic term of the geographic diversification variables with the product diversification and included the cubic term of the geographic diversification variables as well, but they failed to show significance or fulfill the GMM requirements. We also did the estimations without outliers using a three standard deviation criterion and the results do not change. These results are available upon request.

${ }^{20}$ Some of the variables are significantly correlated, but do not exceed the threshold of 0.8 recommended by Mason and Perreau (1991). The variance inflation factor (VIF) of any variable is not higher than the limit of 10 suggested by Hair (1991), with 2.51 being the highest value. Thus, multicollinearity seems not to be a concern in this study.
} 
it is not surprising to find a negative effect which in fact tells us about the counter-cyclical nature of agricultural business. The export volume of the firm also exhibits a negative reaction to growth, which is expected assuming decreasing marginal returns in the short run. The GDP level of the destination markets have a positive effect on the explained variable. Firms' age and fruit specie are not significant when explaining firm performance.

Table 8. Descriptive statistics $(\mathrm{N}=279)$

\begin{tabular}{lcccccccccc}
\hline Variable & Mean & $\begin{array}{c}\text { Std. } \\
\text { Dev. }\end{array}$ & Min & Max & 2010 & 2011 & 2012 & 2013 & 2014 & 2015 \\
\hline Exports Growth (log) & 0.02 & 0.60 & -2.93 & 3.27 & - & 0.25 & 0.02 & -0.00 & -0.12 & -0.03 \\
Intra-regional Diversification & 0.43 & 0.40 & 0.00 & 1.86 & 0.40 & 0.44 & 0.44 & 0.40 & 0.43 & 0.43 \\
Inter-regional Diversification & 0.69 & 0.49 & 0.00 & 1.75 & 0.62 & 0.66 & 0.70 & 0.70 & 0.72 & 0.69 \\
Product Diversification & 0.57 & 0.62 & 0.00 & 2.15 & 0.57 & 0.60 & 0.61 & 0.58 & 0.51 & 0.56 \\
Average GDP (log) & 27.52 & 1.48 & 23.65 & 30.52 & 27.48 & 27.39 & 27.45 & 27.60 & 27.57 & 27.60 \\
Volume of Exports (log) & 12.30 & 1.58 & 7.16 & 16.23 & 12.30 & 12.30 & 12.30 & 12.30 & 12.30 & 12.30 \\
Age & 11.27 & 10.68 & 0.00 & 58.00 & 11.27 & 11.27 & 11.27 & 11.27 & 11.27 & 11.27 \\
\hline
\end{tabular}

Note: Export growth show the growth with respect to the previous year.

Hypothesis 1 states that there is a linear and positive relationship between export performance and the level of intra-regional diversification. Results show that the coefficient of the linear term is positive and significant $\left(G D \_I n t r a=1.082, \mathrm{p}<0.01\right)$. When testing the quadratic term, it turned out to be significant; however, with a different sign than expected $\left(G D \_I n t r a^{2}=\right.$ $0.852, \mathrm{p}<0.1)$. Thus, this hypothesis is only partially supported, but strictly speaking is not.

As expected, we found an inverted U-shape relationship between inter-regional diversification and export performance, supporting hypothesis 2 . The linear term is positive and significant $\left(G D_{-}\right.$Inter $\left.=1.194, \mathrm{p}<0.01\right)$ while the quadratic term is negative and significant $\left(G D_{-}\right.$Inter $\left.{ }^{2}=-0.567\right)$.

To examine these relationships in more detail, we generated Figure 3 which shows export growth at different levels of intra- and interregional diversification, holding all other variables constant. Additionally, we took the first partial derivative of the dependent variable with respect to intra- and inter-regional diversifications to estimate the optimal diversification levels, which turns to be at an entropy measure value of 0.635 and 1.053 respectively. 
Table 9. Regression analysis for panel data with SGMM

\begin{tabular}{|c|c|c|c|}
\hline Variables & & SGMM & \\
\hline Lagged Exports Growth & & $\begin{array}{c}-0.205 * * * \\
(0.051)\end{array}$ & \\
\hline Intra-regional Diversificatic & H1) & $\begin{array}{c}1.082 * * * \\
(0.399)\end{array}$ & \\
\hline Intra-regional Diversificatic & quare (H1) & $\begin{array}{l}-0.852^{*} \\
(0.446)\end{array}$ & \\
\hline Inter-regional Diversificatic & H2) & $\begin{array}{c}1.194 * * * \\
(0.313)\end{array}$ & \\
\hline Inter-regional Diversificatic & quare $(\mathrm{H} 2)$ & $\begin{array}{c}-0.567 * * * \\
(0.201)\end{array}$ & \\
\hline Product Diversification (H3 & & $\begin{array}{c}0.581 * * * \\
(0.221)\end{array}$ & \\
\hline Intra-regional Diversificatic & Product Diversification (H4) & $\begin{array}{c}0.300 \\
(0.338)\end{array}$ & \\
\hline Inter-regional Diversificatic & Product Diversification (H5) & $\begin{array}{c}-0.552 * * * \\
(0.206)\end{array}$ & \\
\hline Age & & $\begin{array}{c}0.001 \\
(0.007)\end{array}$ & \\
\hline Age square & & $\begin{array}{c}-2.48 \mathrm{e}-06 \\
(0.000)\end{array}$ & \\
\hline Average GDP & & $\begin{array}{c}0.101 * * \\
(0.049)\end{array}$ & \\
\hline Volume of Exports & & $\begin{array}{c}-0.071 * * \\
(0.032)\end{array}$ & \\
\hline Berries & & $\begin{array}{c}0.116 \\
(0.122)\end{array}$ & \\
\hline Grapes & & $\begin{array}{l}-0.018 \\
(0.096)\end{array}$ & \\
\hline Citrus & & $\begin{array}{l}-0.091 \\
(0.125)\end{array}$ & \\
\hline Others & & $\begin{array}{c}0.138 \\
(0.099)\end{array}$ & \\
\hline 2013 & & $\begin{array}{l}-0.063 * \\
(0.032)\end{array}$ & \\
\hline 2014 & & $\begin{array}{c}-0.181 * * * \\
(0.041)\end{array}$ & \\
\hline 2015 & & $\begin{array}{c}-0.089^{*} \\
(0.047)\end{array}$ & \\
\hline Constant & & $\begin{array}{c}-2.577^{*} \\
(1.384)\end{array}$ & \\
\hline Observations & 1,116 & Number of firms & 279 \\
\hline Instruments & 133 & F-Test & $5.33^{* * *}$ \\
\hline Hansen t-stat & 127.13 & Hansen p-value & 0.17 \\
\hline Arellano-Bond Test AR(1) & $-4.37 * * *$ & Arellano-Bond Test AR(2) & -0.34 \\
\hline
\end{tabular}

Standard errors in parentheses,

$* * * \mathrm{p}<0.01, * * \mathrm{p}<0.05, * \mathrm{p}<0.1$ 

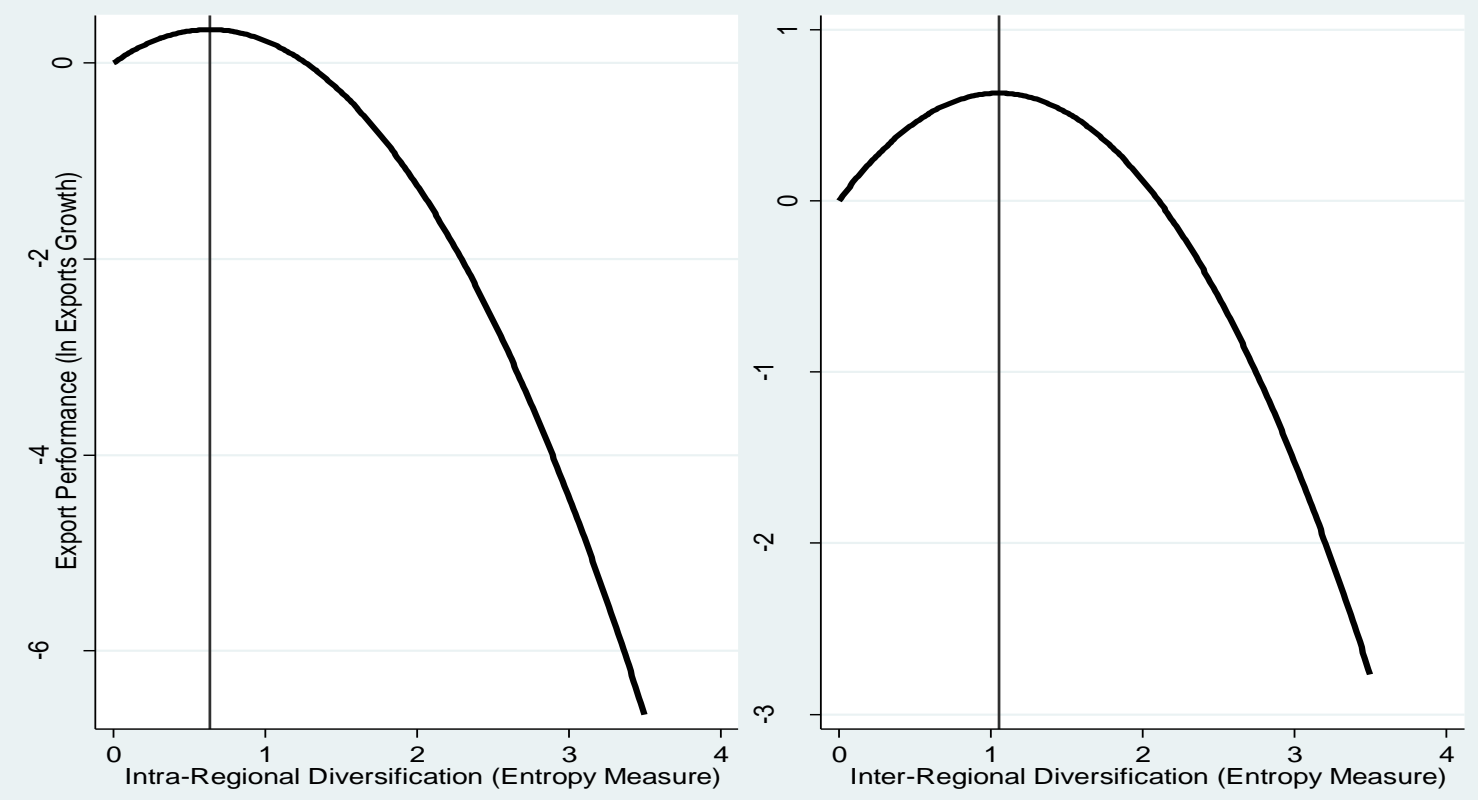

Figure 3. Relationships between intra- and inter-regional diversification and export performance.

As shown in Table 8, the average entropy measures for the sample of firms are 0.43 and 0.69 for intra and inter-regional diversification, hence in both cases firms' strategies favor a lower diversification among regions and within the local region, placing themselves in the increasing part of the curve. To have an idea of what those entropy values mean in terms of market shares, we performed simulations under the following assumptions: a) firms export to all markets, and b) the concentration occurs in only one market leaving the other markets to share equal portions ${ }^{21}$. In the case of inter-regional diversification, the sample average $(0,69)$ shows a high market concentration of approximately $85 \%$, whereas the maximum level of diversification is $30 \%$ (the remaining markets would have shares of $14 \%$ ). According to our results the optimal concentration would be $70 \%$, indicating that dealing with a large portfolio is negative in terms of performance.

Turning to Hypothesis 3, as expected the results show a positive relationship between the level of product diversification and export performance. The coefficient for the level of

\footnotetext{
${ }^{21}$ There are infinite diversification alternatives to reach an index value, hence we needed to set assumptions
} in order to provide a specific distribution. 
product diversification is positive and significant $(P D=0.581, \mathrm{p}<0.01$. Hypotheses 4 and 5 predict a positive moderating effect in the relationship of export performance with intraregional diversification and a negative effect in the case of inter-regional diversification. Results show that the interaction term of product diversification and intra-regional diversification is positive but not significant $\left(G D \_I n t r a \times P D=0.300\right.$, n.s. $)$ while in the case of inter-regional diversification, the coefficient obtained is negative and significant $\left(G D \_I n t e r \times P D=-0.552, \mathrm{p}<0.01\right)$. Therefore, results do not support Hypothesis 4 but fully support Hypothesis 5.

\subsection{Discussion}

The empirical results of this study show that in the case of Chilean fresh fruit exporters, the inter-regional and intra-regional geographic diversification-export performance relationship has an inverted U-shape. Firms with moderate levels of geographic diversification perform better than those with lower levels. However, higher levels of diversification beyond the optimal points ( 0.635 and 1.053 for intra- and inter-regional diversification respectively) turn out to be harmful for export performance. These results indicate that the liability of country and regional foreignness play an important role in firms' export growth, hindering them from achieving the expected level of performance when pursuing a greater geographic diversification strategy. This was expected in the case of inter-regional diversification due to higher distances between different geographic regions, hence higher logistic and management costs, but not in the case of intra-regional diversification, where the distances between countries in the same geographic region are supposed to be lower. Nevertheless, the latter results are in line with those of Qian et al. (2013) who found that higher levels of intraregional diversification increases the level of liability of country foreignness, reducing the positive effect on firm performance. Another finding is that the lack of significance of the cubic term (inverted S-shape relationship evidence) in both levels of geographic diversification indicates that over-internationalization has not overcome the organizational and managerial challenges firms face. An explanation for this result is that in the sample of this study, not many firms have reached this "over internationalized" point during the period of analysis, hence we could not capture this effect. This is also the case in other emerging 
economies, where the newness of the internationalization process results in most of the firms remaining in the initial stages of this process (Contractor et al. 2007; Thomas 2006). This is reflected by the average age of the firms in the sample analyzed, which does not exceed 12 years.

Additionally, we found that related product diversification has a positive effect on firm export performance. The underlying reasons are that diversification in products with similar characteristics allows the firm to take advantage of the knowledge generated from previous products, and to implement it in new products exploiting advantages of economies of scope which results in higher export performance (Kumar 2009; Chang and Wang 2007; Li et al. 2012; Geringer et al. 2000). At the same time, product diversification reduces Chilean fresh fruit exporters dependency on one singular product and the risks due to volatility that different markets can experience.

Our results also suggest that related product diversification has a negative moderating effect in the relationship between firms' inter-regional diversification and their export performance. Both diversification dimensions (product and geographic) individually have positive effects on exports growth. However, firms seem to experience managerial problems when handling both strategies at the same time, harming their performance. Firms must be able to cope in allocating limited resources when implementing product and geographic diversification strategies due the potential tradeoff between both dimensions (Kumar 2009), but when this is not possible, the results can be counterproductive. When firms in the fresh fruit sector decide to export new products and penetrate new markets at the same time, it implies the need to meet different legislations and requirements such as sanitary, phytosanitary and quality-related regulations, and standards. When these requirements are unknown for the firm or stricter than from previous experiences, coordination costs increase resulting in a negative impact on trade and export performance (Melo et al. 2014; Engler et al. 2012). In the case of intra-regional diversification, we did not find evidence of any moderating effect.

\subsection{Conclusions and Implications}

This study contributes to the literature on export diversification by differentiating between intra- and inter-regional geographic diversification when examining their relationship with 
export performance. By doing so, we take into consideration the differences between current firms' networks and their new markets which rise due to cultural, administrative, geographic, and economic distances, and their effects on firm performance (Verbeke and Brugman 2009). Additionally, this study extends the current literature on the diversification-performance relationship with relevant findings on export firms from the agricultural sector as a prime example of emerging economies from Latin America, which grants implications for managers and policy makers:

Managers who can map their firms and/or their competitors regarding these diversificationperformance relationships may be able to adapt their strategies to achieve the optimum levels of diversification that allows maximum advantage of the positive effects on exports growth and avoids levels that may be counterproductive (Contractor et al. 2007). Our results indicate that firms with moderate levels of intra- and inter-geographic diversification can maximize their performance; however, after a certain point of diversification firms have problems to transfer their previous knowledge and experience to new markets, even within the same geographic region. Our results also suggest that implementing a strategy of product and geographic diversification simultaneously negates the individual positive effects of both dimensions on export performance. Exporters need to be cautious in pursuing extensive product and geographic diversification strategies simultaneously, even when the opportunities seem to be economically attractive (Kumar 2009). Changes in fruit consumption patterns and increased willingness to pay in some emerging economies morphs them into key export markets for Chilean fresh fruits (South-South trade), and pushes fruit exporters to incorporate additional countries and products to their portfolio at the same time (Sonntag et al. 2016). To deal with the particularities of higher geographical and product diversification levels, greater specialization of firm subunits, such as the foundation of special internationalization departments and the labor force required, and in many cases even complementary changes in internal firm structures become necessary. Such accompanying measures of internationalization decisions need to be taken into account by managers during employee recruitment and training measures, but also during strategic development processes regarding organizational design (Garri and Konstantopoulos 2013).

Since in the case of the Chilean fruit export sector, the liability of country and regional foreignness seems to be undermining the positive effects that geographic diversification has 
on export performance, the support that public organizations and private trade associations such as PROCHILE, ASOEX (private, non-profit) and FEDEFRUTA (private, non-profit) can give to Chilean fresh fruit exporters is essential to overcome the barriers faced in new and unknown markets to facilitate higher export performance. Hence, policy makers, also in other emerging economies, should not only generate the space to open new markets by initiating free trade agreements, but also provide the means for export firms, especially medium and small exporters, to develop managerial skills which are considered a critical intangible resource in exploring these markets (Kumar 2009). To secure the availability of a skilled labor force supporting internationalization, specialization within the domestic educational systems, comprising school-, university- and practical education, is required. For example, inter-regional geographic diversification should come along with similar diversifications in exchange programs fostering academic mobility (Agosin and BravoOrtega 2009; Altbach and Knight 2007).

This study faced some limitations, which at the same time indicate possible lines for future research. First, the period of study comprises six years (2010-2015). A longer time period of analysis may be necessary to be able to test for different shapes of the diversificationperformance relationship. Second, our study is based on one country (Chile) and one activity in the agricultural sector (fruits). Even when we argued that this facilitates the comparison of the strategies between the firms because they face very similar conditions at the country level, the effect of country location is not captured by our results. Thus, in particular, extending the research to include and combine more agricultural activities could provide valuable information to policy-makers to design a sector diversification strategy for the county targeting resources to enhance performance of the agricultural sector as a whole. The comparison of agricultural firms with those of other sectors would also permit the testing of their strategies and if effects change depending on the activity. 


\title{
Chapter 4
}

\section{Perceived psychic distance and export market selection: Influence and strategies of the Chilean fresh fruit export $\operatorname{sector}^{22}$}

\begin{abstract}
Increasing globalization trends accompanied with increasingly open markets have led export firms into a maelstrom of strong competition and rapid internationalization. As a result, firms' managers are facing daily the need to select markets to remain competitive. The literature had emphasized the relevance of the distance to the market as a key issue for such decisions; however, more recently there is an ongoing debate about the role of perceived psychic distance when firms select new target markets. By employing the cultural, administrative, geographic and economic (CAGE) distance framework proposed by Ghemawat (2001), this paper individually analyzes the influence of the perceived psychic distance dimensions on export market selection by firms' managers and the strategies employed to cope with such distances. This empirical research is based on 30 in-depth interviews with managers in the Chilean fresh fruit export sector. Results indicate that economic and administrative distance dimensions are the ones with higher influence on market selection. On the other hand, the most recurrent strategies to cope with distance are the development of relationships based on trust and commitment with the clients, and to take advantage of the opportunities offered by both public organizations and private export associations. Based on the findings, managerial and policy implications are recommended.
\end{abstract}

Keywords: psychic distance, Chile, Latin America, emerging economies, agricultural products, fruit exports

${ }^{22}$ This is a working paper co-authored by Verena Otter and Alejandra Engler. 


\subsection{Introduction}

Increasing globalization and open world markets resulting from the successive removal of trade barriers in the past decades has delivered important changes in food and agricultural value chains, and an exponential increase in the number of companies internationally expanding into new countries (Swinnen and Maertens 2007; Reardon and Barrett 2000; Otter and Theuvsen 2014). Thus, managers across countries and sectors are nowadays frequently confronted with the critical decision of selecting new target markets, with the awareness that strategically disadvantageous decisions may bring respective long term consequences for the firms (Malhotra et al. 2009). In this regard, the managers' perception of psychic distance may be considered a key influence for foreign market orientation (Stöttinger and Schlegelmilch 1998; Dow and Karunaratna 2006). Psychic distance refers to those factors obstructing adequate information interchange between foreign companies and local markets, such as language, development levels and political systems, among others (Johanson and Vahlne 1977; Johanson and Wiedersheim-Paul 1975). Thus, the psychic distance comprises different dimensions such as cultural, administrative, geographic and economic (Ghemawat 2001). This concept has been extensively employed over the last four decades to study aspects such as foreign market selection, entry mode choice, joint ventures, international performance, knowledge and/or capability transfer and expansion patterns (Hutzschenreuter et al. 2016; Hutzschenreuter et al. 2014; Sousa and Bradley 2006; Avloniti and Filippaios 2014).

Previous studies examining the effect of psychic distance on firms' market selection employing uni-dimensional and multi-dimensional approaches have showed contradictory findings (Stöttinger and Schlegelmilch 1998; Brewer 2007; Dow and Karunaratna 2006; Dow 2000; Berry et al. 2010; Child, Rodrigues and Frynas 2009; Malhotra et al. 2009). This lack of consensus indicates both significant scientific involvement in the development of this concept and its effects, and the need for further research (Hutzschenreuter et al. 2016). Although some studies have pointed out the importance in considering more than one distance measure to avoid misleading results (Ambos and Håkanson 2014; Hutzschenreuter et al. 2016; Berry et al. 2010; Dow and Karunaratna 2006), most of the empirical literature available up to now examines one distance dimension at a time (mainly the cultural). Additionally, in most of these cases, the perception of the psychic distance has been neglected, inadequately incorporated or captured from the incorrect individuals which do not 
make the decisions regarding firms' international expansion (Evans, Treadgold and Mavondo 2000; O’Grady and Lane 1996; Child et al. 2009; Hutzschenreuter et al. 2016; Nebus and Chai 2014; Dow and Karunaratna 2006). By incorporating the perception it is possible to understand not only the factors creating the perception of psychic distance but also how managers cope with it (Dow and Karunaratna 2006; Evans et al. 2000), an aspect that has not received enough attention in the international business literature (Child et al. 2009).

Additionally, most research regarding psychic distance has mainly been based in North America and Europe, while emerging economies remain underrepresented with the few existing studies focused on Asia, particularly India and China (Brewer 2007; Malhotra, Lin and Farrell 2016). According to Malhotra et al. (2009, p.668), emerging economies are underrepresented in international business literature related to distance and have been considered "mostly based on... anecdotal evidence, and deduction and inference from the history of North-South capital flows, rather than a body of systematic research". However, firms from emerging economies present dissimilar characteristics and face different environments and challenges than those from developed countries.; thus, the relevance of the psychic distance for firms located in such countries it is still an open question (Beddi and Mayrhofer 2013; Malhotra et al. 2009; Ghemawat and Hout 2008; Malhotra et al. 2016; Brewer 2007). Finally, the literature examining distance effects in the case of food products is even more scarce (Filippaios and Rama 2011). To our knowledge, there are no studies examining the influence of psychic distance on export market selection for firms from the agricultural sector.

Considering the aforementioned gaps, the objective of this paper is to answer the following three research questions: Which is the most important perceived psychic distance dimension influencing firms' export market selection? What are the factors denoting the influence of the perceived psychic distance on firms' export market selection? Which strategies do firms implement to cope with the perceived psychic distance? To answer these questions, we selected a case study of fresh fruit exporters in Chile.

This study contributes to the literature in three ways: first, by employing the cultural, administrative, geographic and economic (CAGE) distance framework developed by Ghemawat (2001), this study offers a more comprehensive and insightful analysis of the 
influence of psychic distance on export market selection. Second, by considering the perceived psychic distance from the managers' perspectives, we can thoroughly examine the factors influencing export market selection strategies. Simultaneously, it allows us to explain the strategies employed by the managers to cope with these psychic distances. Third, by focusing on the Chilean fruit export sector, this study offers evidence of the effect of psychic distance on firms from the agricultural sector in Latin American, which has been rarely covered in the literature.

The remainder of this paper is structured as follows: section 2 reviews the literature of the psychic distance concept and, thereafter, introduces the CAGE framework. Section 3 describes the data and the methods employed in the study. Section 4 provides the main findings. Finally, section 5 presents the conclusions and implications of the study.

\subsection{Literature review and conceptual framework}

\subsubsection{The concept of psychic distance and its measures}

The concept of psychic distance was first introduced in the international business literature by Beckerman (1956) when studying the role of distance in the trade patterns of Western European countries as a possible influential factor on trade interchange between two countries. However, the commonly accepted starting point for research on this concept is attributed to a group of researchers from the Uppsala University who employed this term to explain the internationalization of Nordic firms (Sousa and Bradley 2006; Dow 2000). According to these authors, psychic distance refers to the factors that hamper an adequate information interchange between companies and foreign markets, such as language, development levels and political systems, resulting in a lack of knowledge about a country (Johanson and Vahlne 1977; Johanson and Wiedersheim-Paul 1975). A lack of information or transparency in foreign markets increase transaction costs for firms, which is also related to higher risk. Imperfect information about a foreign market leads to a higher degree of uncertainty when doing business which may discourage decision-makers to target that specific market, and prefer instead another with a lower psychic distance (Child et al. 2009; Brewer 2007). In this sense, the Uppsala internationalization process model proposes that companies will gradually venture into new markets focusing first on those that are 
psychically closer with respect to their country (Johanson and Vahlne 1977; Johanson and Wiedersheim-Paul 1975). Nevertheless, firms can also internationalize by acting as bornglobal; and thus, experience a rapid expansion into a higher number and more distant international markets since in the infancy stages of the firm (Knight and Cavusgil 2004).

There is a strong disagreement in international business literature regarding the best way to measure psychic distance. While some authors claim that it should be based on the objective differences between two countries, others argue that it should be based on the individual's perceptions reflecting subjective differences (Hutzschenreuter et al. 2016). Dow and Karunaratna (2006) make a clear distinction between these two concepts: where objective distances (psychic distance stimuli) correspond to the factors preventing the correct flow of information between companies and foreign markets at the macro level (such as national indicators), and subjective differences are the perceived psychic distance from the decisionmarker's perspective. Therefore, the perceived psychic distance is a function of the psychic distance stimuli.

The concept of psychic distance was originally conceived as the subjective perception of the distance between the firm's home country and a foreign country (Brewer 2007; Beddi and Mayrhofer 2013). In this sense, Håkanson and Ambos (2010, p.196) argue that "the psychic distance to a specific foreign country is a reflection of the perceiver's knowledge, familiarity and sense of understanding of it". However, this has changed over the years and the international business literature has focused more on the distance aspect, leaving the psychic aspect with less attention (Nebus and Chai 2014). This is evidenced by a higher proportion of literature studying psychic distance using the objective distance between countries as measure of distance (Håkanson and Ambos 2010; Hutzschenreuter et al. 2016). Even if this approach is of greater convenience for empirical studies covering a large number of firms, objective distance based on national indicators hides variations among individuals within countries and sectors. Thus, perceived psychic distance is still considered the most precise approach for investigating distance differences, while additionally allowing for conclusions on respective influences on international business decision (Hutzschenreuter et al. 2014; O'Grady and Lane 1996). To correctly address the effect of the psychic distance, it is imperative to capture this perception from firms' managers who are the final individual responsible for decision-making in the firm (Hutzschenreuter et al. 2016; Nebus and Chai 
2014; Dow and Karunaratna 2006). However, as Child et al. (2009) argues, such focus has not been frequently employed in the available literature. Additionally, it is important to identify not only the factors that create these perceptions, but also the strategies implemented to cope with them in order to derive concrete management and policy implications (Evans et al. 2000; Dow and Karunaratna 2006; Child et al. 2009).

\subsubsection{Psychic distance, a multi-dimensional concept}

As previously mentioned, since its original conception in the Uppsala model, psychic distance considers aspects from different dimensions such as geographical, economic and cultural among others. In this regard, previous studies have shown that different distance dimensions may have distinct effects on firm internationalization. Dow (2000) and Dow and Karunaratna (2006) identified the geographic distance as the main driver while the cultural distance showed poor or no influence. Berry et al. (2010) found a negative influence of cultural, administrative, geographic and financial dimensions when the firms have no previous experience in the host country, but no influence when they have it. Child et al. (2009) found that culture, language and regulations were the most important factors. Malhotra et al. (2009) found that cultural and geographic distance dimensions have a negative impact on market selection while administrative and economic distance have a positive effect. Such differences confirm that the psychic distance should be considered as a multidimensional concept (Beddi and Mayrhofer 2013; Berry et al. 2010; Child et al. 2009; Hutzschenreuter et al. 2016). Therefore, to avoid misleading results and fully understand the effects of psychic distance, it is important to employ a multi-dimensional approach which offers a more comprehensive, holistic and insightful perspective of different distance dimensions in comparison to an uni-dimensional measure (Malhotra et al. 2009; Hutzschenreuter et al. 2016; Child et al. 2009).

\subsubsection{The CAGE framework}

Based on the work of Johanson and Vahlne (1977), Ghemawat (2001) developed the CAGE framework which offers a more comprehensive perspective of the psychic distance concept. He argues that the distance between two countries emerges from their differences in terms of four basic dimensions: cultural, administrative, geographic and economic. 
Cultural distance: culture refers to a "collection of assumptions, values, and normative behaviors of a group of people" (Ojala 2015, p.827). According to Azar and Drogendijk (2016, p.178) "culture consists of basic human norms, ideas and beliefs that develop continuously over the time, helping to guide what would be considered acceptable human behavior within a given society". These characteristics determine the behavior of people among each other as well as inside organizations and firms (Ghemawat 2001). Therefore, cultural distance is defined as differences between two countries regarding characteristics such as religion, values, beliefs, social norms, religion, stereotypes, languages and ethnicities, among others (Ghemawat 2001; Hutzschenreuter et al. 2014; Azar and Drogendijk 2016; Ojala 2015). Cultural distance can lead to a misunderstanding of information and losses of important insight in doing business (Ghemawat 2001). The wider the cultural distance, the harder to collect and interpret information about foreign markets (Håkanson and Ambos 2010) resulting in more misunderstandings and communication problems (Hutzschenreuter et al. 2014). This lack of information and transparency creates difficulties in doing business due to higher transaction costs for firms. Finally, cultural beliefs and values may influence differences in food consumption between countries, which can represent market opportunities or restrictions for some products (e.g. beef in India) (Filippaios and Rama 2011).

Administrative distance: also known in other studies as governance distance, formal institutional distance or regulatory quality (Hutzschenreuter et al. 2016). Administrative distance can be interpreted as the differences between two countries regarding aspects such as political and institutional associations, trade agreements, colonial ties, currency, political hostility, institutional weakness (corruption or social conflict), and the regulatory governance system of policies and customs (Ghemawat 2001). Thus, higher administrative distance is supposed to create an environment of uncertainty for firms regarding the relationships with governments, customers, and other firms, in which managerial decision making is harder and more costly (Hutzschenreuter et al. 2014). Administrative distance generates higher coordination and transaction cost, which some exporters may prefer to avoid (Malhotra et al. 2009).

Geographic distance: Essentially it refers to the physical separation between the home country and a foreign country, which typically has been an indicator of trade resistance 
mainly due to higher transportation costs (Ojala 2015; Hutzschenreuter et al. 2014). However, there are additional factors that need to be taken into consideration such as time, access to waterways, port facilities, topography, and average distances to borders inside the country itself (Ghemawat 2001). In this regard, costs increase as distance increases, especially when transporting perishable products or heavy goods. Even when some costs related to geographic distance such as transport and communication costs have been reduced substantially in the last decades, cross-border businesses are still being affected by higher geographic distance, mainly due to limitations in market knowledge, and monitoring and coordination difficulties exacerbated by time zone differences (Hutzschenreuter et al. 2014; Håkanson and Ambos 2010).

Economic distance: The level of economic development of a country is considered a proxy for market potential (Hutzschenreuter et al. 2014). The difference in consumer income is the most important aspect creating economic distance between two countries; however other factors such as purchasing power parity, customer preferences and countries' macroeconomic stability can affect the level of trade that firms can achieve in international markets (Ghemawat 2001). The economic distance can define the firms' strategies for exporting and/or investing in businesses across countries. Countries with similar economic development share similar conditions such as market structures, transport and communication infrastructure, distributions channels, and consumption patterns which facilitates cross-border business. Therefore, higher economic distance may discourage foreign market entry (Hutzschenreuter et al. 2014; Malhotra et al. 2009). However, higher economic distances may be also related to a higher opportunities for firms to exploit certain advantages such as access to higher income markets (Hutzschenreuter et al. 2014), which is considered a decisive determinant of food consumption (Filippaios and Rama 2011).

By simultaneously examining these four distance dimensions (cultural, administrative, geographic and economic), the CAGE framework provides "the most comprehensive framework for examining the role of distance on firms' internationalization strategy" (Malhotra et al. 2009, p.654). Very similar dimensions and definitions were also included in the studies of Berry et al. (2010), Brewer (2007), Dow (2000) and Håkanson and Ambos (2010). The CAGE framework is widely accepted in the international business literature (Hutzschenreuter et al. 2014; Hutzschenreuter et al. 2016) and has been employed in previous 
empirical studies related to market selection (Child et al. 2009; Makino and Tsang 2011; Malhotra et al. 2009), knowledge and/or capability transfer (Beddi and Mayrhofer 2013; Campbell, Eden and Miller 2012; Gilbert and Heinecke 2014) and performance (Hutzschenreuter et al. 2014; Lavie and Miller 2008). However, to the best of our knowledge only a few studies have employed this multi-dimensional framework to qualitatively analyze the perceived psychic distance of managers. One example is the study of Child et al. (2009) when examining British small and mediums enterprises (SMEs) exporting to Brazil. Another example is the study of Beddi and Mayrhofer (2013) when researching the relationships of French multinational enterprises with subsidiaries in emerging countries. Our study adopts the multi-dimensional perspective based on the CAGE distance framework to intensely analyze the perceived psychic distance of managers who are working in firms from a newly industrialized country and are exporting highly perishable goods (fresh food products).

\subsection{Methods and Data}

By learning about informants' experiences and perceptions, qualitative research provides indepth explanations to understand aspects of social and cultural phenomena that are not possible using quantitative methods (Myers 1997; Ritchie and Lewis 2003; Neves, Gustavo and Bordonal 2013; Bitsch 2005). As stated by Bitsch and Yakura (2007, p.9) "The use of qualitative case studies has been advocated to increase methodological pluralism in agribusiness and agricultural economics research". Additionally, through qualitative methods it is possible to answer explanatory questions about the "how" or "why" of specific issues or events, which have to deal with operational links over the time (Yin 2003). A case study is defined by Stake (1995) as an in-depth investigation that interprets the analysis of a unit such as an individual, group, organization or phenomenon. Since it also allows the capture of indepth knowledge about subjective psychic distance at the individual level (Ojala 2015), the qualitative case study approach is considered appropriate to answer the research questions addressed in this study.

Fruit export companies in Chile are selected as the case under research in this study for two reasons: first, due to an ambitious agricultural policy based on export strategies in the past decades, the agricultural sector of this country has immensely contributed to its economic 
development (Otter et al. 2014; Engler et al. 2012; Otter and Theuvsen 2014). This especially holds true for the fruit sector, which accounts for $50 \%$ of the country's total agricultural exports (Klerkx et al. 2012). Additionally, Chile is one of the most open economies worldwide with 26 free trade agreements in 64 markets (DIRECON 2018). As a result, this country is nowadays considered one of the most stable and prosperous countries in Latin America (Bianchi and Wickramasekera 2016), representing a prime example of other Latin American countries such as Brazil and Argentina which have followed a similar path. And second, despite the highly perishable nature of the fruits and considering that Chile is geographically distant from most of the main fruit markets of the world, this country is the largest grape exporter in the world, the second largest of blueberries and cherries, and the most important fruit exporter of the Southern Hemisphere (ODEPA 2017). To avoid possible cross-industry variances, this study is focused in the Chilean fruit sector as single industry case.

To obtain the data, 30 in-depth semi-structured with close and open-ended interviews were conducted with managers and/or owners of export firms in Chile of different sizes who were responsible for final decision-making concerning market selection, as suggested by previous studies (Dow and Karunaratna 2006; Hutzschenreuter et al. 2016; Nebus and Chai 2014). This kind of interviews allows the acquisition of more detailed information by allowing the interviewee to express their perspective more freely (Neves et al. 2013; Sonntag et al. 2016). The questions and definitions of the CAGE distance dimensions were based on previous psychic distance literature (especially Azar and Drogendijk 2016; Berry et al. 2010; Dow 2000; Ghemawat 2001; Hutzschenreuter et al. 2014; Ojala 2015; Sousa and Bradley 2006).

According to Child et al. (2009), SMEs are supposed to be more affected by psychic distance than large firms. To draw conclusions on size differences, the sample of 30 interviews included ten small companies, ten medium-sized companies, and ten large companies ${ }^{23}$. One

\footnotetext{
${ }^{23}$ To classify firms according to the size, we follow expert criteria (Yuri 2016) and categorize them according to their export volume measured as the average number of boxes of fruit exported per year over the period between 2009-2015. Thus, a firm is classified as large when it exports on average more than 800 thousand boxes per year, as medium size when it exports on average between 800 thousand and 250 thousand boxes per year, and as small firm when it exports on average less than 250 thousand boxes per year. To obtain the averages of exports, we excluded the year with the lowest quantities to avoid biased averages caused by an abnormal year, which are related to bad climatic conditions.
} 
of the sample selection criteria is that firms must have reported uninterrupted exports over the seven-year time period from 2009 till 2015, to ensure that none of the firms act only as a sporadic exporter. As a second selection criterion, firms must have been located in the Valparaíso, Metropolitana, Bernardo O'Higgins, and Maule regions, where most of traditional and non-traditional fruit is produced primarily due to ideal soil and weather conditions (Fleming and Abler 2013). See map of Chile's regions in Figure 4. In this area, largely temperate fruits are grown (e.g. apples, pears, plums, apricots, peaches, cherries, grapes, kiwifruit, blueberries, among others). The 30 companies were selected from a sample of 233 fruit export firms which fulfilled the above requirements. The corresponding information was obtained from the database Eximfruit (2009-2015). As with most qualitative case studies, the companies were purposefully selected to include information rich cases in the research (Bitsch 2005). Thus, we selected firms with different geographic diversification and internationalization strategies to avoid including only firms highly concentrated in specific geographic markets.

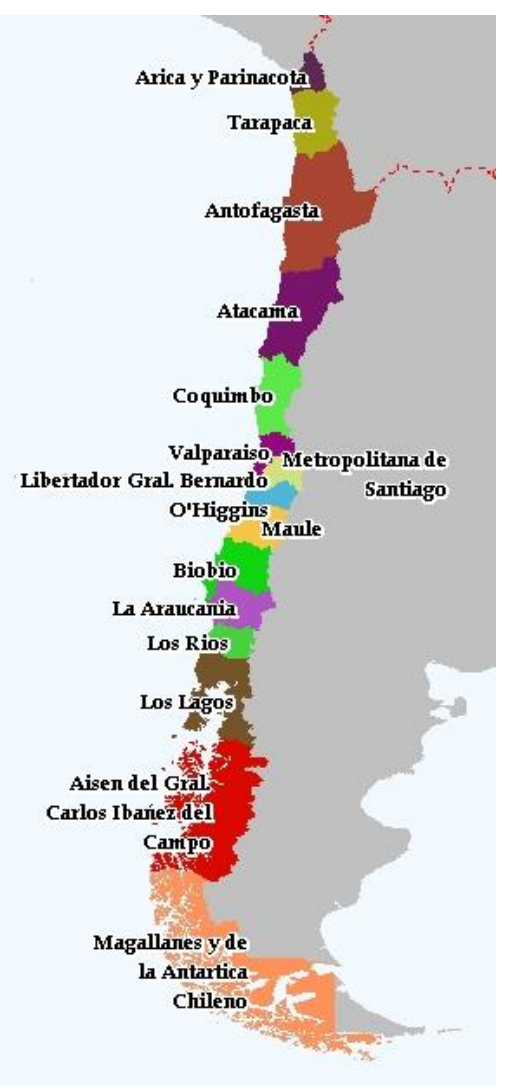

Figure 4. Regions of Chile

Source: (Rulamahue 2018) 
All interviews were conducted in person and in Spanish by the same interviewer between September and December 2016 in Chile. To avoid a possible error source, this study employs single key informants (Sousa and Bradley 2006). The interviews were tape-recorded and transcribed, and last between 30 minutes and one hour and a half. For confidentiality reasons, the identities of the informants and the companies' names are not disclosed. The transcriptions were coded and analyzed using the software ATLAS-ti. The process of codification consists of organizing data in a systematic order, classifying and creating categories that permit a comparative analysis of the interviewees' responses within and between interviews (Saldaña 2013; Bitsch and Yakura 2007). This process allows data to be separated, gathered, collected, recollected and relinked with the purpose of concentrate meaning and explanation (Grbich 2007). The coding process was based on a deductive precoding of the interviewees responses into main categories according to the four CAGE distances, and then establish subcategories to compare the comments within the categories (Sonntag et al. 2016; Saldaña 2013). The coding process is "iterative" (Bitsch and Yakura 2007, p.10) or "cyclical" (Saldaña 2013, p.8); thus, the interviews and codes were reviewed and recoded several times before achieving the final results.

Table 10 presents key characteristics of the sample (for individual information of each firm see Table A2 in the appendix). The number of fulltime employees ranged from one ${ }^{24}$ to 1,100 with an average of 95 , while the number of temporary employees ranged from one to 2,700 with an average of 362 employees. This wide difference stems from differences in governance structures in the supply chain. Those export firms that are vertically integrated and also comprise the production stage (which is highly labor demanding) have a higher number of employees in comparison to those that are only involved in the commercialization of the fruits. At the time of the survey, there are 9 firms in the sample that are not vertically integrated, so they do not possess orchards. The remaining 21 firms are vertically integrated, where on average they owned $66.05 \%$ of the orchards, and the remaining $33.95 \%$ is owned by suppliers. The firms' age ranges between seven and 63 years with a mean of 23 years, and the firms' export experience ranges from seven to 56 years with a mean of 19 years. In total 17 firms export from the moment of their foundation. Over the period under analysis

\footnotetext{
${ }^{24}$ Corresponds to two unipersonal or individual firms.
} 
(2009-2015) the firms exported on average 1,141,414 boxes of fruit with 20,917 boxes being the lowest quantity and 9,269,33 boxes the highest. These quantities show the wide spectrum of export capacity of the firms. The companies are highly export-oriented with an average of $81.33 \%$ of the total sales destined to foreign markets and only eight firms with exports under that average. Regarding the level of geographical and product diversification, the firms surveyed exported on average four different fruit varieties to thirteen countries and four geographic regions (mainly North America, Europe and Far East \& South Pacific). Additionally, 24 firms are family businesses and the remaining six are open capital firms, from which only two were subsidiaries of a foreign firm.

Table 10. Characteristics of the firms

\begin{tabular}{lccc}
\hline Characteristic & Mean & Minimum & Maximum \\
\hline Number of fulltime employees & 95 & 1 & 1,100 \\
Number of temporary employees $^{\mathrm{a}}$ & 362 & 1 & 2,700 \\
${\text { Share of fruit plantations owned by firms }(\%)^{\mathrm{b}}}^{\text {Age (years) }}$ & 66.05 & 6.00 & 100 \\
Export experience (years) & 23 & 7 & 63 \\
Annual exports (boxes of fruit) & 19 & 7 & 56 \\
Share of total sales exported (\%) & $1,141,414$ & 20,917 & $9,269,333$ \\
Number of fruit varieties exported & 81.33 & 40 & 100 \\
Number of export countries & 4 & 1 & 12 \\
Number of export geographic regions & 13 & 2 & 43 \\
\hline
\end{tabular}

Notes: ${ }^{a}$ Only firms with temporary employees were considered.

${ }^{\mathrm{b}}$ Only firms that are vertically integrated were considered.

\subsection{Findings}

During the interview, all four CAGE distance dimensions were described to the interviewees ${ }^{25}$. Then, in order to answer the first research question of this study about the most important perceived psychic distance dimension influencing firms' export market selection, respondents were requested to rate the importance of each dimension on a sevenpoint Likert scale (from 1 = "not important at all" to 7 = "extremely important"). Table 11 shows that the economic and administrative distance dimension were perceived as the most relevant barrier when exporting with an average of 5.24 and 4.59 points, respectively. The cultural distance was considered the least important with an average of 3.41. The different

\footnotetext{
${ }^{25}$ Based on the definitions given in section 4.2.3.
} 
values on perceptions in the four distances validates the use of a multidimensional framework instead of employing one single dimension.

Table 11. Importance of the psychic distance dimensions for export market selection

\begin{tabular}{lccc}
\hline Distance dimension & Mean & Minimum & Maximum \\
\hline Cultural & 3.41 & 1 & 6 \\
Administrative & 4.59 & 1 & 7 \\
Geographic & 4.14 & 2 & 7 \\
Economic & 5.24 & 2 & 7 \\
\hline
\end{tabular}

Additionally, to identify the number of firms influenced by the perceived psychic distance, the respondents were requested to indicate if the different dimensions influence, do not influence, or partially influence the market selection of the firms. As shown in Table 12, the distance dimension more frequently perceived as influencing market selection is the economic with 25 cases, followed by the administrative dimension with 21 cases. The cultural and geographic distance dimensions were perceived as not having an influence on the market selection by most of the firms with 23 and 17 cases respectively. This information confirms the results of Table 11 showing that the economic and administrative distances are the most important dimensions. There were no strong differences in this distribution when considering the size of the firms.

Table 12. Distribution of firms according to the influence of the psychic distance dimensions on export market selection

\begin{tabular}{lcccc}
\hline Distance dimension & $\begin{array}{c}\text { Firms influenced } \\
\text { by distance }\end{array}$ & $\begin{array}{c}\text { Firms partially } \\
\text { influenced by distance }\end{array}$ & $\begin{array}{c}\text { Firms not influenced } \\
\text { by distance }\end{array}$ & Total \\
\hline Cultural & 5 & 2 & 23 & 30 \\
Administrative & 21 & 0 & 9 & 30 \\
Geographic & 12 & 1 & 17 & 30 \\
Economic & 25 & 5 & 0 & 30 \\
\hline
\end{tabular}

In addition, managers were asked about the way that export market selections have changed over time due to the psychic distance, in order to identify their internationalization paths. In this regard, ten firms started exporting to geographically closer markets by first focusing on destination markets within Latin America and then expanded to more distant markets. Twelve firms exported firstly to the United States before expanding to other markets, while the remaining eight firms exported to more distant markets such as Europe and Asia first. 
Table 13. Factors denoting the influence of psychic distance on export market selection.

\begin{tabular}{|c|c|c|}
\hline Distance dimension & Factor & Description \\
\hline \multirow[t]{5}{*}{ Cultural } & Business cultural behavior & $\begin{array}{l}\text { Behavior of foreign companies when doing } \\
\text { business }\end{array}$ \\
\hline & $\begin{array}{l}\text { Information and market } \\
\text { signs }\end{array}$ & $\begin{array}{l}\text { Market information available on foreign } \\
\text { countries. }\end{array}$ \\
\hline & Languages & Main language spoken in foreign countries. \\
\hline & Social Norms & $\begin{array}{l}\text { Values, beliefs, social norms, religion, stereotypes } \\
\text { among other cultural factor in foreign countries. }\end{array}$ \\
\hline & $\begin{array}{l}\text { Consumers' tastes and } \\
\text { preferences }\end{array}$ & $\begin{array}{l}\text { Taste and preferences of consumers in foreign } \\
\text { countries. }\end{array}$ \\
\hline \multirow[t]{7}{*}{ Administrative } & Corruption & $\begin{array}{l}\text { Level of corruption of entities in foreign } \\
\text { countries. }\end{array}$ \\
\hline & Export regulations & $\begin{array}{l}\text { Difference in export regulations (especially } \\
\text { sanitary and phytosanitary) in foreign countries. }\end{array}$ \\
\hline & Political stability & Level of political stability of a country. \\
\hline & Protection of markets & $\begin{array}{l}\text { Degree of market protectionism in favor of local } \\
\text { producers in foreign countries. }\end{array}$ \\
\hline & Tariffs and quotas & $\begin{array}{l}\text { Level of taxes, tariffs and quotas to export to } \\
\text { foreign countries. }\end{array}$ \\
\hline & Trade agreements & $\begin{array}{l}\text { Existence of trade agreements with foreign } \\
\text { countries. }\end{array}$ \\
\hline & Bureaucracy & $\begin{array}{l}\text { Level of bureaucracy in the institutional system in } \\
\text { foreign markets. }\end{array}$ \\
\hline \multirow[t]{6}{*}{ Geographic } & Fruit characteristics & Organoleptic characteristics of the fruits. \\
\hline & Business Networks & $\begin{array}{l}\text { Ease of building local business networks due to } \\
\text { physical proximity to the foreign country. }\end{array}$ \\
\hline & Physical distance & $\begin{array}{l}\text { Physical distance in kilometers to the foreign } \\
\text { country. }\end{array}$ \\
\hline & Transport time & $\begin{array}{l}\text { Time necessary to transport the fruit to the foreign } \\
\text { country. }\end{array}$ \\
\hline & Transport cost & $\begin{array}{l}\text { Cost related to the transport of the fruit to the } \\
\text { foreign country. }\end{array}$ \\
\hline & Time difference & $\begin{array}{l}\text { Difference between time zones with respect to the } \\
\text { foreign country. }\end{array}$ \\
\hline \multirow[t]{4}{*}{ Economic } & Economic development & $\begin{array}{l}\text { Gross Domestic Product (GDP) per capita in the } \\
\text { foreign country. }\end{array}$ \\
\hline & Currency exchange rate & $\begin{array}{l}\text { Currency exchange rate related to USD in the } \\
\text { foreign country. }\end{array}$ \\
\hline & Infrastructure & Level of infrastructure in the foreign country. \\
\hline & Willingness to pay & $\begin{array}{l}\text { Consumers' willingness to pay for the fruits in the } \\
\text { foreign country. }\end{array}$ \\
\hline
\end{tabular}


To answer the second research question of this study, we analyzed each CAGE distance's factors denoting the influence of psychic distance on the export market selection by firms' managers individually. These factors are summarized in Table 13.

In the remainder of this section, we present and discuss the most important factors mentioned by the managers in each CAGE dimension as well as the strategies that they have implemented in the firms to cope with those factors, which is the third research question of this study.

\section{- Cultural Distance Dimension}

\section{Influencing Factors}

The factors most frequently mentioned regarding the cultural distance dimension were social norms, the business cultural behavior and consumers' tastes and preferences, with the first factor directly influencing the other two. The difference in the idiosyncrasy, religion, traditions and beliefs were specified as the most important social aspects affecting market selection: "Culturally, the Asians are very different than us Occidentals. They have a concept that the fruit is a very precious gift... The fruit there has a different social background from what we have here in Chile; therefore, I would say that this is the most important cultural difference" (Exporter 24). Such aspects need to be considered even for supposedly insignificant aspects like packaging design for different markets: "Asian countries are very superstitious... This is very significant in terms of colors, numbers, symbology, animals, so you learn and add this to the design of the boxes, creating a plus" (Exporter 10).

Regarding the cultural behavior of the business, this factor is perceived to affect the way of doing business with clients: "The person that goes there [to Asia] needs to understand the oriental mentality to do business. If we are two Occidentals, we greet, give the business card, we go to the grain and we seat to talk about business. Asians are not like that, they could even do the tea ceremony first" (Exporter 24). In some cases, these cultural differences result in lack of trust when doing business because some managers consider that they are not serious enough or it is perceived they will not stick to the agreements: "In the experience we have had with China, the agreements previously made are not respected, and at the end they do not pay for the fruit as it was agreed. There is a lack of clarity and transparency with them" (Exporter 14). This lack of trust is perceived to be more significant in some countries: "In 
Russia the system works very differently. I have never heard of a Chilean killed because he went to claim a payment, but I have heard many times that they have been told: well, here is the money, they give it in cash and they have a gun at the table and people leave scared to death. And they accept what they give them because they do not want to argue" (Exporter 17).

In comparison to Chile, the consumer's tastes and preferences in some countries can be very different, especially in Asia: "In a fruit we consider the technical properties such as firmness, color and flavor. In China for example (which is the most distant market because is totally different for us), they pay more attention to the physical aspect of the fruit. If it has a different shape, for them it is not the same fruit, even if it has the best flavor of the world. They do not consider technical aspects, but visuals" (Exporter 15). Also, the changes in preferences in some countries over time opens new market opportunities for firms; thus, influencing the market selection and the kind of fruit that is exported: "With students, young people that went out of South Korea realized that there was seedless grape that was good. Thus, when they went back [to South Korea], and they had the purchasing power to request these things, they started to demand those grapes. This [the change] was super strong and fast in Korea. In China this is happening but has been slower because nowadays the Red Globe has been the main variety" (Exporter 26).

All these factors result in longer time periods to develop relationships based on trust and commitment with clients located in countries that are perceived as more culturally distant, especially China, Saudi Arabia, Russia, India and South Korea.

\section{Coping strategies}

The most important strategy mentioned by the interviewees to deal with the influence of higher perceived cultural distance when selecting export markets is to develop a relationship with the clients based on trust and commitment, and sometimes even with their families (Exporters 01, 03, 04, 06, 11, 22, 25, 26, and 30). This is accomplished by maintaining the relationship over a long period of time and frequently visiting each other: "We believe that when you invite someone to your house, it means that your house is in order and you are sure to show it. Then when the client feels that transparency, he will feel more trustful, so you shorten the cultural distances" (Exporter 11). "There is a saying: "When in Rome, do as the 
Romans", basically, that is it. The success of this firm is that by applying that, we have ended up being friends of our clients. We indeed built trustful relationships" (Exporter 03). According to the managers, having this kind of relationship facilitates the business and helps to tackle any problem that may emerge over time. "When the fruit arrives with a problem, we say: let's help each other, I did not send the fruit with a problem and you did not want to receive it with a problem; so, let's fix this like a marriage. Because if they help you once, and the price in the next season drops, they will need your help and you have to help them" (Exporter 01). When there is no trust and commitment, some exporters usually require payment in advance or use credit insurances (Exporters 01, 05, 07, 11, 17, 25, and 30). Additionally, most of the managers expressed that they constantly travel to participate in business trade fairs and visit markets to obtain better knowledge of what is happening (Exporters 09, 10, 17, 18, 22, 26, and 30). Some companies have the advantage of having a foreign owner, so they already have the know-how of the culture and the customers' tastes and preferences in the foreign countries (Exporters 04, 06, 15, 17, and 20). In a similar vein, owners of companies or managers that used to work in other export companies for long periods of time have already the knowledge acquired from previous foreign clients and markets, eliminating the effects of a higher perceived psychic distance as well (Exporters 23 and 30).

Finally, some firms open offices in foreign countries; however, most of them work with Chilean intermediaries and brokers already established in other countries (Exporters 07, 09, $10,15,16,18,21,25,26,27$, and 30). This strategy is less expensive and allows firms to take advantage of third-party cultural knowledge of the country and networks, reducing the lack of transparency and increasing information accessibility in more psychically distant markets. There are similarly cases where the importers have offices in Chile, the cultural distance also diminishes in such cases: "Sometimes the final clients are Chileans that have established there. This year we started to work with a client that has an office in Chile. We deal with the people that are here in Chile, we export to the client there [in the foreign market] but all the logistic is made with Chileans. There are many Chileans settled in China in partnerships with the Chinese. Many started there doing quality control for big firms, they stayed there, established their own contact network and opened their own companies" (Exporter 09). Large companies also implemented a strategy of training programs to teach 
people how to deal with different cultures and establish business relationships with foreign people, especially from those that are more culturally distant (Exporter 22). Language was not identified as a problem because almost all business is conducted in English and when this is not the case, translators are employed. However, to speak the language of the importer seems to be a plus when doing business in some countries: "I have noticed that even when nowadays English is the international language for business, it is incredible how the doors open, especially with Asians and French people, if you make an effort to speak their language" (Exporter 24).

\section{- Administrative Distance Dimension}

\section{Influencing Factors}

The factors most frequently mentioned by the interviewees related to the administrative distance dimension were regulations, political stability and the existence of free trade agreements. Regarding the regulations that firms must abide by to be able to export to some countries, the interviewees mostly referred to sanitary and phytosanitary norms as the most problematic. All the managers mentioned that regulations vary across countries, consequently exporting to different markets become more difficult. European countries have stringent requirements regarding pesticide residues while Latin-American and Asian countries have higher controls regarding plagues and diseases. Thus, exporting to one country could end up being an auto-restriction to export to other markets: "If you want to enter the more specialized supermarkets [located in Europe], you have more limitations of pesticides residues and that stuffs. And to achieve that, you must have a phytosanitary program prioritizing health, which goes against the philosophy of Mexico which to fulfill, you cannot have any plague or anything. Thus, by choosing Europe, Mexico is immediately out” (Exporter 23). Trying to accomplish higher requirements is perceived as more costly and riskier due to the necessary changes in the production and packaging systems, which at the same time, do not diminish the risk of having the fruit rejected: "I would say that Taiwan is one of the most complex markets from the phytosanitary point of view. Complex in the sense that here in the packaging, we implemented a number of measures only thinking about that market, which are very strict, and if we do not fulfill them and we are inspected (as happens many times), we are under the risk of being closed down as a packaging plant" (Exporter 
17). In some countries the regulations imposed are so stringent that are considered as nontariff trade barriers or protectionist measures in favor of home producers or particular interests of that country, especially when supply is high (Exporters 4, 6, 12, 18, 22, and 30). The countries that were most frequently indicated as having the strictest regulations were Mexico, Colombia and China. Other countries mentioned less frequently were South Korea, Taiwan and Ecuador.

With respect to the political stability of foreign markets, this factor is considered as very important: "It has influence, of course. For some years we export to Argelia and the next year there is a civil war in Libya, so we do not export. The political issues have influences. Look at Venezuela!" (Exporter 21). When exporting to unstable countries, the risk of not getting paid by clients is higher: "Generally, in the unstable countries the market is not good and does not pay. If there is instability, then, there are economic problems, and if there are economic problems, people cover first the main physiological needs and then eat fruit. This is an issue, since imported fruit is considered a luxury good, not like for us [Chileans] where eating fruit is very common" (Exporter 30). Even when this factor is relevant for most of the firms, the risk and consequences assumed in the case of small firms can be more severe as their financial and operational resources are more limited in comparison to large firms: "We do not enter risky markets. Maybe there are big exporters that have more contacts, more power there and they can manage the financial risk, but we are not big and cannot allow this. I do not export from my field, I work for the farmer; thus, if I do not get paid the farmer get no payment, and then I am in trouble" (Exporter 02). The most politically unstable countries mentioned by the managers were Venezuela, Argentina, Libya and Algeria.

With respect to the existence of trade agreements with foreign markets (which has an influence in the two previous factors), it is considered by most of the managers when selecting export markets: "Normally when a new trade agreement is established between governments, we are obviously aware of all these signals that let you say: OK, if before I did business here totaling 20\% [of revenue], then probably with the agreement I will increase it to $50 \%$ or $60 \%$ " (Exporter 05 ). Trade agreements improve exporter competitiveness in comparison to firms in other countries and in some cases determines if they can compete in some markets or not: "[The existence of a trade agreement] makes a difference when setting prices... For example, Australia has 0\% [tariff] in Thailand but we have 35\%; so, 
independent of the quality people will obviously prefer the Australian fruit" (Exporter 10). The existence of a trade agreement is also considered to be related with a higher security or stability when doing business: "The rules are clearer when there is a trade agreement, you go with more security in knowing what to expect. New markets without a trade agreement eventually have a higher level of risk because you do not know what is going to happen if there is a problem" (Exporter 19). In some cases, the only way to export directly to foreign markets is if a trade agreement exists. Otherwise the existence of a sanitary protocol between the two countries is necessary, which usually does not exist if the commercial interchange is insignificant.

Another important factor is the level of corruption of governmental entities, especially customs agencies, which can generate a difficult environment to work in (Exporters 03, 09, $11,14,15,16,17,20,22,27,28,29$, and 30): "Mexico is a country where you have to work in a way that we are not willing to work, so we do not go to Mexico" (Exporter 11). "In Colombia there are issues with the bribes... We have sent people there to fix the problems in a good way or a bad, meaning that the bad is to see if you can offer something. We know these markets sometimes work like that, and it is not nice to say this or recognize it, but sadly it is the reality" (Exporter 17). The most frequently mentioned countries in this regard were Mexico, Colombia and Russia.

\section{Coping Strategies}

In the case of regulations, there are some strategies that have been implemented at the national level. Chile has a good and strict regulation system implemented by the Chilean Agriculture and Livestock Service (SAG) which, in the opinion of managers, assures the quality of the fruit that is exported to foreign markets. At the same time, the SAG also negotiates the sanitary protocols for the export and import of fruits; therefore, at the same time, prevents the entry of new plagues and diseases to Chile (Exporters 22 and 29). Another strategy is to take advantage of the support offered by PROCHILE in the continuing negotiation of trade agreements with other countries, and their support for exporters through organizing business meetings with clients and trips to different markets (Exporters 09, 10, 13, 16, 20, 22, and 26). Similar support was mentioned by managers affiliated to private export associations such as the ASOEX: "To open markets, the prospecting tours organized 
by ASOEX and PROCHILE have helped a lot. We have participated almost every year visiting a different country like Indonesia and Malaysia. There you meet people, and even if you do not close a business, you get to know the market, what they want and what they look for" (Exporter 26). ASOEX also supports exporters with technical assistance to help them to comply with international regulations (Exporters 01, 26 and 27). The investment in better controls and voluntary private standards to assure access to stricter markets was also mentioned as a strategy (Exporter 17 and 18). Finally, in the case of unstable countries, some managers request advance payments or employ credit insurance (Exporters 03, 05, 17, 22, 23, and 26).

\section{- Geographic Distance Dimension}

\section{Influencing Factors}

With respect to the geographic distance dimension the most mentioned factors were transportation time, characteristics of the fruit and transportation costs. Transportation time is a critical factor in the case of the fresh fruit since it has a direct influence on the quality and organoleptic conditions of the fruits at the final destination, due to their highly perishable nature: "You have to consider the harvest, then the packaging, the transport, and then [the fruit] has to be commercialized, and most importantly, that at the end the consumer likes it. That is what we look for, and the distance for sure limits this" (Exporter 23). Longer transportation time can be a limitation to the volumes or varieties that can be exported to specific countries because it is not possible to reach them with the fruit in good conditions: "Some years ago India was viewed as the future China for Chile. With more than a billion inhabitants being vegetarians, you said: this is a potential niche. But unfortunately, we have some restrictions that in the short and middle term will be difficult to solve, which is the transit time due to the distance. You cannot reach India in less than 45 days, which is too long, or even 50 days of transit" (Exporter 05). Longer transportation time is also related to a higher risk given the possible changes that the markets can experience (in prices or supply) while the fruits are being transported: “With a 35 day's journey, I could have embarked several ships week after week, so it is a lot of money in the water before you receive the first dollar" (Exporter 11). 
Even if this is not specifically a geographical aspect, the characteristics of the fruit are closely related to transportation time since it determines the markets where specific fruits can be sold: "The distance is limiting when you have a fruit that does not have the condition or as we call it [in the fruit sector], it does not have the "legs" to reach those destinations" (Exporter 06). "Many times, you have a precious fruit, but it takes too much time after harvest and you see that it will not resist [a long transportation time] and you think: I cannot send it to Middle East or Asia, then I send it to the United States which means 15 days [of transport]. Then the decision more than the distance or the shipping is because of the conditions of the fruit" (Exporter 01).

Concerning transportation costs, Chile is considered to be geographically distant from most of the best fruit markets; thus, the export costs are higher in comparison to other fruit producers in the world. In the case of closer markets such as South American countries, the exports are mainly made by land which can be costly as well: "for example a shipment to Europe costs 6,000 USD and Venezuela costs 6,000 USD" (Exporter 03). "The cost of exporting from Chile to Brazil by truck could be higher than getting with a container via ship to the US. The truck is more expensive for a shorter trip, but it is a land trip with many other associated issues" (Exporter 22).

\section{Coping Strategies}

Even when transportation costs can be higher, many managers prefer to use the most direct transport to reduce delivery times. Sometimes the price of the fruit is high enough that it allows the exporter to send the fruit as air-freighted fruit, especially at the beginning of the season. In the case of other fruits with lower prices or which are bulkier such as apples, companies look for better routes with the shipping companies (Exporters 01, 04 and 24). The use of technological advances was another strategy mentioned by managers to reduce the geographic distance (Exporters 05, 10, 15, 21, 23, 24, 29, and 30). In the case of communication, the use of the applications of instant messenger for mobile phones was mentioned as the new way of doing business and keep the communication fluid with clients in foreign countries. "Nowadays, the businesses are done via WhatsApp, so it is not even from one day to the other, it is right away. Let's say that the client asks you to look for two fruits, you send him a photo, he asks you how much [the price], you say this much, and he 
says send me one container, and the deal is closed, that is it! I do not need an order or anything, it is done!" (Exporter 05). In the case of transportation technology, the new cold systems in the containers, cold storages and the implementations of modern packaging systems were the most mentioned factors implemented by exporters to extend the life of the fruits during their transport, reducing the influence of geographic distance in the export market selection: "The cherry, which is one of the most perishable products, nowadays with the technological advances went from five to 50-60 days of post-harvest life. Here you multiply ten times the life of the cherries with the system of controlled atmosphere in the bags" (Exporter 30).

\section{- Economic Distance Dimension}

\section{Influencing Factors}

Regarding the economic distance dimension, the most important factors mentioned were willingness to pay, exchange rates and infrastructure. A factor in the willingness to pay of the markets is the purchasing power of the consumers of specific niches: "Small exporters like us work more with niches. In this concept, if you consider China for example with cherries, they are very pricy product, you perfectly know that you will target a very low percentage of the population which has high incomes and is capable of buying the Chilean cherry" (Exporter 19). However, when they located in big countries, these small niches represent large markets for exporters.

Variation in the exchange rate between currencies is considered to have a significant effect on exports because when it drops in the destination markets, the relative agreed price will increase for the importer. When this decline is strong, the importers are uncapable to pay for the fruit products that were already exported: "With Brazil there is a devaluation, also Russia was almost out [of the market] with the devaluation they had. It was impossible for them to buy fruit" (Exporter 26). As a result, almost all the managers preferred not to export to markets that do not have a very stable currency to avoid payment failures. The most mentioned countries regarding this aspect were Brazil, Russia, Colombia Venezuela, Argentina and Mexico. Changes in exchange rates can also affect the purchasing power and the consumption patterns of a country which has an effect for the operations of export firms: "Canada experienced a reduction in their exchange rate last year and since then they started 
to request smaller packaging" (Exporter 14). Even when the exchange rate in Chile has been relatively stable in the last years, a significant decline in this rate combined with other factors may severely affect exporters: "If there is a combination for example of a significant drop in the dollar from one year to the other with a significant drop in the export volume in one year, the exporter will be in the red and we will need from one to two seasons to recover" (Exporter 20).

Regarding the infrastructure in foreign countries, the lack of cold storage facilities or cold chains represents one of the key aspects in selecting the market, client or product that can be exported, especially for more sensitive products: "India is a good market where a lot of apples are sent, which are more resistant... Breaking the cold chain for an apple is not that serious, it will resist a couple of months more, but you cannot do that to a cherry. So, very low volumes of highly sensitive products are sent to markets that are not well developed" (Exporter 30). "In China we prefer the client that has infrastructure over the client that does not have it" (Exporter 08). The risk of exporting to a country without the correct conditions is very high: "If they pay gold in a country where there is not cold chain, there is no way because the risk is too high" (Exporter 13). In the case of some countries in Latin America, where mostly land exports take place, this situation is not only due to limited cold chain capacity in the trucks during the peak season, but also because of the poor condition of many roads (Exporters 27 and 29).

\section{Coping Strategies}

Similar to the cultural and administrative distance, the relationships based on trust and commitment are very important to solve problems when significant changes in exchange rates occur by helping each other (Exporters 1, 4, 5, 6, 22, 25 and 30). However, when this is not the case, some managers use to request payments in advance or use credit insurance or even currency exchange insurance (Exporters 1, 5, 17 and 23). In the case of big firms, they possess the resources to have a better analysis of market situation and exchange rates in many different countries, which reduces their risk. "[The exchange rate] is part of the evaluation process. Usually, the bigger a firm is, the better market situation analysis they will have” (Exporter 22). Another strategy mentioned by the interviewees was to visit the markets to see if there is good infrastructure to assure the quality of the product in the destination market, 
which decreases the possibility of having claims afterwards due to fruit damage (Exporters 09 and 30). Also, this allows the opportunity for the exporter to know more about the conditions of the country and the market as well as the final prices of the products, which reduces the uncertainty when selecting export markets. Finally, in the last few years many exporters have been moving their exports from more economically stable countries to economically growing but not very stable ones, as they offer higher prices. However, according to a manager, this is not considered a good strategy in the long term: "We have diminished the volumes to Europe and have opened the window to other countries to supply there. When we would like to go back to export to Europe, they will say no because I am with this client now who has been fantastic and has been here and you have not" (Exporter 11).

\subsection{Discussion and Conclusions}

This study examines the influence of the perceived psychic distance on firms' export market selection as well as the strategies implemented by the firms to cope with the main factors denoting this influence. By employing the multi-dimensional CAGE framework (Ghemawat 2001) in the case study of Chilean fresh fruit exporters, this research demonstrates that contrary to previous studies which claim that the psychic distance "has passed its due-date" (Stöttinger and Schlegelmilch 1998, p.367), distance still matters and plays a role in the selection of export markets by these firms. Our results show that the most important psychic distance dimensions perceived by the firms' managers to influence the export market selection are the economic and the administrative followed by the geographic. Similar to previous studies (Dow 2000; Dow and Karunaratna 2006; Brewer 2007), these results confirm that the cultural distance is the least important dimension to measure psychic distance. In fact, with a score of 3.41 the cultural distance was the only dimension rated under the median of the Likert scale (4=important). The differences found in the perception of managers regarding the four distances validate the use of a multi-dimensional framework instead of employing a single-dimension framework, offering a more holistic and complete understanding of the different distance dimensions and their individual effects on market selection. In terms of internationalization, a total of ten firms followed the Uppsala internationalization process evidencing a higher influence of the psychic distance in their 
export market selection, while the remaining 20 firms act as born-global, internationalizing to more psychically distant markets since their inception.

Regarding the factors mentioned by the managers as driving the influence of the psychic distance on export market selection, social norms, business cultural behavior and consumers' taste and preferences appeared the most important with respect to the cultural distance dimension. For these factors, very strong differences between the country of origin and the destination market create barriers and firms may avoid the selection of those countries as export markets. Nevertheless, most of the managers reported to have been able to cope with such differences, mainly by developing relationships based on trust, commitment and transparency with their clients over the time. The importance of this factor has been noted in previous studies (Child et al. 2009). The constant visits of managers to foreign markets is another strategy employed to increase their knowledge of the market and the culture thereby reducing the perceived psychic distance to that country. In line with Child et al. (2009), the establishment of partnerships with firms or intermediaries that already know the markets and the culture has been another strategy implemented by exporters to exploit previous knowhow in reducing transaction costs. In a similar vein, previous knowledge of foreign markets is obtained by the firm when the owner or the manager are foreigners or have previous experience in those markets, which turns into an advantage. Differing from Child et al. (2009), language does not seem to be an important factor in this case study.

In the case of the administrative distance dimension, the main factors mentioned by the managers were regulations, political stability and the existence of trade agreements with the foreign market. Similar to previous studies (Sonntag et al. 2016), results show that the lack of harmonization on food standard regulations stands out as a very problematic situation faced by fruit exporters which clearly determines market selection and is increasingly shifting through more South-South trade in the last years. To assure entry to more stringent markets, many companies have adapted their processes and implemented private standards which have become the main drivers of food and agricultural value chains in the last decades, especially in fresh food products in western markets (Swinnen and Maertens 2007; Reardon and Barrett 2000; Reardon et al. 2009; Otter and Theuvsen 2014). The role of public organizations and private export associations has been essential is this regard, supporting and preparing the 
exporters to comply with these regulations, while at the same time, opening new market options through trade agreements.

Regarding the geographic distance dimension, transportation time, characteristics of the fruits and transportation costs were the most important factors. As main strategies to reduce the influence of psychic distance on market selection, firms chose faster or more direct transportation to export their products depending on the "legs" of the fruit and the price at the final market. Additionally, managers make use of improvements in transport and packaging systems technologies that enables the transportation of fruits to more remote markets without damaging their quality. This strategy have been pointed out as the triggering factor of significant growth in this sector in previous studies (Reardon and Barrett 2000; Agosin and Bravo-Ortega 2009).

Finally, in the case of the economic distance dimension, the most important factors were exchange rates, infrastructure and willingness to pay. Similar to the cultural distance, firms rely on developing relationships based on trust and commitment as the main strategy to solve issues related to changes in exchange rates. Working mainly with clients or markets that have the adequate infrastructure to assure the cold chain for the fruit was also mentioned as a strategy employed by the managers; thus, managers constantly needed to visit foreign clients and markets to control for this. A good analysis of the market situation and the exchange rates in a foreign country was mentioned as the best way to avoid a lack of information that ends up in higher perceived psychic distance regarding that country. However, mostly the large firms are the ones that have the available resources to develop this strategy. In the same direction that previous studies have pointed, a higher distance may have positive effects (Ambos and Håkanson 2014; Malhotra et al. 2009). In this regard, managers mentioned the focus in market niches with a higher difference in the willingness to pay as firm's strategy.

In all the distance dimensions, the requirement of payments in advance or the use of credit and currency exchange insurances are implemented by some exporters when the perceived psychic distance is wide. Nevertheless, these strategies are mainly implemented by large and medium firms due to higher financial and operational resources and bargaining power to set conditions to the importers. Usually small firms lack these resources (Ojala 2015). 
This study contributes to the literature on psychic distance in three ways that have been rarely covered: First, by employing the CAGE multi-dimensional framework developed by Ghemawat (2001) it offers a more comprehensive and holistic understanding of psychic distance than the single dimension approaches. This allows for an individual assessment of the effects of the four distance dimensions on export market selection. Second, by capturing the subjective distance qualitatively at the individual-level instead of the objective distance at the country-level, it gives a better understanding on how the decisions are taken by managers and how distance really influences those decisions. For example, from an objective distance point of view, the cultural distance is large with Middle East and Asian countries. However, as we showed, when the owner of the firms or the manager comes from those countries, the cultural difference dissipates, but this cannot be captured with an objective measure. The approach employed also permits the determination of the direction of the effect of distance on a firm's decision, which is usually preconceived as negative (Ambos and Håkanson 2014; Malhotra et al. 2009). However, as we showed in the case of the willingness to pay, a higher economic distance or a higher willingness to pay in foreign markets in comparison to Chile attract exporters. Finally, by capturing the perceived psychic distance through a qualitative method allows going beyond simply determining the influence of the psychic distance on the export market selection, to additionally shed light in the strategies implemented by managers to cope with the factors driving that influence (Child et al. 2009). Third, this study extends the literature on psychic distance by adding evidence on emerging economies with the analysis of firms from the Chilean fruit export sector as a prime example of agricultural firms from Latin America.

The results of this study have some practical implications: Firms should be aware of the existing differences with foreign countries given that it will allow the identification of which distance dimension is heavily affecting their business. In this way, managers or employees in a firm can undertake appropriate measures to reduce the perceived psychic distance (e.g. by having training regarding sanitary and phytosanitary measures in specific markets or receiving intercultural training) and its effect on their strategic decisions such as market selection (Sousa and Bradley 2006). In the same way that the advantages perceived by firms when having a foreign owner, the selection of managers that have previous experience with some foreign markets may result in lower psychic distance and lower negative effects when 
penetrating unknown or more distant markets. These kind of management skills are an important intangible asset for firms to face the rapid and constant changes experienced in food and agricultural markets (Reardon and Barrett 2000). Even when firms have implemented strategies to cope with the psychic distance, a significant number of managers reported that it still influencing export market selection, at least partially. Therefore, our results shed light on the factors affecting the influence of each distance dimensions on firms' market selection. This is very important due to the current globalization trend affecting firms of different countries and sectors, especially in the case of a country highly open to international trade such as Chile. In this regard, such aspects should be considered by public organizations and private export associations to develop policies and programs to support firms in overcoming psychic distance, especially in more distant markets and in new countries where firms may lack sufficient experience. Particularly, the role of the SAG was found to be very important for the sector. According to the interviewees, this institution should receive more funding from the government to be able to provide more support to exporters, something that should be considered by Chilean policy makers.

This study faces some limitations. Even when Ghemawat's (2001) CAGE framework provides a good multi-dimensional approach, there are many additional factors that may affect the knowledge of a market and the psychic distance. Therefore, more factors should be considered when operationalizing this concept, especially those affecting managers' familiarity with markets (Brewer 2007). Despite that, we offer new evidence of agricultural firms from emerging economies. This study is focused on the Chilean fruit export sector only, and in this regard, even when we claim that using one single industry to avoid cross-industry variances, including more export-based activities will permit a comparison to assess if the influences and strategies implemented are specific to an activity or a country. Additionally, the results of the qualitative case study should in the future be complimented with quantitative measures of psychic distance more extensively to supplement, verify and generalize our findings (Bitsch 2009; Ojala 2015). Finally, further research should capture the perceived psychic distance from importers of Chilean fresh fruit to test its asymmetrical nature. 


\subsection{Appendix A2}

Table A2. Individual characteristics of the firms interviewed

\begin{tabular}{|c|c|c|c|c|c|c|c|c|c|c|c|c|c|}
\hline $\begin{array}{l}\text { Exporter } \\
\text { ID }\end{array}$ & Size & $\begin{array}{r}\text { Emp } \\
\text { Permanent } \\
\end{array}$ & $\begin{array}{l}\text { loyees } \\
\text { Temporary }\end{array}$ & $\begin{array}{l}\text { Vertically } \\
\text { Integrated }\end{array}$ & $\begin{array}{c}\text { Orchards } \\
\text { Owned } \\
(\%) \\
\end{array}$ & $\begin{array}{c}\text { Age } \\
\text { (years) }\end{array}$ & $\begin{array}{c}\text { Export } \\
\text { Experience } \\
\text { (years) }\end{array}$ & $\begin{array}{c}\text { Volume of } \\
\text { Exports/year }\end{array}$ & $\begin{array}{c}\text { Export } \\
\text { Sales/Total } \\
\text { Sales }(\%) \\
\end{array}$ & $\begin{array}{c}\text { Fruits' } \\
\text { varieties } \\
\text { exported } \\
\end{array}$ & $\begin{array}{c}\text { Export } \\
\text { Countries }\end{array}$ & $\begin{array}{l}\text { Export } \\
\text { Regions }\end{array}$ & $\begin{array}{c}\text { Family } \\
\text { Business }\end{array}$ \\
\hline 01 & Large & 11 & 10 & No & 0 & 27 & 23 & 1.255 .794 & 90 & 10 & 25 & 6 & Yes \\
\hline 02 & Medium & 5 & 300 & Yes & 50 & 23 & 12 & 326.047 & 100 & 1 & 3 & 2 & Yes \\
\hline 03 & Large & 50 & 140 & No & 0 & 15 & 13 & 898.016 & 80 & 8 & 20 & 6 & Yes \\
\hline 04 & Medium & 18 & 60 & Yes & 8 & 10 & 10 & 574.316 & 78 & 7 & 12 & 2 & Yes \\
\hline 05 & Medium & 10 & 30 & No & 0 & 22 & 22 & 456.062 & $\mathrm{n} / \mathrm{a}$ & 8 & 19 & 5 & Yes \\
\hline 06 & Large & 70 & 1200 & Yes & 100 & 26 & 18 & 977.159 & 85 & 2 & 15 & 6 & Yes \\
\hline 07 & Medium & 140 & 1000 & Yes & 90 & 13 & 11 & 260.199 & 98 & 2 & 3 & 2 & Yes \\
\hline 08 & Small & 20 & 120 & Yes & 100 & 38 & 38 & 123.116 & 100 & 2 & 7 & 3 & Yes \\
\hline 09 & Medium & 4 & 7 & No & 0 & 9 & 9 & 328.841 & $\mathrm{n} / \mathrm{a}$ & 8 & 10 & 4 & Yes \\
\hline 10 & Medium & 30 & 10 & No & 0 & 16 & 16 & 786.489 & 95 & 3 & 14 & 4 & No \\
\hline 11 & Small & 3 & 0 & No & 0 & 34 & 34 & 134.794 & 80 & 5 & 3 & 3 & Yes \\
\hline 12 & Medium & 13 & 200 & Yes & 100 & 30 & 10 & 250.605 & 95 & 2 & 8 & 4 & Yes \\
\hline 13 & Large & 3 & 12 & Yes & 70 & 22 & 15 & 900.944 & 70 & 2 & 9 & 3 & No \\
\hline 14 & Small & 50 & 350 & Yes & 95 & 12 & 12 & 177.154 & 90 & 2 & 6 & 3 & Yes \\
\hline 15 & Medium & 15 & 120 & Yes & 6 & 17 & 17 & 322.539 & 85 & 1 & 18 & 5 & No \\
\hline 16 & Small & 1 & 1 & No & 0 & 11 & 11 & 139.601 & 60 & 5 & 8 & 4 & Yes \\
\hline 17 & Large & 60 & 275 & Yes & 97 & 22 & 21 & 865.456 & 60 & 4 & 15 & 6 & Yes \\
\hline 18 & Small & 460 & 260 & Yes & 50 & 26 & 26 & 80.852 & 90 & 2 & 2 & 2 & Yes \\
\hline 19 & Small & 8 & 200 & Yes & 30 & 9 & 9 & 82.379 & 80 & 3 & 4 & 3 & No \\
\hline 20 & Small & 30 & 475 & Yes & 20 & 10 & 9 & 114.662 & 85 & 1 & 5 & 2 & Yes \\
\hline 21 & Large & 1100 & 2700 & Yes & 40 & 33 & 28 & 2.664 .976 & 65 & 8 & 34 & 6 & Yes \\
\hline 22 & Large & 300 & 1000 & Yes & 45 & 37 & 37 & 9.269 .333 & 80 & 10 & 43 & 6 & No \\
\hline 23 & Large & $\mathrm{n} / \mathrm{a}$ & $\mathrm{n} / \mathrm{a}$ & Yes & 100 & 9 & 9 & 2.327 .880 & $\mathrm{n} / \mathrm{a}$ & 7 & 19 & 6 & Yes \\
\hline 24 & Large & $\mathrm{n} / \mathrm{a}$ & $\mathrm{n} / \mathrm{a}$ & Yes & 50 & 63 & 56 & 8.566 .043 & 75 & 12 & 43 & 6 & Yes \\
\hline 25 & Small & 28 & 200 & Yes & 100 & 34 & 34 & 81.434 & 40 & 1 & 4 & 3 & Yes \\
\hline 26 & Large & 15 & 6 & Yes & 0 & 27 & 27 & 1.060 .299 & 90 & 3 & 15 & 5 & No \\
\hline 27 & Small & 9 & 40 & Yes & 70 & 20 & 14 & 20.917 & 75 & 1 & 2 & 1 & Yes \\
\hline 28 & Medium & 120 & 700 & Yes & 100 & 45 & 11 & 700.460 & 70 & 2 & 11 & 4 & Yes \\
\hline 29 & Small & 1 & 3 & No & 0 & 8 & 8 & 143.186 & 90 & 6 & 4 & 2 & Yes \\
\hline 30 & Medium & $\mathrm{n} / \mathrm{a}$ & $\mathrm{n} / \mathrm{a}$ & No & 0 & 7 & 7 & 352.865 & 90 & 5 & 15 & 5 & Yes \\
\hline
\end{tabular}




\section{Chapter 5}

\section{General Conclusions}

\subsection{Main Findings}

Firms' internationalization and diversification strategies have been examined by several studies, mostly focused on industrial sectors in developed countries. The findings are mixed, indicating a need for more research, especially with focus on firms from emerging economies. In this regard, the general objective of this dissertation was to analyze the internationalization and diversification strategies of firms from emerging economies using the case of the fresh fruit export sector in Chile.

This dissertation contributes to the existing literature in several ways: First, it develops a more inclusive and nuanced framework than those used in previous studies to classify the level of firms' internationalization, accounting for categories ("host-region") and regions (outside the triad region) that are especially important in the case of firms from emerging economies. Second, it provides an in-depth view of the firms' internationalization strategies and paths by employing a longitudinal analysis (time dimension) over a seven-year period. Third, by focusing on the Chilean fruit export sector, this study extends the current literature on internationalization and diversification by adding information on agricultural export firms from emerging economies in Latin America, which have been rarely covered by the literature. Fourth, it offers a more detailed and complete analysis by separately examining the effects of intra and inter-regional geographic diversification on firms' export performance, as well as the moderating effect of product diversification on these relationships. And fifth, by capturing the perceived psychic distance of firm' managers, this dissertation captures its

actual influence on export market selection and sheds light on the strategies implemented by managers to cope with the main factor creating this distance. To do so, a multi-dimensional framework is employed, offering a more holistic and complete analysis of different psychic distance dimensions.

In the first essay (Chapter 2), we examine the internationalization strategies and paths of Chilean fresh fruit export companies. Similar to previous studies, our results indicate that the majority of companies are transregionally (65.12\%) and globally oriented (16.06\%), showing 
that firms from the agricultural sector have similar strategical behavior than firms from other sectors with regard to their internationalization strategies. Additionally, the framework proposed also permitted to identify a significant percentage of host regional firms (12.5\%) which are firms exporting to one single geographic region different than South America. Such results evidence the adaptability of the framework to agricultural firms form emerging economies and supports the inclusion of the host region category in the framework. Results also showed that the higher levels of internationalization correspond to higher levels of exports and higher business experience.

The inclusion of the scale dimension in the framework allows to recognize that North America is the most important market, especially for the less internationalized firms but particularly for the host regional companies, followed by Europe which is more important among firms sorted into higher internationalization categories. However, both markets have experienced a significant decrease in the exports' shares while Far East \& South Pacific, which is the third most important market, has shown a rapid growth instead. Results also showed an increasing relative importance of South America in firms exports, which indicates that the home region is becoming an important market for many firms.

The results of the longitudinal analysis (time dimension) of the internationalization strategies reveal that regional firms show the lowest internationalization attempts while the host regional firms the highest, evidencing that the born-global firms face lower entry barriers in foreign markets. This analysis also revealed that while the majority of firms follow a linear internationalization path, many firms do not follow a single path and experience non-linear and mixed paths over the time as well. Most of the Chilean fruit exporters do not follow the Uppsala gradualist internationalization approach in terms of psychic distance, as proposed in earlier studies on firms from the industrial sector. Instead they act more as born-global, targeting distant regions since the early stages of the firms. The high share of firms frequently shifting between internationalization categories and changing internationalization paths evidence the high dynamism in the internationalization of the Chilean fruit export sector.

The second essay (Chapter 3) analyzes the effect of geographic and product diversification strategies on firms' export performance. Our results show that moderate levels of geographic (intra and inter) diversification positively affect export performance; however, higher levels 
of diversification beyond the optimal point result counterproductive (inverted U-shaped relationship). These findings indicate that the liability of country and regional foreignness play an important role in the exports growth of firms by keeping them from achieving the level of performance they expected when pursuing a higher geographic diversification strategy. The absence of an inverted S-shaped relationship of firms' geographic diversification with export performance reveals that firms from the Chilean fruit export sector have not reached a point of over-internationalization yet, similar than other emerging economies.

In the case of the related product diversification strategies, we found that more diversified firms have a better export performance than those less diversified due to the advantages of the knowledge generated of previous experiences and economies of scope. Additionally, we found that firms' related product diversification has a negative effect on the relationship between inter-regional diversification and export performance. These results evidence that firms are able to individually exploit the advantages of geographic and product diversification and obtain a better performance; however, when both strategies are implemented together, the results are counterproductive. This is an indicative of the higher regional liability of foreignness faced by firms when pursuing an inter-regional diversification strategy, probably due to the higher psychic distance generated by differences in legislations and requirements such as sanitary, phytosanitary and quality-related regulations.

With the third essay (Chapter 4), we examine the influence of perceived psychic distance on firms' export market selection as well as the strategies implemented by the firms to cope with the main factors denoting this influence. We found that the economic and the administrative distance dimensions are the most important, while the cultural dimension was considered as less important. These results confirm that there exist differences in the perception of different psychic distance dimensions; therefore, a multi-dimensional framework offers a more comprehensive and complete understanding of the distance effects on market selection.

The most significant factors influencing firms' export market selection in the case of the cultural dimension were the social norms, the business cultural behavior and the consumers' tastes and preferences. In this regard, the most frequently mentioned strategy to cope with 
such factors was to develop relationships with clients based on trust and commitment over time. Having a foreign owner seems to be an advantage to cope with higher cultural distance in some cases as well. Regarding the administrative dimension, the main factors were the regulations, the political stability and the existence of trade agreements. In this case, managers mentioned that the main strategy is to take advantage of the support and the efforts of public organizations and private trade associations which facilitate to deal with administrative distances. Voluntary private standards and the establishment of better controls in the firms were also mentioned as strategies. The transport time, the characteristics of the fruit and the transport cost were the most important factors with regard to the geographic distance dimension. According to the managers, the main strategy is to use the most direct transport when the prices are higher or the faster routes depending on the quality of the fruit. Making use of technological advances in communication, transport and packaging systems were also mentioned as strategies to deal with higher geographic distances. Finally, for the economic dimension, the main factors were buyers' willingness to pay, the currency exchange rate and the infrastructure. In this regard, similarly than in the case of the cultural distance, relationships based on trust and commitment were the most important strategy to deal with problems due to economic differences. Additionally, managers mentioned the constant analysis of market situation and currency exchange rates, frequent visits to check markets' and clients' infrastructure as other strategies implemented. In all the distance dimensions managers mentioned the requirement of payment in advance, the use of credit insurance or even currency exchange insurance as additional strategies when the differences are perceived as highly significant. However, these latter strategies might be implemented only by large firms which have enough resources and bargaining power.

\subsection{Policy and Managerial Implications}

The high dependency of the less internationalized firms (particularly the host regional) on the North American market represents a high risk due to the unstable trade policies implemented by the United States over the last years. Thus, the role of public organizations and private trade associations to keep stable relationships with that important market is especially vital for these firms. At the same time, these organizations should provide 
accompaniment to such firms to identify market opportunities that allow them to broaden their export scope and scale. In a similar vein, most of the home regional firms remain in the same category which indicates the need of more support of extension services and export/trade associations to these firms in order to overcome the entry barriers that are curtailing their expansion beyond home regional markets.

We found a high correlation between the level of firms' internationalization with their age and their export level. Because firms' capabilities and resources are crucial to successfully enter new dissimilar markets and to improve internationalization, export support organizations can aid smaller and less experienced firm, by providing information on particular markets, background information on importers, legal conditions and ways of doing business in more distant regions. This is also crucial for the significant number of born-global firms which assume higher risks by internationalizing in more distant markets since early stages. Additionally, private associations should place focus in their role as lobby groups to influence the political decisions and keep the efforts to search, open and facilitate the access to new markets for the Chilean fruit exports.

The high internationalization dynamism of the Chilean fruit sector demands dynamic strategies not only from the export firms but also from the policymakers and trade facilitation agencies to help and prepare firms to become internationalized and maintain their international presence over the time.

Regarding the diversification strategies, by mapping themselves and their competitors regarding the diversification-performance relationship, firms can identify the optimum levels and adapt their diversification strategies to take the maximum advantage of the positive effect on their export performance and avoid levels that turn out to be counterproductive.

The changes experienced in global agri-food markets due to economic growth and new trends and consumption patterns in some countries (especially emerging economies) have forced Chilean fresh fruit exporters to simultaneously implement product and geographic diversification strategies. However, according to our results, firms seem to experience managerial problems when implementing both strategies at the same time, resulting in negative effects on export performance. Thus, public organizations and private trade associations should support firms to develop proper managerial skills to be able to exploit 
the positives effects that both diversification strategies generate due to economies of scope and scale.

With respect to the influence of psychic distance on the firms' diversification strategies, our results show that distance still matters, especially its economic and administrative dimensions. Despite the strategies implemented by managers to try to cope with psychic distance, it still influences market selection in a significant number of firms. In this regard, firms must be aware of the distances affecting them more and the direction of such effects to either implement measures for their managers and employees to diminish such influence, or to exploit the advantage that they may have in comparison to other firms due to smaller distances. In a similar vein, the support of extension services and export/trade associations in training and preparing export firms' managers to deal with the factors that are still hampering the successful penetration in some foreign markets, especially the more distant, is important. The increasing relative importance of exports to South American countries reflected in the results of the first essay (Chapter 2) of this dissertation indicates the importance of the home region as an interesting market. However, even when the cultural and geographic distance is short to these countries for Chilean firms, the results of our third essay (Chapter 3) indicate that the high transport costs, the lack of transparency and the political and economic instability in some South American countries seem to be the main reasons curtailing higher export volumes. In this regard, the intervention of public organizations and private trade associations is imperative in order to help fresh fruit exporters to solve or deal with these problems, as the home region seems to be a very good market option, especially due to the geographically and culturally proximity to Chile.

In general, the role of public organizations such as PROCHILE and SAG and private associations such as FEDEFRUTA and ASOEX, the public-private partnerships between those institutions, and the close work with fruit growers and exporters (especially ASOEX) have had a significant positive impact on the success and globalization of the Chilean fresh fruit value chain. It is important that these organizations keep their support to maintain Chile as one of the fresh fruit global export leader and to prepare the sector to face the drastic changes that food and agricultural value chains have been facing over the last decades and will certainly do so in the future. 


\subsection{Limitations and Further Research}

As every study, this dissertation has some limitations that should be mentioned and which at the same time indicate research lines for further studies. Our study is based on the case of the Chilean fruit export sector which represents a prime example of emerging economies in Latin America, specially from the agricultural sector. However, the possible existing differences between sectors, industries and countries regarding cultural, political and economic systems might hinder the general applicability of the results obtained. In this regard, the inclusion of more export-based activities in different sectors or countries in further research analyzing firms' internationalization and diversification strategies would permit to test whether such strategies are sector or country dependent or can be more generalizable.

This dissertation focuses on exports as the only international business entry modes. Different strategies, effects and barriers might be expected from different entry modes. Thus, future research may include and simultaneously analyze additional entry modes such as foreign direct investment or strategic alliances to extend empirical evidence and improve the understanding of internationalization and diversification strategies.

We employ a longitudinal database that comprises a seven-year time period in the first essay (Chapter 2) and a six-year time period in the second essay (Chapter 3). Even when longitudinal analyses offer a more complete and comprehensive view of the issue under study in comparison to cross-sectional data, conducting this study with a longer period of analysis and the additional use of other information sources may permit to observe and test different internationalization patterns and diversification-performance effects in the Chilean fruit export sector.

The first and second essays (Chapters 2 and 3) of this dissertation do not include many firms' specific characteristics that may affect the internationalization and diversification strategies due to the difficulties of finding good longitudinal information which contains this information. Therefore, further research should include more of these variables, if available, to control for their possible effects.

In the specific case of the first essay (Chapter 2), the objective was to analyze the firms' internationalization strategies and paths with a special focus on the locus of destinations; therefore, we employed geographically based definitions of the regions. However, employing 
different regional definitions considering other dimensions such as cultural, administrative and economic may show different internationalization strategies and paths, something that can be tested in future studies. (Agosin and Bravo-Ortega 2009)

Finally, in the specific case of the third essay (Chapter 4), even when measuring the managers' perception of the psychic distance is essential to capture the real effect of such distance on firm decisions, future studies may capture the objective psychic distance (psychic distance stimuli) as well and employ both measures when analyzing their effects on market selection or other international entry modes (as mentioned above in this section). 


\section{References}

Aggarwal, R., J. Berrill, E. Hutson, and C. Kearney. 2011. "What is a multinational corporation? Classifying the degree of firm-level multinationality." International Business Review 20(5):557-577.

Agosin, M., and L.D. Arango. 2015. "Export diversification dynamics in Latin Amercia.” In O. Morrissey, R. A. López, and K. Sharma, eds. Handbook on Trade and Development. Cheltenham: Edward Elgar Publishing Limited, pp. 288-309.

Agosin, M., and C. Bravo-Ortega. 2009. "The Emergence of New Successful Export Activities in Latin America: The Case of Chile.” IDB Working Paper No. 236, InterAmerican Development Bank.

Aksoy, A. 2005a. “Global agricultural trade policies.” In A. Aksoy and J. Beghin, eds. Global agricultural trade and developing countries. Washington, DC: World Bank Publications, pp. 37-54.

Aksoy, A. 2005b. "The evolution of agricultural trade flows." In A. Aksoy and J. Beghin, eds. Global agricultural trade and developing countries. Washington, DC: World Bank Publications, pp. 17-35.

Altbach, P.G., and J. Knight. 2007. "The internationalization of higher education: Motivations and realities." Journal of Studies in International Education 11(3/4):290305.

Ambos, B., and L. Håkanson. 2014. "The concept of distance in international management research." Journal of International Management 20(1):1-7.

Arnade, C., and A. Sparks. 1993. "Chile's agricultural diversification.” Agricultural Economics 9:1-13.

Asmussen, C.G. 2009. "Local, regional, or global? Quantifying MNE geographic scope." Journal of International Business Studies 40(7):1192-1205.

Aulakh, P.S. 2007. "Emerging multinationals from developing economies: Motivations, paths and performance." Journal of International Management 13(3):235-240.

Aulakh, P.S., M. Kotabe, and H. Teegen. 2000. "Export strategies and performance of firms 
from emerging economies: evidence from Brazil, Chile, and Mexico." Academy of Management Journal 43(3):342-361.

Avloniti, A., and F. Filippaios. 2014. "Unbundling the differences between Psychic and Cultural Distance: An empirical examination of the existing measures.” International Business Review 23(3):660-674.

Azar, G., and R. Drogendijk. 2016. "Cultural distance, innovation, and export performance: an examination of perceived and objective cultural distance." European Business Review 28(2):176-207.

Balabanis, G.I. 2001. "The relationship between diversification and performance in export intermediary firms.” British Journal of Management 12(1):67-84.

Banalieva, E., and C. Dhanaraj. 2013. "Home-region orientation in international expansion strategies.” Journal of International Business Studies 44(2):89-116.

Barney, J. 1991. "Firm Resources and Sustained Competitive Advantage." Journal of Management 17(1):99-120.

Barrena, J., L. Nahuelhual, A. Engler, R. Echeverría, and G. Cofre. 2013. "Heterogeneity of farms entering export supply chains: the case of fruit growers from central-south Chile." Spanish Journal of Agricultural Research 11(2):281-293.

Beckerman, W. 1956. "Distance and the Pattern of Intra-European Trade." The Review of Economics and Statistics 38(1):31-40.

Beddi, H., and U. Mayrhofer. 2013. "Headquarters-subsidiaries relationships of French multinationals in emerging markets.” Multinational Business Review 21(2):174-194.

Benito-Osorio, D., A. Colino, L.Á. Guerras-Martín, and J.Á. Zúñiga-Vicente. 2016. “The international diversification-performance link in Spain: Does firm size really matter?" International Business Review 25(2):548-558.

Berrill, J. 2015. “Are the World's Largest Firms Regional or Global ?" Thunderbird International Business Review 57(2):87-101.

Berrill, J., and G. Mannella. 2013. "Are firms from developed markets more international than firms from emerging markets?" Research in International Business and Finance 
27(1):147-161.

Berry, H., M.F. Guillén, and N. Zhou. 2010. "An institutional approach to cross-national distance.” Journal of International Business Studies 41:1460-1480.

Bianchi, C. 2014. "Internationalisation of emerging market firms: an exploratory study of Chilean companies." International Journal of Emerging Markets 9(1):54-78.

Bianchi, C., and R. Garcia. 2007. "Export Marketing Strategies of an Emerging Country: An Exploratory Study of the Main Challenges and Factors Leading to Success for Chilean Food Exporters." Journal of Food Products Marketing 13(3):1-19.

Bianchi, C., and R. Wickramasekera. 2016. "Antecedents of SME export intensity in a Latin American Market.” Journal of Business Research 69(10):4368-4376.

Bitsch, V. 2009. "Grounded Theory: A Research Approach to Wicked Problems in Agricultural Economics." International Conference of Agricultural Economists in Beijing, China, 16-22.08.2009.

Bitsch, V. 2005. "Qualitative Research: A Grounded Theory Example and Evaluation Criteria." Journal of Agribusiness 23(1):75-91.

Bitsch, V., and E.K. Yakura. 2007. "Middle Management in Agriculture :" International Food and Agribusiness Management Review 10(2):1-28.

Boehe, D.M., and A. Jiménez. 2016. "How does the geographic export diversificationperformance relationship vary at different levels of export intensity?" International Business Review 25(6):1262-1272.

Bond, S.R. 2002. "Dynamic panel data models: a guide to micro data methods and practice." Portuguese Economic Journal 1(2):141-162.

Bond, S.S., A. Hoeffler, and J. Temple. 2001. "GMM estimation of empirical growth models." Economics Papers, Economics Group, Nuffield College: University of Oxford W21(01):33.

Borda, A., J.M.G. Geleilate, W. Newburry, and S.K. Kundu. 2017. "Firm internationalization, business group diversification and firm performance: The case of Latin American firms.” Journal of Business Research 72:104-113. 
Brewer, P.A. 2007. “Operationalizing Psychic Distance: A Revised Approach.” Journal of International Marketing 15(1):44-66.

Calof, J.L., and P.W. Beamish. 1995. "Adapting to foreign markets: Explaining internationalization.” International Business Review 4(2):115-131.

Campbell, J.T., L. Eden, and S.R. Miller. 2012. "Multinationals and corporate social responsibility in host countries: Does distance matter?" Journal of International Business Studies 43(1):84-106.

Cavusgil, S.T. 1984. "Differences Among Exporting Firms Based on Their Degree of Internationalization.” Journal of Business Research 12(2):195-208.

Cavusgil, S.T. 1980. "On the internationalization process of the firm." European Research 8:273-281.

Cerrato, D. 2009. "Does innovation lead to global orientation? Empirical evidence from a sample of Italian firms.” European Management Journal 27(5):305-315.

Chadha, P., and J. Berrill. 2016. "An empirical investigation into the internationalization patterns of Japanese firms.” Asia Pacific Business Review 22(4):595-611.

Chang, S.C., and C.F. Wang. 2007. "The effect of product diversification strategies on the relationship between international diversification and firm performance." Journal of World Business 42(1):61-79.

Chao, M.C.H., and V. Kumar. 2010. "The impact of institutional distance on the international diversity-performance relationship." Journal of World Business 45(1):93-103.

Chen, C.J., and C.M.J. Yu. 2012. "Managerial ownership, diversification, and firm performance: Evidence from an emerging market." International Business Review 21(3):518-534.

Chetty, S., and C. Campbell-Hunt. 2003. "Paths to internationalisation among small- to medium-sized firms: A global versus regional approach." European Journal of Marketing 37(5/6):796-820.

Child, J., S.B. Rodrigues, and J.G. Frynas. 2009. "Psychic distance, its impact and coping modes." Management International Review 49:199-224. 
Cieślik, J., E. Kaciak, and N. Thongpapanl. 2015. "Effect of export experience and market scope strategy on export performance: Evidence from Poland." International Business Review 24(5):772-780.

Cieślik, J., E. Kaciak, and D.H.B. Welsh. 2010. “The effect of early internationalization on survival, consistency, and growth of exports sales." Journal of Small Business \& Entrepreneurship 21(1):39-64.

Cieślik, J., E. Kaciak, and D.H.B. Welsh. 2012. "The impact of geographic diversification on export performance of small and medium-sized enterprises (SMEs)." Journal of International Entrepreneurship 10(1):70-93.

Contractor, F.J., V. Kumar, and S.K. Kundu. 2007. "Nature of the relationship between international expansion and performance: The case of emerging market firms." Journal of World Business 42(4):401-417.

Contractor, F.J., S.K. Kundu, and H. Chin-Chun. 2003. "A three-stage theory of international expansion: the link between multinationality and performance in the service sector." Journal of International Business 34(1):5-18.

Craig, C.S., and S.P. Douglas. 1997. "Executive insights: Managing the transnational value chain-strategies for firms from emerging markets." Journal of International Marketing 5(3):71-84.

Crick, D., S. Chaudhry, and S. Batstone. 2000. "Revisiting the Concentration Versus Spreading Debate as a Successful export growth strategy: the case of UK SMEs exporting agricultural-related products." Entrepreneurship \& Regional Development 12(1):49-67.

Cuervo-Cazurra, A. 2008. "The multinationalization of developing country MNEs: The case of multilatinas.” Journal of International Management 14(2):138-154.

Cyrino, A.B., E.P. Barcellos, and B. Tanure. 2010. "International trajectories of Brazilian companies: Empirical contribution to the debate on the importance of distance." International Journal of Emerging Markets 5(3/4):358-376.

D’Angelo, A., A. Majocchi, A. Zucchella, and T. Buck. 2013. "Geographical pathways for SME internationalization: insights from an Italian sample.” International Marketing 
Review 30(2):80-105.

Delios, A., and P.W. Beamish. 2005. "Regional and Global Strategies of Japanese Firms." Management International Review 45(1):19-36.

DIRECON. 2018. "Acuerdos Comerciales Vigentes." Available at: https://www.direcon.gob.cl/acuerdos-comerciales/ [Accessed December 20, 2017].

DIRECON. 2015. "Presencia de inversiones directas de capitales chilenos en el mundo 1990 - diciembre 2014." :24. Available at: https://www.direcon.gob.cl/wpcontent/uploads/2015/05/Presencia-ID-Cl-en-mundo-1990-dic2014.pdf [Accessed May 1, 2016].

Dow, D. 2000. “A note on psychological distance and export market selection.” Journal of International Marketing 8(1):51-64.

Dow, D., and A. Karunaratna. 2006. "Developing a multidimensional instrument to measure psychic distance stimuli." Journal of International Business Studies 37(5):578-602.

Engler, A., L. Nahuelhual, G. Cofré, and J. Barrena. 2012. "How far from harmonization are sanitary, phytosanitary and quality-related standards? An exporter's perception approach.” Food Policy 37(2):162-170.

Evans, J., A. Treadgold, and F. Mavondo. 2000. "Explaining export development through psychic distance.” International Marketing Review 17(2):164-168.

Eximfruit. 2009-2015. Chilean fruit export analysis. Santiago, Chile: Inglobo.

Fedefruta. 2018. “Qué es Fedefruta.” Available at: https://fedefruta.cl/que-hacemos/que-esfedefruta/ [Accessed September 1, 2018].

Fernández Olmos, M., and I. Díez-Vial. 2015. "Internationalization pathways and the performance of SMEs.” European Journal of Marketing 49(3/4):420-443.

Filippaios, F., and R. Rama. 2011. “Cultural distance and internationalization: the world's largest food and drink multinationals." Agribusiness 27(4):399-419.

Fleming, D.A., and D.G. Abler. 2013. "Does agricultural trade affect productivity? Evidence from Chilean farms." Food Policy 41:11-17. 
Foster, W., and A. Valdes. 2006. "Chilean Agriculture and Major Economic Reforms: Growth, Trade, Poverty and the Environment." Region et Developpement (23):187-214.

Garri, M., and N. Konstantopoulos. 2013. "Management of internationalization: structural modifications and inter-organizational significance." Ekonomika ir vadyba: aktualijos ir perspektyvos 1(29):126-135.

Geldres-Weiss, V. V., and J. Monreal-Pérez. 2018. "The Effect of Export Promotion Programs on Chilean Firms' Export Activity: A Longitudinal Study on Trade Shows and Trade Missions.” Journal of Promotion Management 24(5):660-674.

Geringer, J.M., S. Tallman, D.M. Olsen, J. Michael, S. Tallman, and D.M. Olsen. 2000. "Diversification Product and International Firms Among Japanese Multinational." Strtegic Management Journal 21(1):51-80.

Ghemawat, P. 2001. "Distance Still Matters: the hard reality of global expansion." Harvard Business Review 79:137-147.

Ghemawat, P., and T. Hout. 2008. "Tomorrow's Global Giants Not the Usual Suspects." Harvard Business Review 86(11):80-88.

Gilbert, D.U., and P. Heinecke. 2014. "Success Factors of Regional Strategies for Multinational Corporations: Exploring the Appropriate Degree of Regional Management Autonomy and Regional Product/Service Adaptation." Management International Review 54(5):615-651.

Grbich, C. 2007. Qualitative data analysis: An introduction. London: SAGE Publications.

Grosse, R. 2016. "How emerging markets firms will become global leaders." International Journal of Emerging Markets 11(3):274-287.

Guillén, M.F., and E. García-Canal. 2009. "The American Model of the Multinational Firm and the 'New' Multinationals From Emerging Economies." Academy of Management Perspectives 23(2):23-35.

Gwynne, R.N. 1999. “Globalisation, commodity chains and fruit exporting regions in Chile.” Tijdschrift voor Economische en Sociale Geografie 90(2):211-225.

Gwynne, R.N. 2003. "Transformation in Chile." Tijdschrift voor Economische en Sociale 
Geografie 94(3):310-321.

Håkanson, L., and B. Ambos. 2010. "The antecedents of psychic distance." Journal of International Management 16(3):195-210.

Hennart, J.-F. 2011. "A theoretical assessment of the empirical literature on the impact of multinationality on performance.” Global Strategy Journal 1(1-2):135-151.

Hennart, J.F. 2007. "The theoretical rationale for a multinationality-performance relationship.” Management International Review 47(3):423-452.

Hermelo Diaz, F., and R. Vassolo. 2012. "How much does country matter in emerging economies? Evidence from Latin America.” International Journal of Emerging Markets $7(3): 263-288$.

Heyder Makus, C., Theuvsen, L., M. 2011. "Internationalisation and Firm Performance in Agribusiness: Empirical Evidence from European Cooperatives.” International Journal of Food System Dynamics 2(1):77-93.

Heyder, M., C. Makus, and L. Theuvsen. 2011. "Internationalization and Firm Performance in Agribusiness: Empirical Evidence from European Cooperatives.” Int. J. Food System Dynamics 2(1):77-93.

Hirsch, S., and B. Lev. 1971. "Sales stabilization through export diversification.” The Review of Economics and Statistics 53(3):270-277.

Hitt, M., R. Hoskisson, and H. Kim. 1997. "International diversification: Effects on innovation and firm performance in product-diversi.” Academy of Management Journal, 40(4):767-798.

Hitt, M., L. Tihanyi, T. Miller, and B. Connelly. 2006. "International diversification: Antecedents, outcomes, and moderators.” Journal of Management 32(6):831-867.

Hoskisson, R., C.-M. Lau, L. Eden, and M. Wright. 2000. "Strategy in Emerging Economies.” The Academy of Management Journal 43(3):249-267.

Hutzschenreuter, T., I. Kleindienst, and S. Lange. 2014. "Added psychic distance stimuli and MNE performance: Performance effects of added cultural, governance, geographic, and economic distance in MNEs' international expansion." Journal of International 
Management 20(1):38-54.

Hutzschenreuter, T., I. Kleindienst, and S. Lange. 2016. "The Concept of Distance in International Business Research: A Review and Research Agenda." International Journal of Management Reviews 18(2):160-179.

Hymer, S. 1976. International Operations of National Firms: A Study of Foreign Direct Investment. Boston, MA: MIT Press.

Jacquemin, A.P., and C.H. Berry. 1979. "Entropy Measure of Diversification and Corporate Growt." The Journal of Industrial Economics 27(4):359-369.

Johanson, J., and J.-E. Vahlne. 1977. “The Internationalization Process of the Firm-A Model of Knowledge Development and Increasing Foreign Market Commitments." Journal of International Business Studies 8(1):23-32.

Johanson, J., and J.-E. Vahlne. 1990. “The Mechanism of Internationalisation.” International Marketing Review 7(4):11-24.

Johanson, J., and J.-E. Vahlne. 2009. "The Uppsala internationalization process model revisited: From liability of foreignness to liability of outsidership." Journal of International Business Studies 40(9):1411-1431.

Johanson, J., and F. Wiedersheim-Paul. 1975. "The Internationalization of the Firm-Four Swedish Cases.” Journal of Management Studies 12(3):305-323.

Kim, H., R. Hoskisson, and S.-H. Lee. 2015. 'Why strategic factors markets matter: 'New' multinationals' geographic diversification and firm profitability." Strategic Management Journal 36:518-536.

Kistruck, G.M., I. Qureshi, and P.W. Beamish. 2013. "Geographic and Product Diversification in Charitable Organizations.” Journal of Management 39(2):496-530.

Klerkx, L., P. Villalobos, and A. Engler. 2012. "Variation in implementation of corporate social responsibility practices in emerging economies 'firms: A survey of Chilean fruit exporters." Natural Resources Forum 36:88-100.

Knight, G.A., and S.T. Cavusgil. 2004. "Innovation, Organizational Capabilities, and the Born-Global Firm.” Journal of International Business Studies 35(2):124-141. 
Kuivalainen, O., S. Sundqvist, S. Saarenketo, and R.B. McNaughton. 2012. "Internationalization patterns of small and medium-sized enterprises." International Marketing Review 29(5):448-465.

Kuivalainen, O., S. Sundqvist, and P. Servais. 2007. "Firms' degree of born-globalness, international entrepreneurial orientation and export performance." Journal of World Business 42(3):253-267.

Kumar, M.V.S. 2009. "The relationship between product and international diversification: the effects of short-run constraints and endogeneity." Strategic Management Journal 30(1):99-116.

Lakner, S., T. Brenes-Muñoz, and B. Brümmer. 2017. "Technical Efficiency in Chilean Agribusiness Industry: A Metafrontier Approach.”Agribusiness 33(3):302-323.

Lavie, D., and S.R. Miller. 2008. "Alliance Portfolio Internationalization and Firm Performance.” Organization Science 19(4):623-646.

León, J. 2016. “Expert Interview.” Curicó, Chile at 22. April 2016.

Li, L., G. Qian, and Z. Qian. 2012. “The performance of small and medium-sized technologybased enterprises: Do product diversity and international diversity matter?" International Business Review 21(5):941-956.

Llorca-Jaña. 2015. "Business history in Chile: where are we now?" Contribuciones Científicas y Tecnológicas 40:1-4.

Lopez, L.E., S.K. Kundu, and L. Ciravegna. 2009. "Born global or born regional? Evidence from an exploratory study in the Costa Rican software industry." Journal of International Business Studies 40(7):1228-1238.

Lu, J., and P. Beamish. 2004. "International Diversification and Firm Performance: The SCruve Hypothesis.” Academy of Management Journal 47(4):598-609.

Maertens, M., and J. Swinnen. 2015. "Agricultural trade and development: A value chain perspective.” WTO Staff Working Paper No. ERSD-2015-04,

Makino, S., and E.W.K. Tsang. 2011. "Historical ties and foreign direct investment: An exploratory study." Journal of International Business Studies 42:545-557. 
Malhotra, S., X. Lin, and C. Farrell. 2016. "Cross-national uncertainty and level of control in cross-border acquisitions: A comparison of Latin American and U.S. multinationals." Journal of Business Research 69(6):1993-2004.

Malhotra, S., K. Sivakumar, and P. Zhu. 2009. "Distance factors and target market selection: the moderating effect of market potential.” International Marketing Review 26(6):651673.

Mason, C.H., and W.D. Perreault. 1991. "Collinearity, power, and interpretation of multiple regression analysis.” Journal of Marketing Research 28(3):268-280.

McNaughton, R.B. 2003. "The Number of Export Markets that a Firm Serves: Process Models versus the Born-Global Phenomenon." Journal of International Entrepreneurship 1(3):297-311.

Melo, O., A. Engler, L. Nahuehual, G. Cofre, and J. Barrena. 2014. "Do Sanitary, phytosanitary, and quality-related standards affect international trade? Evidence from Chilean fruit exports." World Development 54:350-359.

Mullen, C., and J. Berrill. 2015. "Minoritynationals: An empirical analysis of the concentration of geographic sales expansion in MNCs." The Multinational Business Review 23(4):277-305.

Myers, M.D. 1997. "Qualitative Research in Information Systems.” MIS Quarterly 21(2):241-242.

Nebus, J., and K.H. Chai. 2014. "Putting the 'psychic' back in psychic distance: Awareness, perceptions, and understanding as dimensions of psychic distance." Journal of International Management 20(1):8-24.

Neves, M.F., V.T. Gustavo, and R.K. Bordonal. 2013. "Competitiveness of the Orange Juice Chain in Brazil." International Food and Agribusiness Management Review 16(4):141158.

O’Grady, S., and H. Lane. 1996. "The psychic distance paradox." Journal of International Business Studies 27(2):309-333.

O’Hagan-Luff, M., and J. Berrill. 2016. "US firms - How global are they ? A longitudinal 
study.” International Review of Financial Analysis 44:205-216.

ODEPA. 2017. Chilean Agriculture Overview 2017. ODEPA.

ODEPA. 2018. "Exportaciones de frutas y hortalizas frescas." Available at: https://www.odepa.gob.cl/Certificado fitosanitario [Accessed September 1, 2018].

OECD. 2010. "Countries." Chile signs up as first OECD member in South America. Available at: http://www.oecd.org/chile/chilesignsupasfirstoecdmemberinsouthamerica.htm [Accessed November 16, 2017].

Oh, C.H., T. Sohl, and A.M. Rugman. 2015. "Regional and product diversification and the performance of retail multinationals.” Journal of International Management 21(3):220234.

Ojala, A. 2015. "Geographic, cultural, and psychic distance to foreign markets in the context of small and new ventures." International Business Review 24(5):825-835.

Osegowitsch, T., and A. Sammartino. 2008. "Reassessing (Home-) Regionalisation.” Journal of International Business Studies 39(2):184-196.

Otter, V., A. Engler, and L. Theuvsen. 2014. "The influence of the interplay of supply chain network relationships on farmers' performance in the Chilean NTAE sector." Journal on Chain and Network Science 14(3):149-169.

Otter, V., and L. Theuvsen. 2014. "Governance and Standards in Chilean-German Food Supply Chains." In L. Theuvsen and A. Voss, eds. International High-Value Chains. Göttingen: Cuvillier Verlag, pp. 143-167.

Pangarkar, N. 2008. "Internationalization and performance of small- and medium-sized enterprises." Journal of World Business 43(4):475-485.

Park, K., and S.C. (Shawn) Jang. 2010. "Firm growth patterns: Examining the associations with firm size and internationalization." International Journal of Hospitality Management 29(3):368-377.

Qian, G., T.A. Khoury, M.W. Peng, and Z. Qian. 2010. "The performance implications of intra- and inter-regional geographic diversification.” Strategic Management Journal 
31:1018-1030.

Qian, G., L. Li, and A.M. Rugman. 2013. "Liability of country foreignness and liability of regional foreignness: Their effects on geographic diversification and firm performance." Journal of International Business Studies 44(6):635-647.

Reardon, T., and C.B. Barrett. 2000. "Agroindustrialization, globalization, and international development: An overview of issues, patterns, and determinants." Agricultural Economics 23(3):195-205.

Reardon, T., C.B. Barrett, J.A. Berdegué, and J. Swinnen. 2009. "Agrifood Industry Transformation and Small Farmers in Developing Countries." World Development 37(11):1717-1727.

Retamales, J.B., and J.C. Sepúlveda. 2011. "Fruit production in Chile: Bright past, uncertain future." Revista Brasilera de Fruticultura 33:173-178.

Reuber, A.R., P. Dimitratos, and O. Kuivalainen. 2017. "Beyond categorization: New directions for theory development about entrepreneurial internationalization." Journal of International Business Studies 48(4):411-422.

Ritchie, J., and J. Lewis. 2003. Qualitative research practice: A guide for social science students and researchers. London: SAGE Publications.

Roodman, D. 2009a. "How to Do xtabond2: An Introduction to Difference and System GMM in Stata." Stata Journal 9(1):86-136.

Roodman, D. 2009b. "Practitioners' corner: A note on the theme of too many instruments." Oxford Bulletin of Economics and Statistics 71(1):135-158.

Rugman, A.M., and C.H. Oh. 2013. "Why the Home Region Matters: Location and Regional Multinationals." British Journal of Management 24(4):463-479.

Rugman, A.M., C.H. Oh, and D.S.K. Lim. 2012. "The regional and global competitiveness of multinational firms." Journal of the Academy of Marketing Science 40(2):218-235.

Rugman, A.M., and A. Verbeke. 2004. “A perspective on Regional and Global Strategies of Multinational Enterprises.” Journal of International Business Studies 35(1):3-18.

Rugman, A.M., and A. Verbeke. 2007. "Liabilities of Regional Foreignness and the Use of 
Firm-Level versus Country-Level Data: A Response to Dunning et al. (2007).” Journal of International Business Studies 38(1):200-205.

Rugman, A.M., and A. Verbeke. 2008. "The theory and practice of regional strategy: a response to Osegowitsch and Sammartino." Journal of International Business Studies 39(2):326-332.

Rulamahue. 2018. "Mapa regiones de Chile Continental." Available at: http://www.rulamahue.cl/ [Accessed September 18, 2018].

Ruzo, E., F. Losada, A. Navarro, and J.A. Díez. 2011. "Resources and international marketing strategy in export firms.” Management Research Review 34(5):496-518.

Sagheer, S., S.S. Yadav, and S.G. Deshmukh. 2009. "Developing a conceptual framework for assessing competitiveness of India's agrifood chain." International Journal of Emerging Markets 4(2):137-159.

Sahaym, A., and D. Nam. 2013. "International diversification of the emerging-market enterprises: A multi-level examination.” International Business Review 22(2):421-436.

Saldaña, J. 2013. The Coding Manual for Qualitative Researchers. London: SAGE Publications.

Sammartino, A., and T. Osegowitsch. 2013. "Dissecting home regionalization: how large does the region loom ?" Multinational Business Review 21(1):45-64.

Sethi, D. 2009. "Are multinational enterprises from the emerging economies global or regional?" European Management Journal 27(5):356-365.

Shannon, C.E. 1948. "A Mathematical Theory of Communication.” Bell System Technical Journal 27(3):379-423.

Sheth, J. 2004. “Making India globally competitive.” Vikalpa 29(4):1-9.

Sonntag, W., L. Theuvsen, V. Kersting, and V. Otter. 2016. "Have industrialized countries shut the door and left the key inside? Rethinking the role of private standards in the international fruit trade." International Food and Agribusiness Management Review 19(2):151-170.

Sousa, C.M.P., and F. Bradley. 2006. “Cultural Distance and Psychic Distance: Two Peas in 
a Pod?” Journal of International Marketing 14(1):49-70.

Sparks, A.L., and B. Bravo-Ureta. 1993. "International Food \& Agribusiness Marketing Production in Chile." Journal of International Food \& Agribusiness Marketing 4(4):4160.

Stake, R.E. 1995. The art of case study research. Thousand Oaks: SAGE Publications.

Stöttinger, B., and B.B. Schlegelmilch. 1998. "Development Through Psychic Distance: Enlightening or Elusive?” International Marketing Review 15(5):357-372.

Swinnen, J., and M. Maertens. 2007. "Globalization, privatization, and vertical coordination in food value chains in developing and transition countries." Agricultural Economics 37(1):89-102.

Tallman, S., and J. Li. 1996. "Effects of International Diversity and Product Diversity on the Performance of Multinational Firms.” The Academy of Management Journal 39(1):179_ 196.

Thomas, D.E. 2006. "International diversification and firm performance in Mexican firms: A curvilinear relationship?” Journal of Business Research 59(4):501-507.

Thomas, D.E., and L. Eden. 2004. "What is the Shape of the Multinationality-Performance Relationship?” Multinational Business Review 12(1):89-110.

Verbeke, A., and P. Brugman. 2009. "Triple-testing the quality of multinationalityperformance research: An internalization theory perspective." International Business Review 18(3):265-275.

Wehner, L. 2011. "Chile's Rush to Free Trade Agreements." Revista de Ciencia Política 31(2):207-226.

Welch, C., and E. Paavilainen-Mäntymäki. 2014. "Putting Process (Back) In: Research on the Internationalization Process of the Firm." International Journal of Management Reviews 16(1):2-23.

World Bank. 2017. "World Bank Country and Lending Groups." Available at: https://datahelpdesk.worldbank.org/knowledgebase/articles/906519

[Accessed February 3, 2018]. 
Yin, R.K. 2003. Case Study Research Design and Methods. Thousand Oaks: SAGE Publications.

Yuri, J.A. 2016. "Expert Interview.” Talca, Chile at 01. September 2016.

Zaheer, S. 1995. "Overcoming the liability of foreignness." Academy of Management Journal 38(2):341-363. 